Estado nutricional e consumo de macronutrientes de idosos da cidade de Joinville, SC.

MARCO FÁBIO MASTROENI

São Paulo 


\section{Estado nutricional e consumo de macronutrientes de idosos da cidade de Joinville, SC.}

MARCO FÁBIO MASTROENI

Tese de Doutorado apresentada ao Departamento de Nutrição da Faculdade de Saúde Pública da Universidade de São Paulo para obtenção do Grau de Doutor em Saúde Pública.

Área de concentração: Nutrição.

ORIENTADORA: PROF ${ }^{\mathrm{a}}$. DR ${ }^{\mathrm{a}}$. MARIA DE FÁTIMA NUNES MARUCCI

São Paulo 


$$
44573 / 2004 \text { doe }
$$

Autorizo, exclusivamente para fins acadêmicos e científicos, a reprodução total ou parcial desta tese, por processos fotocopiadores.

Assinatura:

Data: 


\section{DEDICATÓRIA}

Este estudo é dedicado aos idosos que,

durante décadas, contribuíram para o desenvolvimento do país e, agora, merecem atenção especial no momento mais delicado de suas vidas. 


\section{AGRADECIMENTOS}

A realização deste trabalho só foi possível graças à colaboração de várias pessoas e Instituições, às quais sou grato e registro aqui meus sinceros agradecimentos:

À Profa. Dra. Maria de Fátima Nunes Marucci pela orientação prestada.

À Profa. Dra. Nilza Nunes da Silva, pela destreza e amizade com que me orientou na elaboração do plano amostral;

Ao Prof. Dr. Gilmar S. Erzinger pelo apoio e colaboração no desenvolvimento deste estudo junto a Universidade da Região de Joinville - UNIVILLE, sem o qual, não teria sido possível seu desenvolvimento;

Aos estagiários do Curso de Educação Física da Univille, que se propuseram a acordar às 06:00 $\mathrm{h}$ da manhã para participar do estudo, mesmo em período de férias;

Às bolsistas do Curso de Farmácia Bioquímica, Ana Cláudia, Ana Julia e Naiana, sempre prestativas e alegres desde o primeiro dia de atividades;

À Marineusa Gimenes H. Hoffmann e funcionários do Laboratório Gimenes pelo suporte na coleta de sangue e processamento das amostras de forma dedicada e eficiente;

À Secretaria Municipal da Saúde, Joinville-SC, pelo eficiente apoio na disponibilidade dos postos de saúde; 
Ao amigo Wilson, da Fundação IBGE-Joinville, sempre disposto a auxiliar na obtenção dos dados necessários ao planejamento do estudo;

Às pessoas que trabalham na Faculdade de Saúde Pública e que, em algum momento, contribuíram para indicar o melhor caminho;

À Regina Tomie Ivata Bernal, pelo rápido e eficiente auxílio na parte estatística; Ao Instituto de Geriatria e Gerontologia da PUCRS, em especial, Profa. Dra. Ivana B. M. da Cruz, de onde obtive a base para ingressar na área da saúde;

À CAPES (Coordenação de Aperfeiçoamento de Pessoal de Nível Superior), pela bolsa de estudo concedida;

Ao Sr. Antônio e Sra. Ivete, que me acolheram em sua residência por várias vezes durante o desenvolvimento do estudo;

À minha família, em especial, minha mãe Dona Domenica, sempre pronta para estender a mão a qualquer momento de minha vida;

À minha namorada Silmara, que esteve perto desde o primeiro dia em que nos conhecemos, graças a este estudo. 


\section{RESUMO}

Mastroeni MF. Estado nutricional e consumo de macronutrientes de idosos da cidade de Joinville, SC. São Paulo; 2004. [Tese de Doutorado - Faculdade de Saúde Pública da USP].

Objetivo. O envelhecimento populacional é um fenômeno universal e em Joinville, entre 1980-2000, houve aumento de 151\% das pessoas com mais de 60 anos, caracterizando rápido crescimento deste grupo etário nessa cidade. Este estudo teve como objetivo avaliar o estado nutricional e o consumo de macronutrientes de idosos da cidade de Joinville. Métodos. Na primeira etapa, 660 idosos foram entrevistados em domicílio, utilizando-se amostragem aleatória e sistemática em múltiplos estágios nos setores censitários urbanos de Joinville. Na segunda etapa, 221 idosos que compareceram aos postos de saúde, foram examinados quanto a características bioquímicas, antropométricas e dietéticas. Resultados. A média de idade dos individuos examinados foi 68,4 anos, sendo a maioria $(59,3 \%)$ mulheres. Estas apresentaram valores médios de $\mathrm{IMC}$, perímetro do braço e prega cutânea tricipital significativamente $(\mathrm{p}<0,05)$ maiores que os homens. As concentrações médias de glicose, colesterol total, LDL-c e triglicerídeos no sangue, foram consideradas limítrofes segundo valores de referência. $O$ valor total calórico para homens $(1.515,1$ $\mathrm{kcal}) \mathrm{e}$ mulheres $(1.339,6 \mathrm{kcal})$ foi considerado abaixo do recomendado pelo National Research Council. A contribuição percentual média de macronutrientes, para ambos os sexos, enquadrou-se dentro dos valores aceitáveis, havendo maior consumo de carboidratos e proteínas pelas mulheres. Conclusões. $O$ estado nutricional do grupo investigado foi considerado adequado quanto às variáveis antropométrica e dietética. Os valores limítrofes do perfil bioquímico revelaram situação preocupante para o desenvolvimento de doenças crônicas não transmissíveis, as quais podem ser prevenidas através de intervenções educacionais abordando temas como dieta e estilo de vida saudáveis.

Descritores: Estado nutricional. Consumo alimentar. Idosos. Joinville. 


\section{SUMMARY}

Mastroeni MF. Estado nutricional e consumo de macronutrientes de idosos da cidade de Joinville, SC. 2002. [Nutritional status and food intake of elderly from Joinville city. 2002.]. São Paulo (BR); 2004. [Tese de Doutorado - Faculdade de Saúde Pública da USP].

Objective: The population aging is an universal phenomenon and in Joinville city, between 1980-2000, there was an increase of $151 \%$ of older people (more than 60 years old), showing a fast growth of this age group in this city. The objective of this study was the evaluation of the nutritional status and food intake of elderly from Joinville city. Methods: In the first stage, 660 subjects were interviewed at their houses, using a systematic and aleatory sampling in multiples stages of Joinville urban sectors. In the second stage, 221 subjects that showed up at the health center were investigated about biochemical, anthropometric and dietetic characteristics. Results: The mean age of examined individuals was 68,4 years, being most $(59,3 \%)$ of them women. These showed medium values of BMI, arm circumference and triceps skinfold significantly $(p<0,05)$ larger than men. The mean concentrations of glucose, total cholesterol, LDL-c and triglycerides in the blood, were considered bordering according to reference values. The values of energy for men $(1.515,1 \mathrm{kcal})$ and women $(1.339,6 \mathrm{kcal})$ were considered below than recommended by National Research Council. The percentile contribution of macronutrientes, for men and women, was considered among the acceptable values, having larger carbohydrates consumption and proteins for the women. Conclusions: The nutritional status of investigated group was considered adequate based on the anthropometric and dietetic variables. The bordering values of biochemical variables showed alarming situation for the development of chronic diseases, which can be forewarned through education interventions approaching themes as diet and healthy lifestyle.

Descriptors: Nutritional status. Dietary intake. Elderly. Joinville. 


\section{ÍNDICE}

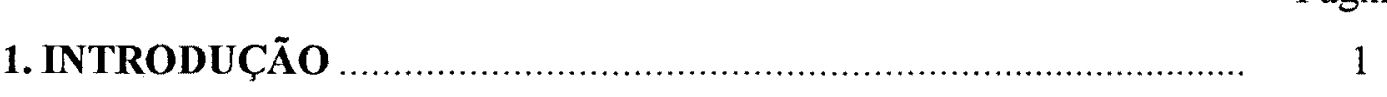

1.1. Envelhecimento ............................................................................

1.2. Panorama do envelhecimento populacional no Brasil ...................... 2

1.3. Dieta e envelhecimento ................................................................ 5

1.4. Estado nutricional ..........................................................................

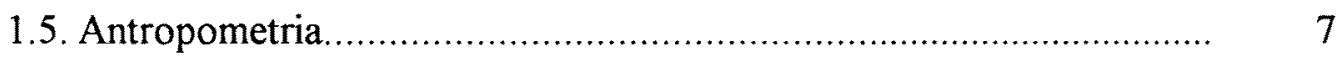

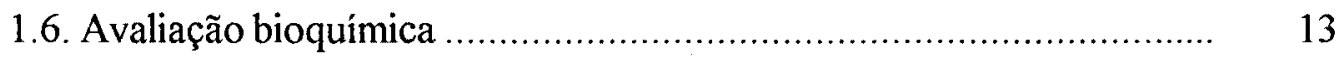

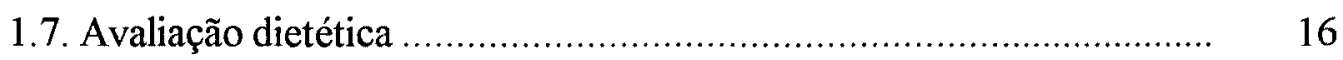

1.8. Estado de Santa Catarina .............................................................. 19

1.9. A cidade de Joinville, SC ........................................................ 19

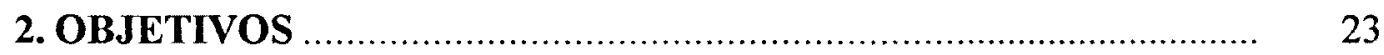

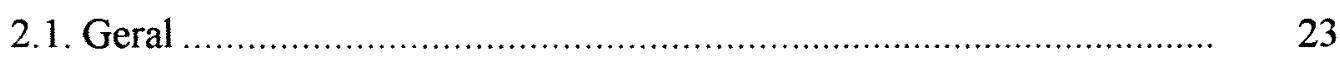

2.2. Específicos ...................................................................... 23

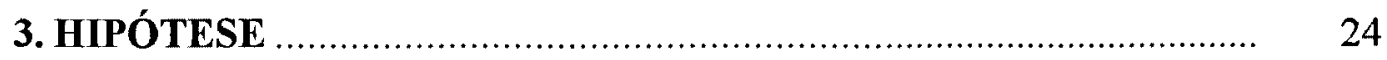

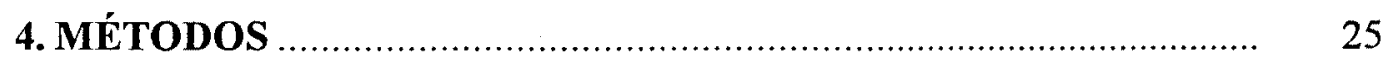

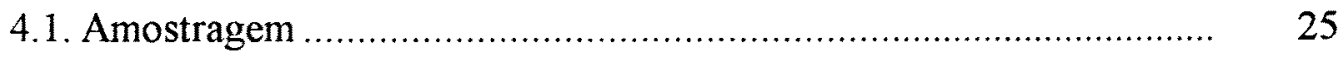

4.1.1. Composição da amostra ......................................................... 25

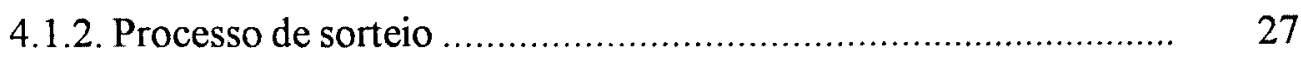

4.2. Treinamento ............................................................................ 33

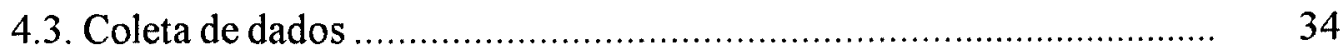

4.3.1. Dados de identificação ……………........................................ 34

4.3.2. Dados sócio-econômicos .......................................................... 36

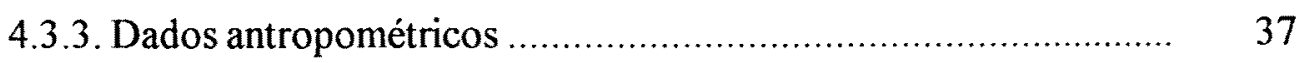

4.3.4. Dados bioquímicos .............................................................. 41

4.3.5. Dados do consumo de macronutrientes e energia .................... 43

4.4. Variáveis de estudo ..................................................................... 44

4.4.1. Variáveis demográficas ............................................................. 44

4.4.2. Variáveis sócio-econômicas ..................................................... 44

4.4.3. Variáveis antropométricas ...................................................... 


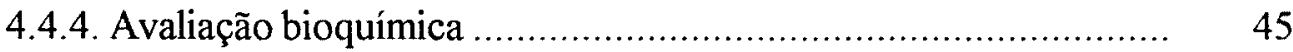

4.4.5. Avaliação dietética ................................................................ 46

4.5. Processamento e análise dos dados ................................................ 47

4.6. Análise estatística ..................................................................... 47

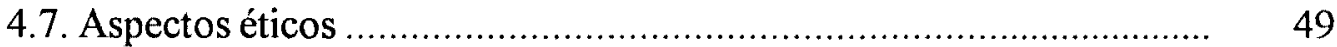

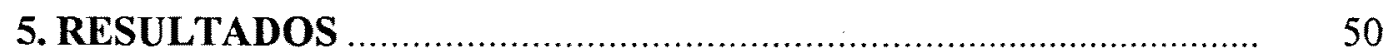

5.1. Sorteio dos setores censitários ...................................................... 50

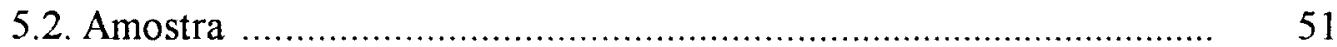

5.3. Etapa 1: domicílio, 660 idosos .................................................... 51

5.3.1. Descrição dos dados ................................................................ 51

5.3.2. Representatividade da etapa 2: 221 idosos ……..................... 54

5.4. Etapa 2: postos de saúde, 221 idosos ……………........................ 56

5.4.1. Análise das variáveis .......................................................... 57

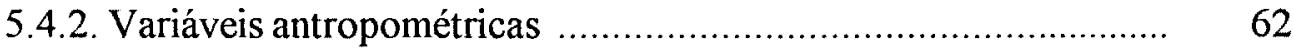

5.4.3. Associação de IMC com variáveis sócio-econômicas ............... 67

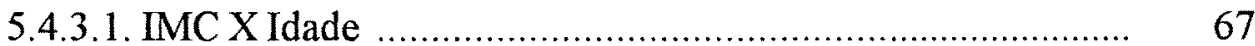

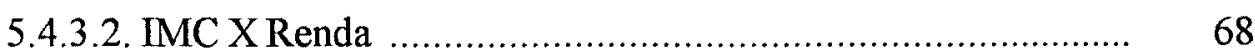

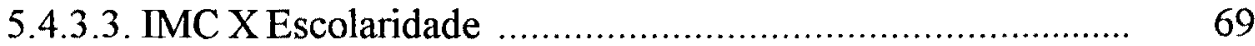

5.4.4. Variáveis bioquímicas .......................................................... 70

5.4.4.1. IMC $X$ Perfil bioquímico alto (glicose $\geq 126 \mathrm{mg} / \mathrm{dL}$, colesterol total $\geq 240 \mathrm{mg} / \mathrm{dL}$, LDL-c $\geq 160 \mathrm{mg} / \mathrm{dL}$ e triglicerídeos $\geq 200 \mathrm{mg} / \mathrm{dL}$ ).

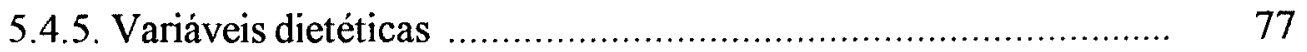

5.4.5.1. IMC X Contribuição calórica total (kcal) ............................. 80

5.4.5.2. IMC X Contribuição na dieta, com $\geq 65 \%$ de Carboidratos, $\geq 35 \%$ de Proteinas e $\geq 35 \%$ de Lipídios ...............................................

5.4.5.3. Contribuição, na dieta, com $\geq 35 \%$ de lipídios $X$ colesterol total $\geq 240 \mathrm{mg} / \mathrm{dL}$, LDL-c $\geq 160 \mathrm{mg} / \mathrm{dL}$ e triglicerídeos $\geq 200 \mathrm{mg} / \mathrm{dL} . \quad 82$

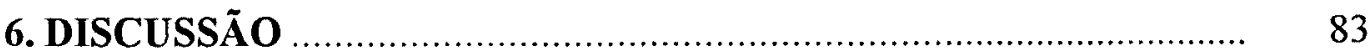

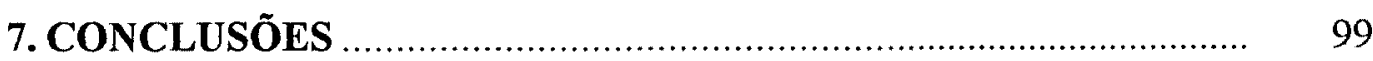

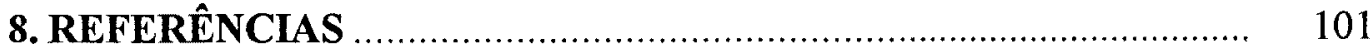




\section{ANEXOS}

Anexo 1. Formulário de registro de dados

Anexo 2. Formulário para inquérito alimentar

Anexo 3. Termo de consentimento informado

Anexo 4. Aprovação do Comitê de Ética em Pesquisa da FSP/USP 


\section{LISTA DE TABELAS}

Página

Tabela 1. Características gerais do Município de Joinville, Santa Catarina, Brasil, no ano de 2000.

Tabela 2. Cálculo do número total de moradias na amostra e dentro de cada setor censitário.

Tabela 3. Descrição dos 407 setores censitários que compõem o município de Joinville, destacando setores eliminados e sorteados. 2002 . .

Tabela 4. Relação das medidas e respectivos tamanhos adotados no inquérito alimentar Recordatório de 24 horas.

Tabela 5. Valores de referência, em jejum, para as variáveis bioquímicas analisadas

Tabela 6. Distribuição dos pesos para correção da variação das taxas de examinados em 221 idosos da área urbana de Joinville-SC, segundo sexo e grupo etário. 2002 .

Tabela 7. Distribuição dos pesos para correção da variação das taxas de examinados em 221 idosos da área urbana de Joinville-SC, segundo sexo e grupo etário. 2002.

Tabela 8. Distribuição do número de moradias sorteadas, número esperado de idosos, número de moradias visitadas, número de idosos obtidos, número de idosos entrevistados e taxa de resposta, segundo o setor censitário.

Tabela 9. Distribuição das freqüências absoluta (n) e relativa (\%) de 660 idosos da área urbana de Joinville-SC, segundo dados sócio-econômicos, demográficos e sexo. 2002.

Tabela 10. Distribuição das freqüências absoluta $(n)$ e relativa $(\%)$ de idosos em duas amostras da área urbana de Joinville-SC, segundo dados sócio-econômicos e demográficos. 2002.

Tabela 11. Médias, erros-padrão e intervalos de confiança (I.C.) dos grupos de examinados e de não examinados de uma amostra de idosos da área urbana de Joinville-SC, segundo idade. 2002. 
Tabela 12. Distribuição dos idosos segundo a amostra de examinados, segundo o Censo 2000 para o Município de Joinville, e segundo o Censo 2000 para os idosos do Brasil.

Tabela 13. Distribuição dos pesos para correção da variação das taxas de examinados em 221 idosos da área urbana de Joinville-SC, segundo setor censitário.

Tabela 14. Distribuição das freqüências absoluta (n) e relativa (\%) de 221 idosos da área urbana de Joinville-SC, segundo dados sócio-econômicos, demográficos e sexo. 2002.

Tabela 15. Distribuição das freqüências absoluta (n) e relativa (\%) de 221 idosos da área urbana de Joinville-SC, segundo variáveis sócioeconômicas, demográficas e sexo. 2002.

Tabela 16. Médias, erros-padrão e intervalos de confiança de variáveis antropométricas dos idosos que compareceram na segunda etapa do estudo, segundo sexo. 2002.

Tabela 17. Freqüências relativas (\%) dos percentis IMC de 217 idosos da área urbana de Joinville-SC, segundo proposto por Kuczmarski e col. (2000) por sexo. 2002.

Tabela 18. Freqüências relativas (\%) dos percentis de perímetro do braço de 218 idosos da área urbana de Joinville-SC, segundo proposto por Kuczmarski e col. (2000), por sexo. 2002.

Tabela 19. Distribuição das freqüências absoluta (n) e relativa (\%) dos percentis de prega cutânea tricipital de 218 idosos da área urbana de Joinville-SC, segundo proposto por Kuczmarski e col. (2000), e sexo. 2002.

Tabela 20. Relação entre IMC e renda em 221 idosos da área urbana de Joinville-SC, segundo o sexo. 2002.

Tabela 21. Relação entre IMC e escolaridade em 221 idosos da área urbana de Joinville-SC, segundo o sexo. 2002.

Tabela 22. Médias, erros-padrão e intervalos de confiança (I.C.) de variáveis bioquímicas de idosos da área urbana de Joinville-SC, segundo sexo. 2002 . 
Tabela 23. Freqüência absoluta (n) e relativa (\%) de variáveis bioquímicas de 218 idosos residentes na área urbana de Joinville-SC, segundo valores de referência e sexo. 2002.

Tabela 24. Médias, erros-padrão e intervalos de confiança (I.C.) para classe de idosos com variáveis bioquímicas aumentada, alta ou muito alta, segundo sexo. 2002.

Tabela 25. Relação entre IMC e perfil bioquímico alto em 221 idosos da área urbana de Joinville-SC, segundo o sexo. 2002.

Tabela 26. Médias, erros-padrão e intervalos de confiança (I.C.) de variáveis dietéticas de 221 idosos da área urbana de Joinville-SC, segundo o valor energético da dieta e de macronutrientes por sexo. 2002.

Tabela 27. Distribuição de 221 idosos da área urbana de Joinville-SC, segundo a contribuição de macronutrientes referencial na dieta e sexo (NRC 1989; Trumbo e col. 2002).

Tabela 28. Relação entre IMC e variáveis dietéticas acima do desejável (Trumbo e col. 2002), em 221 idosos da área urbana de Joinville-SC, segundo o sexo. 2002.

Tabela 29. Relação entre contribuição na dieta com $\geq 35 \%$ de lipídios e colesterol total $\geq 240 \mathrm{mg} / \mathrm{dL}$, LDL-c $\geq 160 \mathrm{mg} / \mathrm{dL}$, triglicerídeos $\geq 200$ $\mathrm{mg} / \mathrm{dL}$, em 221 idosos da área urbana de Joinville-SC, segundo o sexo. 2002. 


\section{LISTA DE FIGURAS}

Página

Figura 1. Evolução da população idosa no Brasil entre 1980-2000.

3

Figura 2. Localização geográfica da cidade de Joinville no Estado de Santa Catarina.

Figura 3. Distribuição da população residente em Joinville no ano de 2000, segundo grupo etário.

Figura 4. Evolução da população idosa de Joinville entre 1980-2000

Figura 5. Composição do cadastro das unidades primárias para o sorteio de primeiro estágio.

Figura 6. Cálculo da fração global de amostragem $(f)$ utilizada para o estudo.

Figura 7. Representação do setor censitário urbano Bom Retiro - 186, da cidade de Joinville, segundo malha setorial do censo de 2000 (IBGE 2000a). Em vermelho, destaca-se a quadra de número 3.

Figura 8. Representação da localização do ponto médio do braço: a) acrômio; b) ponto médio do braço; c) olécrano.

Figura 9. Representação da medida do perímetro do braço: a) zero da fita métrica; b) valor observado.

Figura 10. Representação da medida da prega cutânea tricipital.

Figura 11. Representação dos 42 setores censitários sorteados (em vermelho) sobre o mapa da cidade de Joinville.

Figura 12. Distribuição de idosos da área urbana de Joinville-SC, segundo estado civil e sexo. 2002.

Figura 13. Distribuição de idosos da área urbana de Joinville-SC, segundo grupo etário e sexo. 2002.

Figura 14. Distribuição de idosos da área urbana de Joinville-SC, segundo escolaridade e sexo. 2002.

Figura 15. Distribuição dos idosos da área urbana de Joinville-SC, segundo renda e sexo. 2002. 
Figura 16. Distribuição de 217 idosos da área urbana de Joinville-SC, segundo os percentis de IMC, proposto por Kuczmarski e col. (2000), e sexo. 2002.

Figura 17. Distribuição de 218 idosos da área urbana de Joinville-SC, segundo os percentis de perímetro do braço, proposto por Kuczmarski e col. (2000), e sexo. 2002

Figura 18. Distribuição de 218 idosos da área urbana de Joinville-SC, segundo percentis de prega cutânea tricipital, proposto por Kuczmarski e col. (2000), e sexo. 2002.

Figura 19. Idade de 221 idosos residentes na área urbana de Joinville-SC, segundo IMC. 2002.

Figura 20. Distribuição de 218 idosos da área urbana de Joinville-SC, segundo valores de referência de colesterol total e o sexo. 2002.

Figura 21. Distribuição de 214 idosos da área urbana de Joinville-SC, segundo valores de referência de LDL-c, e o sexo. 2002.

Figura 22. Distribuição de 218 idosos da área urbana de Joinville-SC, segundo valores de referência de triglicerideos e o sexo. 2002.

Figura 23. Contribuição percentual de macronutrientes da dieta de 221 idosos residentes na área urbana de Joinville-SC, segundo sexo. 2002.

Figura 24. Contribuição calórica total (Energia) de 221 idosos residentes na área urbana de Joinville-SC, segundo idade. 2002.

Figura 25. Contribuição calórica total (Energia) de 221 idosos residentes na área urbana de Joinville-SC, segundo IMC. 2002. 


\section{INTRODUÇÃO}

\subsection{Envelhecimento}

Ao revisar a história do pensamento humano, pode-se notar que as definições sobre o envelhecimento são tão antigas quanto os registros culturais do próprio homem. Mas o que é envelhecer? Algumas definições de envelhecimento envolvem princípios negativos quando caracterizam o processo como sendo a perda gradativa das funções biológicas, o aumento da probabilidade de morte ou associam envelhecimento com patologias (Jeckel Neto 2000). O envelhecimento humano é um processo biológico natural, e não patológico, caracterizado por uma série de alterações morfo-fisiológicas, bioquímicas e psicológicas que ocorrem no organismo ao longo da vida ou, segundo alguns autores, logo após a maturação sexual, estendendo-se até a longevidade máxima (Roland 1991, Wilmoth 1998, Jeckel Neto 2000). As mudanças na composição do corpo e funções dos tecidos passam a se adequar às funções metabólicas alteradas com o envelhecimento (Horwitz, 1988). Ocorre uma diminuição da acuidade dos sentidos (sabor, odor, visão, audição e tato), em diferentes níveis. Também, ocorre redução da secreção gástrica de ácido clorídrico, diminuindo a absorção de cálcio, ferro e vitamina $B_{12}$ (Roland 1991). Um fato importante refere-se ao uso freqüente de medicamentos, devido à prescrição médica e também à auto-medicação, provocando alteração do paladar e inadequação do consumo alimentar (Marucci e Gomes 1997).

O tempo e a maneira como se processam essas alterações dependem de cada individuo, do conjunto gênico de sua espécie e dos fatores ambientais incidentes, como hábito alimentar e estilo de vida. No entanto, o conhecimento que se tem sobre os seus mecanismos ainda é incipiente, e teorias têm sido elaboradas na tentativa de explicá-lo. Apesar de não haver consenso e de existirem posições adversas, acreditase que o ambiente afeta a longevidade em algum nível de organização corporal (Wilmoth 1998, Roland 1991).

A longevidade máxima do ser humano, ou a capacidade de vida da espécie, aproximadamente 120 anos (Bunout e Cambiazo 1999), tem sido pouco alterada nos últimos 10 mil anos; o que tem aumentado significativamente é a esperança de vida 
ao nascer (longevidade média) que, em alguns países como o Japão, já chega aos 80 anos de idade (Cançado 1994; Hayflick 1996). Com isto, nas últimas décadas, populações de países desenvolvidos e em desenvolvimento passaram a experimentar envelhecimento substancial devido, primeiramente, aos avanços ocorridos na promoção de saúde, como o controle de doenças infecto-contagiosas, e à melhoria na qualidade de vida da população (OPS 1994).

\subsection{Panorama do envelhecimento populacional no Brasil}

Alguns autores mencionam que, desde a década de 90 , o envelhecimento populacional é tido como um fenômeno universal característico tanto de países desenvolvidos como de países em desenvolvimento (Kalache e col. 1987; Ramos e col. 1987). Já na década de 80, Ramos e col. (1987) alertavam para o rápido processo de envelhecimento da população brasileira, particularmente no que se refere a suas implicações sociais e em termos de saúde pública. O Brasil, para muitos, ainda é um país de jovens, sendo o envelhecimento populacional similar associado aos países mais desenvolvidos, como os da Europa e América do Norte. No entanto, nos dias de hoje, tal afirmação não corresponde por completo à realidade. Ela fazia sentido até há alguns anos, pois as taxas de crescimento anual da população brasileira mantiveramse altas por muitas décadas, notadamente nas de 50 e 60 (Paschoal 1997). Kalache e col. (1987), na década de 80, estimaram que, no período de 1980 a 2000, paralelamente a um crescimento da população total de $56 \%$, haveria aumento da população idosa no Brasil de mais de $100 \%$. O grupo etário com 60 anos e mais passaria de $5 \%$ da população total, em 1960 , para $14 \%$ em 2025 , quando então, o Brasil figurará com uma proporção de idosos semelhante ao que é hoje registrada em países desenvolvidos (Kalache e col. 1987). Segundo o último Censo realizado em 2000, a população de pessoas com 60 e mais anos no Brasil já representa $8,5 \%$ da população total, registrando aumentando de $100 \%$ em 20 anos, conforme ilustrado na Figura 1 (Fundação IBGE 2003). Nos próximos 20 anos, a população idosa do Brasil poderá ultrapassar 30 milhões de pessoas e deverá representar $13 \%$ da população ao final deste período (Fundação IBGE 2002). Chaimowicz (1997) estimou que, em 2050 , a proporção de idosos deverá duplicar, alcançando $15 \%$ do total da população 
e revela que doenças crônicas não transmissiveis e distúrbios mentais já têm determinado, atualmente, maciça utilização dos serviços de saúde. Outro pesquisador acredita que, em 2050, a expectativa de vida ao nascer chegará a 85 anos de idade, elevando a parcela de idosos da população, principalmente nos países em desenvolvimento (Wilmoth 1998).

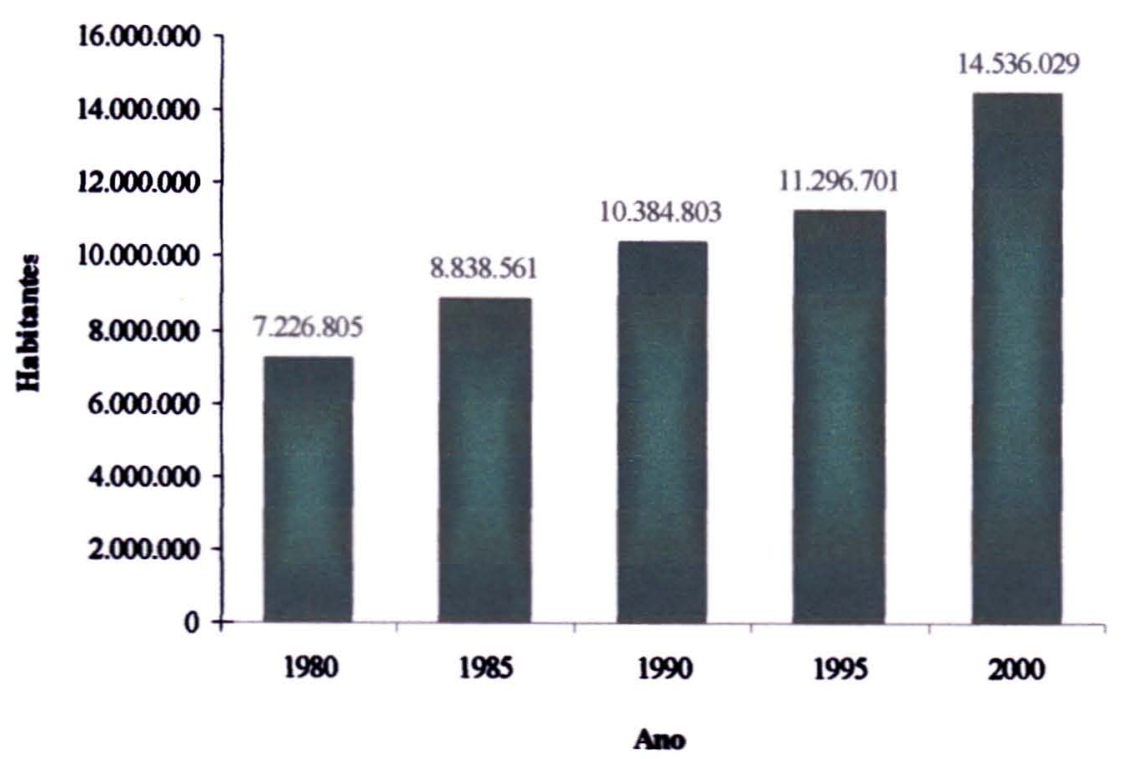

Figura 1. Evolução da população idosa no Brasil entre 1980-2000. Fonte: Fundação IBGE (2003).

Durante o século XX, ocorreram importantes mudanças no tipo de doenças e nas causas de morte da população brasileira. Nas primeiras quatro décadas do século $\mathrm{XX}$, o Brasil apresentou características demográfico-sanitárias encontradas em países tipicamente em desenvolvimento, tendo como maior causa de mortalidade as doenças infecto-parasitárias. A partir de 1940, começou a ocorrer incremento das doenças não transmissiveis, as quais passaram a representar a causa primária da mortalidade da população até os dias de hoje (Cruz e Alho 2000). Carvalho e Garcia (2003) comentam que a partir de 1940, e até os anos 60, a população brasileira apresentouse como quase estável, com distribuição etária praticamente constante. Nesse periodo, houve significado declínio da mortalidade e leve queda da fecundidade.

Em grande parte, essa mudança epidemiológica deveu-se a uma estabilização na estrutura etária que apresentava baixas oscilações nas taxas de natalidade e 
mortalidade até meados do século XX (Camargo 1990). Este quadro mudou entre as décadas de 40 a 70, quando a taxa de mortalidade populacional passou a apresentar declínio acentuado devido à diminuição na mortalidade infantil. A partir da década de 70, a expectativa de vida da população brasileira passou a aumentar gradativamente ao longo dos anos, ocorrendo o inverso com a taxa de fecundidade, a qual vem mantendo declínio até os dias de hoje (Cruz e Alho 2000, Paschoal 1997, Fundação IBGE 2001). Se, a partir do ano 2000, não houver mais declínio da fecundidade no Brasil, o que é de todo improvável, mesmo assim continuará o processo de envelhecimento da população, até que desapareça, totalmente, de sua configuração etária, os efeitos diretos e indiretos da alta fecundidade do passado (Carvalho e Garcia, 2003).

Um estudo desenvolvido pela Fundação IBGE durante 21 anos (1980-2001) mostrou que, no Brasil, a esperança de vida ao nascer vem favorecendo o sexo feminino. Em 1980, enquanto as mulheres possuíam uma esperança de vida ao nascer de 66,0 anos, os homens detinham uma vida média de 59,6 anos, representando uma diferença de 6,4 anos. Vinte e um anos mais tarde, as mulheres, no Brasil, já estariam vivendo, em média, 7,8 anos a mais que os homens (72,9 anos, para o sexo feminino e 65,1 anos, para o sexo masculino) (Fundação IBGE 2001). O aumento da expectativa de vida de uma população é naturalmente decorrente da melhoria das condições de vida e de trabalho, do nível educacional e de escolaridade e do atendimento às necessidades de saúde dessa mesma população (Paschoal 1997).

O ritmo de crescimento mais lento da esperança de vida masculina, comparativamente ao da feminina, encontra explicação no aumento gradativo da sobremortalidade masculina nas idades jovens e adultas jovens. Essa sobremortalidade é expressa pela relação entre as taxas específicas de mortalidade de homens e mulheres. Por exemplo, nos últimos anos, as taxas de mortalidade masculinas, na faixa dos 20 a 29 anos de idade, chegam a ser mais de três vezes superiores às correspondentes femininas (Fundação IBGE 2001).

No Brasil, assim como nos demais países, avanços da medicina no tratamento das doenças não transmissíveis, mudanças no estilo de vida, e da dieta, têm contribuido para o estabelecimento das alterações no processo de envelhecimento da 
população. A prática de dieta saudável é um dos requisitos necessários para garantir envelhecimento saudável e a manutenção da integridade fisica ao longo dos anos.

\subsection{Dieta e envelhecimento}

O significado da dieta nos diferentes estágios da vida, como no crescimento, desenvolvimento e envelhecimento, cada vez mais, torna-se objeto de estudo e pesquisa na medida em que se relaciona com a saúde do organismo (Roland 1991).

De modo geral, a nutrição pode ser dividida em alimentação, metabolismo e excreção, de forma que cada um destes, participa no processo de desenvolvimento e envelhecimento. Alterações nestes processos dão lugar a mudanças orgânicas e funcionais que podem ser corrigidas no começo, porém, a persistência pode conduzir a um estado irreversível que comprometerá a qualidade de vida do indivíduo. Neste sentido, a alimentação deve ser composta por uma ampla variedade de alimentos, obtidos de fonte animal e ou vegetal (Coelho 1995). Estima-se que as necessidades energéticas de pessoas com idade entre 51-75 anos diminuam para $90 \%$ da quantidade energética necessária aos 23 anos, e para as pessoas com idade acima de 75 anos, cerca de $75-80 \%$ dessa quantidade. Essa diminuição dependerá da atividade fisica exercida pelo indivíduo (Roland 1991).

Considerando interações entre nutrição e envelhecimento, é importante estabelecer como a nutrição e outros fatores relacionados ao estilo de vida podem contribuir para o processo do envelhecimento e desencadeamento de condições crônico-degenerativas. A progressiva diminuição do aporte energético a medida que a idade avança, inevitavelmente associada à redução da ingestão de nutrientes e macronutrientes, revela a crucial importância da densidade de nutrientes presente na dieta. Os efeitos combinados ao processo do envelhecimento, doenças degenerativas, interação droga-nutriente e uma suposta modificação da biodisponibilidade de nutrientes dificultam a definição de necessidades (Schlienger e col. 1995). Apesar dessas necessidades ainda não serem bem conhecidas, a prevenção, o estabelecimento de um programa de intervenção da dieta adequado e o reconhecimento inicial de um estado nutricional inadequado, são considerados a melhor forma de obter conhecimento sobre dieta e envelhecimento. 
No curso da evolução, os seres humanos se adaptaram progressivamente à grande variedade de alimentos existentes. A revolução da agricultura, aproximadamente há 10.000 anos, trouxe profundas mudanças à nossa dieta. A capacidade de produzir e estocar alimentos tornou-se muito comum. Após a revolução industrial, há cerca de 200 anos, fortes mudanças ocorreram, na forma de produção, processamento, estoque e distribuição dos alimentos, que culminaram em modificações na dieta e no hábito alimentar da população. $O$ beneficio imediato destas mudanças trouxe, como principais resultados, a diminuição da desnutrição e a redução de muitas doenças em países desenvolvidos. Estas características, associadas também, à redução de doenças infecto-contagiosas ao longo do século XX, têm proporcionado aumento significativo da expectativa de vida em muitos paises (WHO 1990). Mas, se por um lado obtiveram-se beneficios com o aumento da oferta de alimentos, por outro, este fato também acarretou sérios problemas à saúde pública. Atualmente, com o advento tecnológico paralelo ao envelhecimento populacional substancial, o mundo, principalmente os paises de civilização ocidental, passou a produzir quantidade quase ilimitada de alimentos altamente palatáveis, calóricos e de fácil acesso, ingeridos por uma população com estilo de vida sedentário, provocando o surgimento preocupante de um número elevado de novos problemas relacionados à nutrição, ocasionados pelo desequilibrio no consumo de nutrientes e levando a um quadro de má alimentação (Brown 1990; Bray 1987).

Dados referentes a ingestão e utilização dos nutrientes que compõem a dieta de um individuo, ou população, podem ser utilizados para contribuir na avaliação do estado nutricional.

\subsection{Estado nutricional}

A alteração do estado nutricional é o maior problema de saúde em idosos (Delarue e col. 1994). Para a população adulta brasileira, em estudo realizado no início da década de 90, Coitinho e col. (1991) apontavam para a baixa prevalência relativa de indivíduos antropometricamente "normais" e altos índices de excesso de peso. Como agravante, os autores relataram ainda, que os adultos e idosos têm sido 
particularmente negligenciados em estudos epidemiológicos e intervenções nutricionais no Brasil.

Pesquisa realizada pelo Instituto Nacional de Alimentação e Nutrição INAN, com adultos e idosos no Brasil, revelou que a situação nutricional de adultos e idosos sofreu grande alteração em 15 anos (1974-1989). O estudo mostrou diminuição de $36 \%$ na prevalência de baixo peso e grande aumento no excesso de peso: $100 \%$ para os homens e $70 \%$ para as mulheres (Coitinho e col. 1991).

Para que se possa verificar até que ponto alterações na nutrição prejudicam o estado nutricional do idoso, é preciso que se faça avaliação nutricional, até porque, muitas vezes essas alterações são determinantes da má nutrição (Ortega e col. 1995), fato comum entre os idosos e que desfavoravelmente afeta prognósticos, atrasa o descobrimento de doenças, reduz a função imune e eleva a susceptibilidade a infecções (Nikolaus e col. 1995).

Uma abordagem completa do estado nutricional pode incluir antropometria; avaliações bioquímica, clínica e dietética (Lasheras e col. 1999, Kuczmarski 1998). Alguns autores consideram, ainda, avaliação psicossocial (Czajka-Narins 1995) e fatores sócio-econômicos (Kuczmarski 1998). Técnicas apropriadas de avaliação detectam deficiência e excesso nutricional em diferentes estágios do desenvolvimento, para que a ingestão dietética possa ser corrigida através de suporte nutricional e aconselhamento antes de uma lesão mais grave aparecer (Czajka-Narins 1995).

A avaliação do estado nutricional pode ser utilizada em diferentes situações, como por exemplo: 1. em nível individual, para diagnosticar, intervir, selecionar ou monitorar um indivíduo; 2 , em nível populacional, em programas de avaliação do padrão nutricional (Kuczmarski MF e Kuczmarski RJ 1998). Dentre as técnicas de avaliação do estado nutricional, a antropometria tem sido muito utilizada em estudos epidemiológicos devido, principalmente, ao seu baixo custo e fácil aplicação.

\subsection{Antropometria}

A antropometria é um método não invasivo (Onis e Habicht 1996, Delarue e col. 1994), que objetiva determinar e monitorar o peso corporal, a composição 
corporal e avaliar a distribuição de gordura corporal, relacionando-a com o desenvolvimento de doenças crônicas (Kuczmarski MF e Kuczmarski RJ 1998). Considerado o método mais utilizado em avaliação nutricional de idosos, os dados antropométricos freqüentemente utilizados para este grupo etário compreendem peso, estatura, pregas cutâneas, perímetros do braço, da cintura e do quadril (Schlenker 1998a).

Existem evidências de que a composição corporal é alterada em função da idade, apesar do grau de alteração ser variável entre os indivíduos. Ocorrem significantes mudanças na massa magra e nos padrões de distribuição de gordura (Schlenker 1998a). A estatura tende a diminuir cerca de 1-2 cm/década, sendo essa diminuição mais acentuada em idosos. O peso também diminui com o avanço da idade, e varia com o sexo, e essa redução de peso inclui o declínio da massa muscular e da massa celular em geral. Em países desenvolvidos, foi verificado que o İndice de Massa Corporal (IMC), calculado através da relação peso/altura ${ }^{2}$ e expresso em kg/m² diminuiu após os 70 anos de idade (WHO 1995).

A avaliação do estado nutricional de idosos através de medidas antropométricas requer o uso de valores de referência para comparação. Poucos países apresentaram estudos definindo valores de referência antropométrica para pessoas acima de 60 anos. Frisancho (1984), em estudo onde investigou 21.752 americanos não institucionalizados, com idade entre 25 e 74 anos, utilizando os dados do National Health and Nutrition Examination Surveys (NHANES I e NHANES II), estabeleceu um novo padrão antropométrico para a população americana na década de 90. Esses dados antropométricos foram estabelecidos para serem utilizados em conjunto com outras avaliações, como dietética, bioquímica e clínica, a fim de se determinar o estado nutricional de populações idosas.

Burr e Phillips (1984), que relataram a deficiência de valores antropométricos para pessoas acima de 75 anos na Inglaterra, investigaram 1.500 ingleses com idade superior a 65 anos e estabeleceram padrões de referência na forma de percentis. No estudo, os autores descreveram a diminuição do IMC e massa muscular com o avanço da idade, para ambos os sexos, e a maior perda de gordura corporal para o sexo feminino, com a passar dos anos. 
Chumlea (1987), investigou 269 idosos americanos institucionalizados e estabeleceu valores antropométricos de referência para pessoas acima de 62 anos de idade. Assim como Frisancho (1984), Chumlea (1987) apenas descreveu valores antropométricos para as populações investigadas, sem avaliar o estado nutricional.

Na Europa, estudo denominado Euronut SENECA (Survey in Europe on Nutrition and the Elderly, a Concerted Action), que desenvolveu pesquisas relacionadas à nutrição e envelhecimento desde 1986, descreveu a antropometria de 2.332 idosos com idade igual ou superior a 60 anos. O estudo, conduzido em diversos países da Europa, mostrou que existem variações antropométricas entre os diferentes países avaliados, onde a média do IMC para homens variou de 24,4 a 30,3 $\mathrm{kg} / \mathrm{m}^{2}$. Em relação às mulheres essa mesma medida variou entre 23,9 e $30,5 \mathrm{~kg} / \mathrm{m}^{2}$. Para as medidas de prega cutânea tricipital, os autores sugeriram que as mulheres apresentaram maior acúmulo de gordura subcutânea do que os homens (Groot e col. 1991).

Na França, Delarue e col. (1994) estabeleceram percentis antropométricos de referência para a população idosa francesa, em estudo que investigou 626 idosos não institucionalizados, com idade igual ou superior a 65 anos. Nesse estudo, os autores relataram ter ocorrido diminuição do peso e das variáveis antropométricas relacionadas a gordura corporal e massa muscular, com o aumento da idade. Outro aspecto abordado pelos autores foi a existência de diferenças inter-regionais para índices antropométricos entre os idosos, demonstrando a importância da obtenção de valores antropométricos em diferentes populações.

Troiano e col. (1996), a partir de pesquisa meta-analítica abrangendo 19 estudos publicados na literatura científica internacional, estimaram o relacionamento entre IMC e mortalidade. Os resultados do estudo revelaram que o risco de mortalidade aumentou em homens com 50 anos ou mais de idade e que apresentaram IMC inferior a $23 \mathrm{~kg} / \mathrm{m}^{2}$ ou superior a $28 \mathrm{~kg} / \mathrm{m}^{2}$.

Cervato e col. (1997) investigaram os fatores de risco para doenças cardiovasculares em 557 indivíduos com idade entre 20 e 88 anos residentes no município de Cotia, São Paulo. Nesse estudo, a prevalência de obesidade (IMC $\geq 30,0$ $\mathrm{kg} / \mathrm{m}^{2}$ ) foi de $38 \%$, sendo $31,8 \%$ entre os homens e $41,7 \%$ entre as mulheres. 
Vellas e col. (1997), em estudo longitudinal realizado durante 10 anos no Novo México, investigaram o estado nutricional de 304 idosos com idade superior a 60 anos e não institucionalizados utilizando, entre outras variáveis, o IMC. Dos 304 indivíduos avaliados, com média de idade de 72 anos, 97 (34,2\%) estavam adequados quanto ao estado nutricional, 74 (26,5\%) foram enquadrados como fracos ou magros, $54(19,1 \%)$ morreram e $57(20,1 \%)$ decidiram sair do estudo.

$\mathrm{Na}$ Espanha, Lasheras e col. (1999) avaliaram o estado nutricional, a partir da antropometria e outras variáveis, de 352 idosos institucionalizados e não institucionalizados com idade entre 65 e 95 anos. Nesse estudo, a média do IMC para homens e mulheres institucionalizados e não institucionalizados foi superior a 25,0 $\mathrm{kg} / \mathrm{m}^{2}$. Os valores para prega cutânea triciptal e circunferência do braço foram significativamente maiores em individuos não institucionalizados, para homens e mulheres, mas todos foram enquadrados como sendo normais.

Estudo recente, utilizando dados de 5.700 idosos americanos com idade acima de 50 anos, obtidos a partir do NHANES III, descreveu novos valores antropométricos para idosos americanos (Kuczmarski e col. 2000). Nesse estudo, os autores revelaram que a média de peso foi significativamente menor para pessoas com mais de 80 anos, e que o IMC e a massa muscular também diminuíram com o amento da idade. Comparado ao grupo com 50-59 anos, a média de peso corporal no grupo de 80 anos ou mais foi $14,2 \mathrm{~kg}$ menor para os homens e $13,9 \mathrm{~kg}$ menor para as mulheres, mostrando a importância da avaliação nutricional a partir de medidas antropométricas em idosos.

Perissinotto e col. (2002), em pesquisa realizada na Itália com 3.356 idosos não institucionalizados com idade entre 65-84 anos, descreveram as características antropométricas da população idosa italiana relacionando-as com sexo e idade. Para ambos os sexos, peso e altura diminuíram significativamente com o aumento da idade. O IMC foi significativamente maior $\left(27,6 \mathrm{~kg} / \mathrm{m}^{2}\right)$ nas mulheres em relação aos homens $\left(26,4 \mathrm{~kg} / \mathrm{m}^{2}\right)$. A obesidade (IMC $\geq 30,0 \mathrm{~kg} / \mathrm{m}^{2}$ ) esteve presente em $28 \%$ das mulheres e 16\% dos homens, concluindo que as mulheres apresentaram maior distribuição de gordura corporal do que os homens.

Ledikwe e col. (2003), investigaram o risco nutricional em 179 idosos com 65 anos ou mais de idade, residentes na área rural da Pensilvânia, Estados Unidos. 
Neste estudo, 44,4\% dos homens e $34,6 \%$ das mulheres apresentaram IMC $\geq 30,0$ $\mathrm{kg} / \mathrm{m}^{2}$, não ocorrendo diferença significativa para média de IMC entre homens $(28,5$ $\left.\mathrm{kg} / \mathrm{m}^{2}\right)$ e mulheres $\left(28,3 \mathrm{~kg} / \mathrm{m}^{2}\right)$. Nenhum dos indivíduos avaliados apresentou IMC $<18,5 \mathrm{~kg} / \mathrm{m}^{2}$.

No Brasil, a preocupação em avaliar características antropométricas da população idosa também se faz presente.

Em 1989, estudo denominado Pesquisa Nacional sobre Saúde e Nutrição, desenvolvido em 363 municípios brasileiros, descreveu o perfil nutricional da população idosa brasileira com base no Índice de Massa Corporal (peso/estatura ${ }^{2}$ ). Nesse estudo, foram investigados 4.277 indivíduos não institucionalizados com idade superior a 60 anos (Tavares e Anjos 1999). As prevalências gerais de magreza (IMC $<18,5 \mathrm{~kg} / \mathrm{m}^{2}$ ) e sobrepeso (IMC $\geq 25,0 \mathrm{~kg} / \mathrm{m}^{2}$ ) foram, respectivamente, $7,8 \%$ e $30,4 \%$ em homens e $8,4 \%$ e $50,2 \%$ em mulheres. A magreza foi mais freqüente em mulheres no grupo etário de 70-79 anos. O sobrepeso foi mais prevalente nas áreas urbanas de todas as regiões para homens e mulheres em todos os graus (Tavares e Anjos 1999), principalmente na região Sul, com cerca de $34 \%$ dos homens e $43 \%$ das mulheres com excesso de peso. Nesta região, e para pessoas com 65 e mais anos de idade, $7,9 \%$ dos homens e 19,2\% das mulheres apresentaram $\mathrm{IMC} \geq 30,0 \mathrm{~kg} / \mathrm{m}^{2}$. Na época, os autores relataram a presença de um quadro preocupante de alterações nutricionais em idosos no Brasil, principalmente em mulheres. (Coitinho e col. 1991).

O excesso de peso tem conseqüências deletérias à saúde. Além dos problemas psicológicos que acarreta, conseqüência dos padrões estéticos prevalentes, o sobrepeso e a obesidade são fatores de risco e/ou agravamento de uma série de doenças. Entre elas, destacam-se a hipertensão, a hipercolesterolemia, o diabetes mellitus, as doenças cardiovasculares, algumas formas de câncer, entre outras. Em vista destas associações, não é surpreendente que se verifique também, clara correlação entre obesidade e maiores taxas de mortalidade (Coitinho e col. 1991). Monteiro e col. (2003), em estudo elaborado a partir de três inquéritos comparáveis realizados no último quarto do século vinte nas regiões Nordeste e Sudeste do país, evidenciou tendência secular da obesidade segundo níveis de escolaridade da população. Enquanto no primeiro periodo (1975-1989) o risco de obesidade foi 
ascendente em todos os níveis de escolaridade para homens e mulheres, no segundo período (1989-1997), o aumento da obesidade foi máximo para indivíduos sem escolaridade, registrando-se estabilidade ou mesmo diminuição da enfermidade nos estratos femininos de média ou alta escolaridade.

Marucci (1992), em estudo desenvolvido na cidade de São Paulo, investigou a antropometria de 127 idosos ambulatoriais com idade igual ou superior a 60 anos. Neste estudo, os homens apresentaram IMC de $24,6 \mathrm{~kg} / \mathrm{m}^{2}$, e as mulheres 27,1 $\mathrm{kg} / \mathrm{m}^{2}$. Em relação ao perímetro do braço, os homens apresentaram $28,4 \mathrm{~cm}$, e as mulheres, $30,3 \mathrm{~cm}$. Segundo a autora, os valores de perímetro do braço para homens é geralmente superior ao das mulheres, o que indica maior massa muscular para os homens. Neste estudo, foi excepcional o fato de se encontrar valor maior para indivíduos do sexo feminino. A prega cutânea tricipital também foi mensurada, sendo a dos homens inferior $(14,0 \mathrm{~mm})$ a das mulheres $(22,3 \mathrm{~mm})$. A medida da prega cutânea tricipital contribui para a avaliação da composição corporal, uma vez que possibilita a estimativa da quantidade de gordura total do corpo, assumindo que em torno de $50 \%$ da gordura corporal é subcutânea e pode ser indicativa de obesidade. Para a autora, as médias de prega cutânea tricipital encontradas no estudo indicaram obesidade e maior quantidade de gordura nas mulheres.

Cabrera e Jacob Filho (2001), em estudo desenvolvido na cidade de Londrina, Paraná, caracterizaram o perfil antropométrico de 847 idosos ambulatoriais com idade igual ou superior a 60 anos. Apesar da pesquisa ter sido realizada em idosos ambulatoriais, os resultados foram similares aos encontrados em indivíduos não institucionalizados. Nesse estudo, $9,3 \%$ dos homens e $23,8 \%$ das mulheres apresentaram IMC $\geq 30,0 \mathrm{~kg} / \mathrm{m}^{2}$. Quando separados por grupo etário, o grupo de $70-$ 79 anos foi o que apresentou maior prevalência de obesidade (21,9\%), em relação aos grupos de 60-69 anos (19,9\%) e 80 anos ou mais $(11,4 \%)$. Os autores sugeriram uma maior tolerância à obesidade entre as mulheres, contribuindo para a maior longevidade das idosas obesas em relação aos homens e explicando as diferenças nos índices de prevalência de obesidade entre os sexos.

Outro estudo brasileiro desenvolvido em Bambuí, Minas Gerais, também investigou o IMC de 1.451 idosos não institucionalizados com idade superior a 60 anos (Barreto e col. 2003). Nesse estudo, os autores relataram a ocorrência da 
obesidade em $12,8 \%$ dos idosos, e foi associada positivamente ao sexo feminino e à maior renda familiar. O baixo peso (considerado como IMC $\leq 20,0 \mathrm{~kg} / \mathrm{m}^{2}$ ) ocorreu em $14,8 \%$ dos idosos, aumentou com a idade, foi maior nos homens e nas familias com menor renda.

Um estudo recente, que investigou várias características antropométricas em 1.894 individuos com idade igual ou superior a 60 anos no município de São Paulo no ano de 2000, denominado Projeto SABE, relatou os seguintes valores médios para os homens: $\mathrm{IMC}=25,0 \mathrm{~kg} / \mathrm{m}^{2}$, perímetro do braço $=29,16 \mathrm{~cm}$ e prega cutânea tricipital $=13,71 \mathrm{~mm}$. Para as mulheres, os valores encontrados foram: $\mathrm{IMC}=27,26$ $\mathrm{kg} / \mathrm{m}^{2}$, perímetro do braço $=31,02 \mathrm{~cm}$ e prega cutânea tricipital $=25,22 \mathrm{~mm}$ (Marucci e Barbosa 2003).

Apesar de o IMC ser considerado indicador do estado nutricional segundo a Organização Mundial da Saúde (WHO 1995), estudos que descrevam dados de pregas cutâneas tricipital e subescapular; perímetros da cintura, do quadril e da panturrilha de idosos brasileiros, são ainda escassos. O Brasil, que apresenta diferentes características regionais, ainda carece de estudo que estabeleça o padrão antropométrico dos diferentes grupos etários que compreende a população brasileira.

Ainda que a antropometria seja considerada eficiente método de avaliação do estado nutricional, na medida do possível, deve-se realizar a avaliação bioquímica dos indivíduos, a qual irá confirmar ou acusar estados avançados de desnutrição.

\subsection{Avaliação bioquímica}

Variáveis bioquímicas são consideradas indicadores que refletem alteração do estado nutricional de um indivíduo (Kuczmarski MF e Kuczmarski RJ 1998). A descrição do perfil bioquímico caracteriza importante parte na avaliação do estado nutricional, tornando possivel detectar distúrbio nutricional ou confirmar um ou mais estágios avançados desse distúrbio (Groot e col. 1991). Existem diferentes variáveis bioquímicas que podem ser utilizadas na avaliação do estado nutricional de um indivíduo. Algumas das mais utilizadas compreendem concentração de glicose, de colesterol total, de triglicerídeos, de lipoproteínas de alta densidade (HDL-c) e de lipoproteinas de baixa densidade (LDL-c). Além do estado nutricional, essas 
variáveis podem diagnosticar o desenvolvimento de doenças não transmissiveis. Por exemplo, alto nível de colesterol total no sangue ( $\geq 240,0 \mathrm{mg} / \mathrm{dL})$, especialmente alto nível de LDL-c ( $\geq 160,0 \mathrm{mg} / \mathrm{dL})$, aumenta o risco para doença coronariana. Baixo nível de HDL-c $(<35,0 \mathrm{mg} / \mathrm{dL})$ parece aumentar o risco para doença coronariana, enquanto elevado nível de HDL-c diminui o risco (Kuczmarski 1998, Giannini 1998)

Vários estudos têm investigado o perfil bioquímico de populações idosas. Pesquisadores do Euronut SENECA investigaram os níveis séricos de lipídios de 2.151 idosos residentes em diferentes países da Europa. Neste estudo, os homens apresentaram niveis de colesterol total que variaram de 201,5 a $253,2 \mathrm{mg} / \mathrm{dL}$, e as mulheres entre 226,2 e 299,9 mg/dL. Para HDL, os valores encontrados em homens foram inferiores aos encontrados nas mulheres. Para níveis de triglicerideos, as maiores médias foram encontradas em noruegueses, também superiores nas mulheres. Houve diferença significativa entre os sexos apenas para colesterol total e HDL. Segundo os autores do estudo, os resultados obtidos através das variáveis bioquímicas analisadas indicaram que os idosos que vivem nos países do Mediterrâneo apresentam, em média, menores níveis lipídicos no soro (Kafatos e col. 1991).

Ledikwe e col. (2003), a partir de um estudo envolvendo 20.000 idosos residentes na área rural da Pensilvânia, Estados Unidos, e com 65 anos ou mais de idade, investigaram, entre outros marcadores bioquímicos, o colesterol total de 179 indivíduos. Destes, $16 \%$ dos homens e $24 \%$ das mulheres apresentaram valores de colesterol total acima de $240 \mathrm{mg} / \mathrm{dL}$, classificado como alto segundo a "III Diretrizes Brasileira sobre Dislipidemias e Diretriz de Prevenção da Aterosclerose do Departamento de Aterosclerose da Sociedade Brasileira de Cardiologia" (Sociedade Brasileira de Cardiologia 2001).

No Brasil, Marucci (1992) avaliou a glicemia de 127 idosos ambulatoriais com idade igual ou superior a 60 anos na cidade de São Paulo. Neste estudo, o valor médio de glicose encontrado foi $112,0 \mathrm{mg} / \mathrm{dL}$, onde $32 \%$ dos homens e $33 \%$ das mulheres apresentaram valores de glicose acima de $110,0 \mathrm{mg} / \mathrm{dL}$. Em relação a colesterol total, a média encontrada foi $227,0 \mathrm{mg} / \mathrm{dL}$, onde $87 \%$ dos homens e $49 \%$ das mulheres apresentaram valores para colesterol total acima de $200 \mathrm{mg} / \mathrm{dL}$. Para 
HDL-c, a média encontrada nos homens foi de $41,0 \mathrm{mg} / \mathrm{dL}$ e, nas mulheres, 47,0 $\mathrm{mg} / \mathrm{dL}$. Em relação a LDL-c, a média encontrada para o grupo estudado foi 163,0 $\mathrm{mg} / \mathrm{dL}$, estando $85 \%$ dos homens e $58 \%$ das mulheres com valores acima de 130,0 $\mathrm{mg} / \mathrm{dL}$. Embora $13 \%$ dos homens e 16\% das mulheres apresentassem valores de triglicerídeos acima de $200 \mathrm{mg} / \mathrm{dL}$, a valor médio encontrado para o grupo foi 138,0 $\mathrm{mg} / \mathrm{dL}$.

Cervato e col. (1997) investigaram a taxa de glicose sangüinea, o colesterol total e lipidios de 557 indivíduos com idade entre 20 e 88 anos residentes no município de Cotia, São Paulo. Esses pesquisadores relataram prevalência de 4,9\% para diabetes, e $25,9 \%$ para dislipidemias. A maioria dos indivíduos com dislipidemia apresentou baixos valores de HDL-c.

Fornés e col. (2000), em estudo desenvolvido também em Cotia-SP com 1.045 adultos (20 ou mais anos de idade), investigaram as concentrações de colesterol total, HDL-c, triglicerídeos e LDL-c. Neste estudo, 12\% dos indivíduos apresentaram LDL-c alto $(\geq 160,0 \mathrm{mg} / \mathrm{dL})$, sendo a maioria $(63,2 \%)$ mulheres. Em contrapartida, $60,0 \%$ das mulheres apresentaram HDL-c superior a $35 \mathrm{mg} / \mathrm{dL}$, considerado efeito protetor ao desenvolvimento de doenças do aparelho circulatório.

Cabrera e Jacob Filho (2001), em estudo desenvolvido na cidade de Londrina-PR, analisaram os valores de glicemia, colesterol total, HDL-c e triglicerídeos de 847 idosos ambulatoriais com idade igual ou superior a 60 anos. Os autores relataram que, dos 160 indivíduos com IMC $\geq 30,0 \mathrm{~kg} / \mathrm{m}^{2}, 18,2 \%$ dos homens e $26,9 \%$ da mulheres apresentaram diabetes mellitus (glicose $\geq 126 \mathrm{mg} / \mathrm{dL}$ ); $20,0 \%$ dos homens e $26,9 \%$ das mulheres apresentaram colesterol total alto ( $\geq 240,0 \mathrm{mg} / \mathrm{dL}$ ); $18,6 \%$ dos homens e $34,6 \%$ das mulheres apresentaram triglicerideos alto $(\geq 200,0$ $\mathrm{mg} / \mathrm{dL}$ ) e $14,6 \%$ dos homens e $45,8 \%$ das mulheres apresentaram HDL-c inferior a $35,0 \mathrm{mg} / \mathrm{dL}$ ).

Outro estudo realizado no Rio de Janeiro por Coeli e col. (2002), investigou a mortalidade em 2.974 declarações de óbitos de idosos (60 anos ou mais) ocorridas no ano de 1994. Destas, 291 óbitos tiveram o diabetes mellitus como causa básica e associada. Dos 291 óbitos estudados, 47,4\% ocorreram em homens, e 52,6\% em mulheres. Os óbitos em mulheres predominaram no grupo etário de 80 anos ou mais 
$(39,2 \%)$. As taxas de mortalidade apresentaram crescimento contínuo com o avançar da idade.

Barreto e col. (2003), em estudo realizado na cidade de Bambuí-MG, investigaram os níveis de glicose no plasma de 1.451 idosos. Dos 185 indivíduos com IMC $\geq 30,0 \mathrm{~kg} / \mathrm{m}^{2}, 53$ apresentaram diabetes mellitus, revelando associação positiva com a obesidade.

Tanto a avaliação antropométrica como bioquímica são considerados métodos de avaliação do estado nutricional. Outro método que auxilia na avaliação nutricional diz respeito à avaliação dietética. Para que se possa intervir de forma eficiente quanto a eventual má nutrição diagnosticada na avaliação nutricional, a avaliação dietética fornece dados importantes sobre o consumo de nutrientes do individuo.

\subsection{Avaliação dietética}

A avaliação dietética é freqüentemente utilizada em estudos epidemiológicos para verificar padrões de consumo e hábito alimentar. A alimentação é um importante fator para a avaliação nutricional. Eventuais alterações na dieta podem iniciar uma seqüência de eventos capaz de modificar o estado nutricional de um individuo (Kuczmarski MF e Kuczmarski RJ 1998). Os métodos de avaliação da dieta variam de acordo com as diferentes situações do estudo. Para estudos epidemiológicos, é importante que o método seja simples e que possa ser rapidamente administrado a um grande número de pessoas e, ao mesmo tempo, que seja representativo da dieta do individuo (Lasheras e col. 1999). A escolha do melhor método deve levar em consideração o tamanho da população que se deseja estudar e os recursos disponíveis para tal, de forma a garantir o sucesso do trabalho. Existem vários métodos para avaliação da dieta: diário alimentar, questionário de freqüência do consumo alimentar, recordatório de 24 horas, entre outros (Czajka-Narins 1995). Destes, o recordatório de 24 horas é um dos mais utilizados em pesquisas envolvendo grupos de população de 50 ou mais indivíduos. Neste método, o indivíduo informa sobre o consumo de alimentos e bebidas ingeridos nas últimas 24 horas. Algumas vantagens incluem o tempo curto de realização e a característica de 
não necessitar de acentuada memória para o registro dos dados. As desvantagens do recordatório de 24 horas estão relacionadas a incapacidade, por parte de alguns indivíduos, em responder com precisão as espécies e quantidades dos alimentos ingeridos; eventuais ingestões atípicas efetuadas no dia anterior e, em algumas situações, vergonha em responder a verdade (Kuczmarski MF e Kuczmarski RJ 1998, Czajka-Narins 1995).

Alguns estudos têm registrado a avaliação dietética de pessoas acima de 60 anos. Moreiras e col. (1991) avaliaram o consumo alimentar de 2.458 idosos não institucionalizados em diferentes países da Europa. Os autores relataram haver diferença significativa entre os sexos para total calórico e consumo de nutrientes em todas os países investigados. A média de total calórico variou de 1.960 a $3.035 \mathrm{kcal}$ em homens, e 1.506 a $2.605 \mathrm{kcal}$ em mulheres. A contribuição percentual de proteínas da dieta variou de 12,4 a 16,6\% para homens, e 12,9 a 18,3\% para mulheres. Segundo os autores do estudo, a média de contribuição calórica de proteínas na dieta obtida no estudo excedeu os padrões de dieta da Europa (Moreiras e col. 1991). Uma dieta rica em proteínas pode levar a hiperfiltração renal crônica e, desta forma, contribuir para a deterioração dos rins (Brenner e col. 1982). Em relação a carboidratos, a contribuição na dieta variou de 39,9 a $53,8 \%$ para homens, e 40,5 a $57,1 \%$ para mulheres. Para lipídios, a contribuição na dieta variou de 25,0 a $41,9 \%$ nos homens, e 26,3 a 44,7\% nas mulheres Moreiras e col. (1991).

Vellas e col. (1997), em estudo realizado Novo México, avaliaram a dieta de 304 idosos não institucionalizados acima de 60 anos de idade. As mulheres que apresentaram total calórico inferior a $25 \mathrm{kcal} / \mathrm{kg}$ ou superior a $30 \mathrm{kcal} / \mathrm{kg}$, segundo recomendado pela Recommended Daily Allowance - RDA, foram mais susceptiveis a tornarem-se debilitadas, magras ou morrerem, em relação às mulheres que consumiram uma dieta intermediária (entre 25 e $30 \mathrm{kcal} / \mathrm{kg}$ ). Esses autores revelaram, ainda, que as mulheres com maior consumo de proteinas $(1,2-1,76 \mathrm{~g} / \mathrm{kg}$ de peso corporal) demonstraram ter menos problemas de saúde ao longo dos 10 anos de estudo em relação às mulheres que consumiram abaixo de $0,8 \mathrm{~g}$ de proteína por $\mathrm{kg}$ de peso corporal, sugerindo que o requerimento para consumo médio de proteína em pessoas acima de 60 anos deva ser maior do que o estabelecido em 1985 pelo World Health Organization/FAO/UNU Expert Committee. 
$\mathrm{Na}$ Espanha, Lasheras e col. (1999) avaliaram a dieta de 352 idosos institucionalizados e não institucionalizados com idade entre 65 e 95 anos. Nesse estudo, os autores revelaram que a dieta dos idosos investigados foi baixa em carboidratos e rica em gordura. Para os idosos não institucionalizados, 45,1\% dos homens e $24,5 \%$ das mulheres consumiam menos do que $15 \%$ de proteína na dieta, $95,0 \%$ dos homens e $84,7 \%$ das mulheres consumiam menos do que $55 \%$ de carboidratos, $59,7 \%$ das mulheres e $13,3 \%$ dos homens consumiam menos do que $30 \%$ de lipídios na dieta. O valor energético obtido da dieta também foi considerado baixo, sendo $1.893,8 \mathrm{kcal}$ para homens e $1.621,8 \mathrm{kcal}$ para mulheres, ambos não institucionalizados.

Em estudo recente conduzido com americanos, Ledikwe e col. (2003) investigaram o risco nutricional e obesidade de 179 idosos residentes na área rural. Neste estudo, o total calórico consumido pelos homens foi significativamente superior $(1.810 \mathrm{kcal} / \mathrm{dia})$ em relação às mulheres $(1.410 \mathrm{kcal} / \mathrm{dia})$. Quanto à contribuição dos macronutrientes, os homens também consumiram mais proteínas (70,0 g/dia), carboidratos $(239,0 \mathrm{~g} / \mathrm{dia})$ e lipídios $(64,1 \mathrm{~g} /$ dia $)$, em relação às mulheres: $54,1 \mathrm{~g} / \mathrm{dia}, 193,8 \mathrm{~g} / \mathrm{dia}$ e $49,2 \mathrm{~g} / \mathrm{dia}$, respectivamente para proteínas, carboidratos e lipídios.

No Brasil, existem poucos dados referentes à avaliação dietética de idosos não institucionalizados em diferentes regiões do país. Marucci (1992), verificou o hábito alimentar de 308 idosos matriculados em ambulatório geriátrico na cidade de São Paulo. A autora mostrou que os alimentos construtores (carnes, leite e derivados, ovos) contribuíram com 30,3\% do total da dieta, os energéticos (cereais, gorduras, feculentos, açúcar e doces) contribuíram com $27,9 \%$ e os reguladores (frutas, verduras e legumes) com $32,7 \%$.

Najas e col. (1994) verificaram o padrão alimentar de 283 idosos em diferentes estratos sócio-econômicos residentes na área urbana de São Paulo e verificaram que $90 \%$ dos indivíduos ingeriram alimentos feculentos, arroz, pão e macarrão. Quanto ao grupo de alimentos protéicos, $70 \%$ ou mais dos idosos consumiram feijão, carne de boi, aves, leite e ovos. Dos reguladores, mais de $85 \%$ dos idosos tinham por hábito consumir frutas, verduras folhosas e legumes. Cervato e col. (1997) investigaram a dieta habitual de 557 individuos com idade entre 20 e 88 
anos residentes no município de Cotia, São Paulo. Segundo os autores, o total calórico da dieta reduziu com a idade: de um valor mediano de, aproximadamente $2.000 \mathrm{kcal} / \mathrm{dia}$ para cerca de $1.300 \mathrm{kcal}$ no grupo etário de 60 anos e mais, no caso das mulheres e de $2.700 \mathrm{kcal}$ para $1.900 \mathrm{kcal}$, para os homens. Em relação à contribuição energética entre os macronutrientes para os 557 indivíduos estudados, os carboidratos contribuíram com $56 \%$, os lipídios com $29 \%$ e as proteínas com $15 \%$.

Em Santa Catarina, até o momento, não existe registro de estudos que investigaram o estado nutricional e consumo de macronutrientes em pessoas com idade igual ou superior a 60 anos e não institucionalizadas. Face ao rápido aumento deste grupo etário no país, esta é uma questão importante que merece especial atenção.

\subsection{Estado de Santa Catarina}

Santa Catarina está localizada entre os estados do Rio Grande do Sul e Paraná, formando a região sul do país. Representada por 29 regiões e 293 municípios, a população catarinense é caracteristicamente homogênea devido, principalmente, a colonização européia que aportou no litoral no início do século XVI.

Segundo o último censo demográfico de 2000, a esperança de vida ao nascer de Santa Catarina ocupa a segunda maior posição do Brasil, 71,3 anos, atrás apenas do Rio Grande do Sul, com 71,6 anos e maior que a média nacional que em 2000 era de 70,5 anos.

Entre as cidades mais importantes do estado destacam-se a capital Florianópolis, e os municípios de Blumenau e Joinville (Santa Catarina 2003).

\subsection{A cidade de Joinville, SC}

Joinville está localizada geograficamente na região sul do Brasil, a nordeste do Estado de Santa Catarina (Figura 2) e possui, atualmente, 428.974 habitantes (Figura 3). 


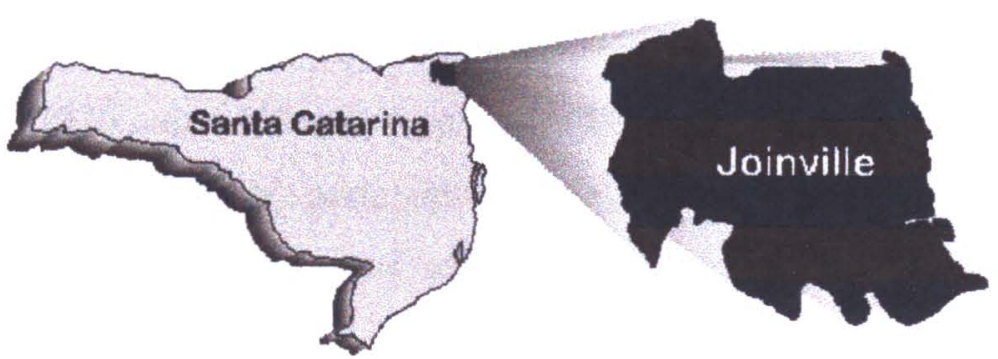

Figura 2. Localização geográfica da cidade de Joinville no Estado de Santa Catarina.

Município pólo da Microrregião Nordeste do Estado de Santa Catarina, Joinville foi fundada por imigrantes europeus em março de 1851 (Cunha 2001), completando em 2003, 152 anos de existência. Atualmente, a cidade ainda mantém a característica européia, principalmente no que diz respeito ao estilo de vida não sedentário da população.

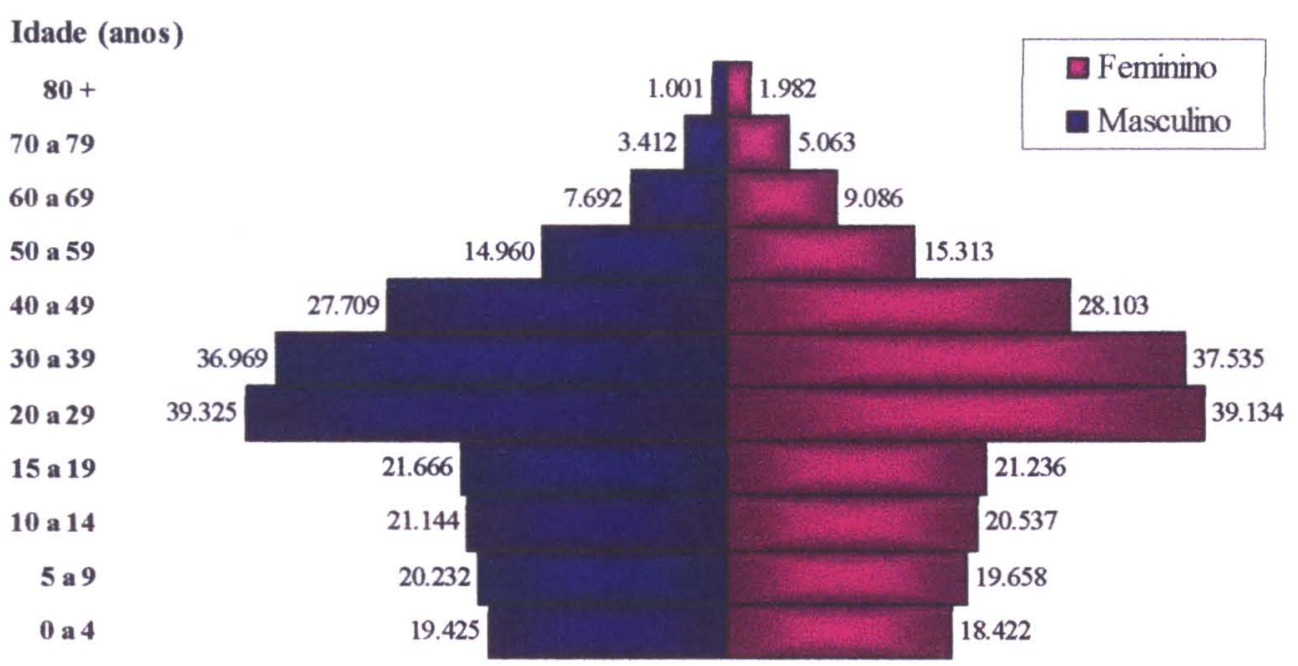

Figura 3. Distribuição da população residente em Joinville no ano de 2000, segundo grupo etário. Fonte: Fundação IBGE (2003). 
Além da paixão pelas flores, estabelecida por descendentes alemães e que se mantém desde 1936 com a criação da primeira Festa das Flores, outra grande paixão do joinvillense é a bicicleta, onde um grande número de trabalhadores continua mantendo o hábito de se deslocar até seu local de trabalho utilizando-se da conhecida "magrela" (Joinville 2003).

Outra característica importante da cidade é o eficiente sistema de saúde que atende a população. Atualmente, a rede ambulatorial do Sistema Único de Saúde SUS, conta com 262 unidades, entre as quais: 67 centros de saúde, 38 consultórios, 44 unidades de saúde da família, 32 clínicas especializadas, entre outros (Ministério da Saúde 2003).

Algumas características gerais do Município encontram-se descritas na Tabela 1 .

Tabela 1. Características gerais do Município de Joinville, Santa Catarina, Brasil, no ano de 2000.

\begin{tabular}{lrr}
\hline Características & & $1.079,72$ \\
\hline Área $\left(\mathrm{km}^{2}\right)$ & 428.974 habitantes \\
População & & Indústria \\
Economia & & Plana \\
Região geográfica & 28.236 habitantes \\
Número de idosos ( $\geq 60$ anos) & $\mathbf{n}$ & $\%$ \\
Mortalidade & 1.944 & 100,0 \\
Mortalidade total da população & 472 & 24,2 \\
$\quad$ Aparelho circulatório & 281 & 14,5 \\
$\quad$ Neoplasias & 215 & 11,1 \\
$\quad$ Causas externas & 976 & 50,2 \\
$\quad$ Outras causas & 1.072 & 55,1 \\
Mortalidade de pessoas $\geq 60$ anos de idade & 336 & 31,3 \\
$\quad$ Aparelho circulatório & 144 & 13,4 \\
$\quad$ Neoplasias & 28 & 2,6 \\
Causas externas & 564 & 52,6 \\
$\quad$ Outras causas & &
\end{tabular}

Fonte: Ministério da Saúde (2000); Fundação IBGE (2001). 
Acompanhando o processo de envelhecimento da população mundial, a população idosa de Joinville também vem aumentando consideravelmente nos últimos anos. A Figura 4 mostra o aumento de $151 \%$ na população idosa de Joinville nos últimos 20 anos, passando de 11.263 idosos em 1980, para 28.236 idosos em 2000 (Fundação IBGE 2003). Este expressivo crescimento do número de idosos na cidade em questão realça a incontestável necessidade de se estabelecer programas de saúde pública que incentivem a manutenção da prática de um estilo de vida saudável, para os que já possuem, e a adesão àqueles que segue o estilo inadequado de viver.

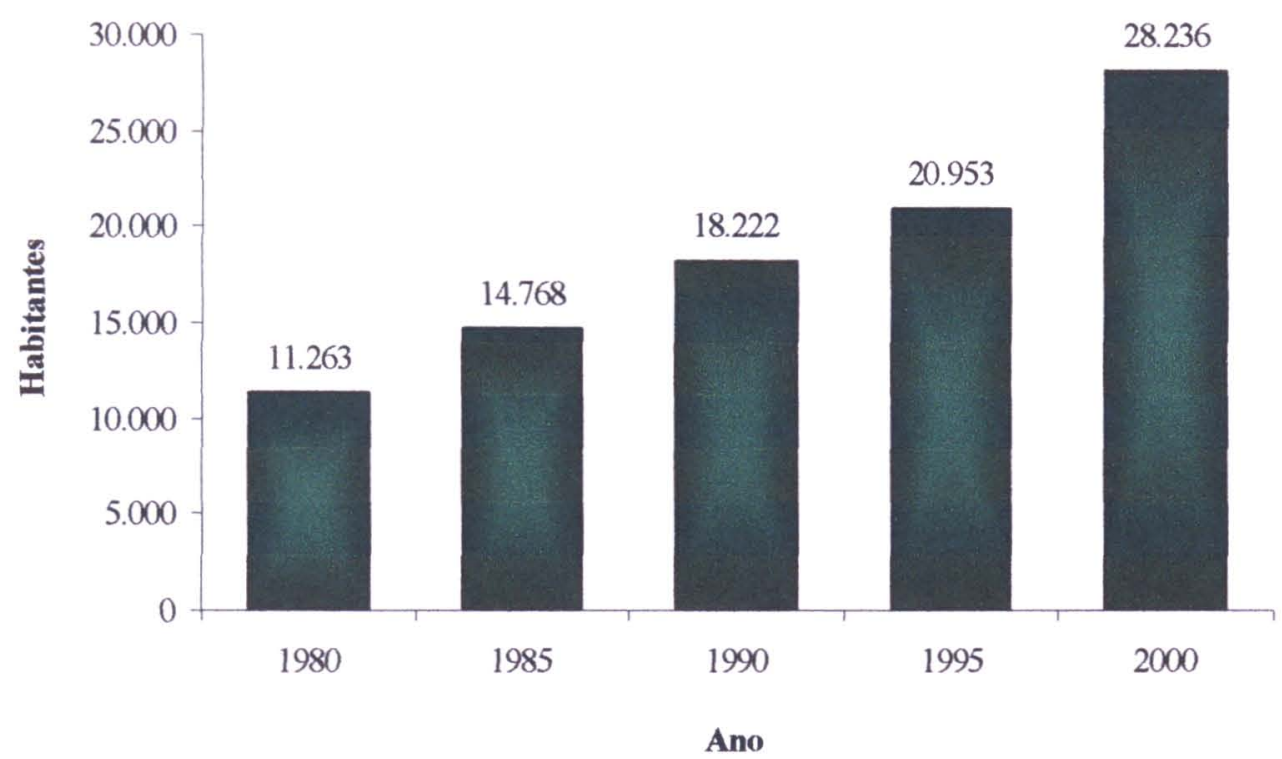

Figura 4. Evolução da população idosa de Joinville entre 1980-2000. Fonte: Fundação IBGE (2003). 


\section{OBJETIVOS}

\subsection{Geral}

Avaliar o estado nutricional e o consumo de macronutrientes de idosos da cidade de Joinville, SC.

\subsection{Específicos}

1. Analisar a antropometria em relação a Índice de Massa Corporal, perímetro do braço e prega cutânea tricipital, segundo o sexo;

2. Analisar as variáveis bioquímicas: glicose, colesterol total, HDL-c, LDLc e triglicerídeos, segundo o sexo;

3. Analisar a dieta em relação a energia e macronutrientes (proteínas, carboidratos e lipídios), segundo o sexo; 


\section{HIPÓTESE}

O estado nutricional dos idosos da cidade de Joinville-SC encontra-se adequado. 


\section{MÉTODOS}

Este estudo foi desenvolvido na cidade de Joinville-SC, no período de 02/2001 a 04/2003, com a participação dos Departamentos de Nutrição e de Epidemiologia da Faculdade de Saúde Pública - Universidade de São Paulo. O estudo contou, ainda, com o apoio dos Departamentos de Farmácia e de Educação Física da Universidade da Região de Joinville-UNIVILLE, Secretaria de Saúde de Joinville, Laboratório Gimenes e Fundação Instituto Brasileiro de Geografia e Estatística de Joinville.

\subsection{Amostragem}

Trata-se de estudo de base populacional, transversal e realizado mediante inquérito domiciliar. A população de estudo foi composta por 28.236 idosos (Fundação IBGE 2000a) com idade igual ou superior a 60 anos (Brasil 1996), de ambos os sexos, não institucionalizados e residentes na cidade de Joinville-SC, no ano de 2002.

\subsubsection{Composição da amostra}

O tamanho da amostra foi definido a partir dos recursos financeiros, recursos humanos e de tempo, disponíveis para o desenvolvimento do estudo. Assim, determinou-se como aceitável entrevistar entre 600 e 800 idosos.

Nessas circunstâncias, o erro de amostragem para estimar proporções em processo aleatório simples, manteve-se abaixo de $5 \%$, indicando um número mínimo de 384 entrevistas para coeficiente de confiança igual a 95\%, conforme Silva (2000). O número mínimo fixado entre 600 e 800 idosos, atendeu à necessidade de proteger à precisão fixada devido ao efeito de homogeneidade intra setor censitário (Kish 1965), a ser tomado como unidade primária de amostragem.

O sorteio de 800 idosos foi realizado em dois estágios, sob o método de partilha proporcional ao tamanho - PPT (KISH 1965, Silva 2000), tomando o setor 
censitário e a moradia como respectivas unidades de primeiro e segundo estágio. Tolos os idosos localizados em cada moradia foram entrevistados.

Adotando-se 20 entrevistas como sendo o número máximo tolerado a ser obtido dentro de cada unidade primária (Kish 1965). estimou-se o número de moradias a serem visitadas, em cada setor, através da razão:

$$
20 \times(2,1 / 10)=95,24
$$

onde a razão $2,1 / 10$ é o número de idosos residentes (28.236 idosos/132.388 domicílios), esperado encontrar por moradia (Fundação IBGE 2000a).

Calculou-se o número total de moradias a serem sorteadas a partir do número máximo de 800 idosos, estipulado para compor a amostra, seguindo-se a razão:

$800 /(2,1 / 10)=3.809,5$, arredondado para 4.000 moradias.

Dividiu-se o número total de moradias a serem sorteadas pelo número de moradias a serem visitadas em cada setor, fornecendo, como resultado, o número de setores censitários que compõem a amostra de primeiro estágio:

$$
4.000 / 95,24=41,99 \text {. }
$$

Finalmente, a amostra de idosos foi obtida multiplicando-se o número máximo de entrevistas em cada setor pelo número de setores que compõem a amostra de primeiro estágio:

$20 \times 42=840$.

A Tabela 2 resume os cálculos efetuados para definir o número total de moradias na amostra, e dentro de cada setor censitário. 
Tabela 2. Cálculo do número total de moradias na amostra e dentro de cada setor censitário.

\begin{tabular}{ccc}
\hline Unidades & Cálculo & Total \\
\hline Idosos & - & $\mathbf{8 0 0}$ \\
Moradias & $\mathbf{8 0 0 \times ( 2 , 1 / 1 0 )}$ & $3.809,5=\mathbf{4 . 0 0 0}$ \\
Setores & $4.000 / 95,24$ & $41,99=\mathbf{4 2}$ \\
\hline
\end{tabular}

\subsubsection{Processo de sorteio}

$\mathrm{Na}$ Tabela 3 estão descritos os 407 setores censitários que compõem o município de Joinville. $\mathrm{O}$ esquema do processo de sorteio dos setores censitários utilizados para compor estudo foi demonstrado na Figura 5.

\section{Município de Joinville: 407 Setores censitários}

Distrito de Joinville possui 387 setores $\left\{\begin{array}{l}\text {.Área urbana: } 375 \text { (setores 1-375) } \\ \text {.Área rural: } 12 \text { (setores 376-387) }\end{array}\right.$

Distrito de Pirabeiraba possui 20 setores $\left\{\begin{array}{l}. \text { Área urbana: } 10 \text { (setores 1-10) } \\ \text {.Área rural: } 10 \text { (setores 11-20) }\end{array}\right.$

Total de setores da área urbana no município de Joinville: 385

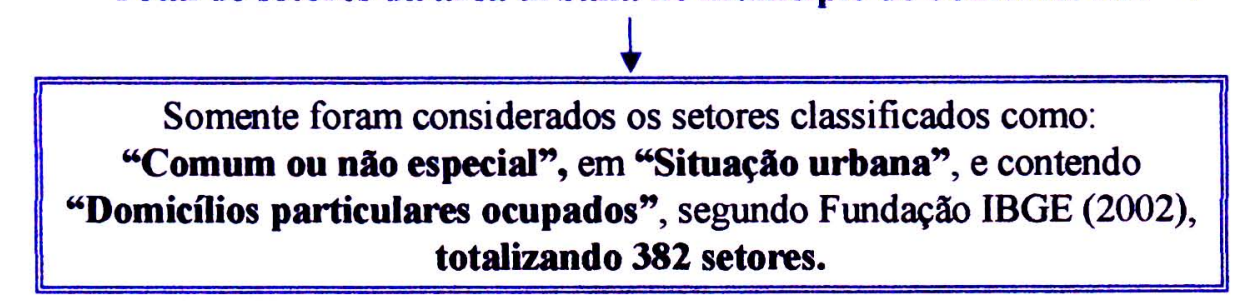

Figura 5. Composição do cadastro das unidades primárias para o sorteio de primeiro estágio. 
Tabela 3. Descrição dos 407 setores censitários que compõem o município de Joinville, destacando setores eliminados e sorteados. 2002.

\begin{tabular}{|c|c|c|c|c|}
\hline $\begin{array}{c}\text { Setor } \\
\text { censitário }\end{array}$ & $\begin{array}{c}\text { Situapá do } \\
\text { setor }\end{array}$ & Tipo do setor & $\begin{array}{c}\text { Domidilios - área } \\
\text { urbena }\end{array}$ & Nome do Distrito \\
\hline 1 & 1 & 0 & 387 & Joimville \\
\hline 2 & 1 & 0 & 407 & Joimville \\
\hline 3 & 1 & 0 & 283 & Joimville \\
\hline 4 & 1 & 0 & 432 & Joimville \\
\hline 5 & 1 & 0 & 433 & Joimville \\
\hline 6 & 1 & 0 & 256 & Joimville \\
\hline 7 & 1 & 0 & 309 & Joimville \\
\hline 8 & 1 & 0 & 264 & Joimville \\
\hline 9 & 1 & 0 & 246 & Joimville \\
\hline 10 & 1 & 0 & 309 & Joimville \\
\hline 11 & 1 & 0 & 308 & Joimville \\
\hline 12 & 1 & 0 & 301 & Joimville \\
\hline 13 & 1 & 0 & 233 & Joimille \\
\hline 14 & 1 & 0 & 305 & Joimville \\
\hline 15 & 1 & 0 & 280 & Joimville \\
\hline 16 & 1 & 0 & 280 & Joinville \\
\hline 17 & 1 & 0 & 278 & Joimville \\
\hline 18 & 1 & 0 & 265 & Joimville \\
\hline 19 & 1 & 0 & 266 & Joimville \\
\hline 20 & 1 & 0 & 463 & Joimville \\
\hline 21 & 1 & 0 & 437 & Joimville \\
\hline 22 & 1 & 0 & 327 & Joimville \\
\hline 23 & 1 & 0 & 251 & Joimville \\
\hline 24 & 1 & 0 & 379 & Joimville \\
\hline 25 & 1 & 0 & 315 & Joimville \\
\hline 26 & 1 & 0 & 354 & Joimville \\
\hline 27 & 1 & 0 & 311 & Joimville \\
\hline 28 & 1 & 0 & 271 & Joimville \\
\hline 29 & 1 & 0 & 414 & Joimville \\
\hline 30 & 1 & 0 & 320 & Joimville \\
\hline 31 & 1 & 0 & 393 & Joinville \\
\hline 32 & 1 & 0 & 380 & Joimville \\
\hline 33 & 1 & 0 & 279 & Joimville \\
\hline 34 & 1 & 0 & 376 & Joimille \\
\hline 35 & 1 & 0 & 294 & Joimville \\
\hline 36 & 1 & 0 & 254 & Joimville \\
\hline 37 & 1 & 0 & 304 & Joimville \\
\hline 38 & 1 & 0 & 205 & Joimville \\
\hline 39 & 1 & 0 & 269 & Joimville \\
\hline 40 & 1 & 0 & 266 & Joimville \\
\hline 41 & 1 & 0 & 238 & Joimville \\
\hline 42 & 1 & 0 & 280 & Joimville \\
\hline 43 & 1 & 0 & 361 & Joimville \\
\hline 44 & 1 & 0 & 255 & Joimville \\
\hline 45 & 1 & 0 & 274 & Joimville \\
\hline 46 & 1 & 0 & 383 & Joinville \\
\hline 47 & 1 & 0 & 301 & Joimville \\
\hline 48 & 1 & 0 & 237 & Joimville \\
\hline 49 & 1 & 0 & 300 & Joimville \\
\hline 50 & 1 & 0 & 341 & Joimville \\
\hline 51 & 1 & 0 & 315 & Joimville \\
\hline 52 & 1 & 0 & 321 & Joimville \\
\hline 53 & 1 & 0 & 344 & Joimville \\
\hline 54 & 1 & 0 & 219 & Joimville \\
\hline 55 & 1 & 0 & 268 & Joinville \\
\hline 56 & 1 & 0 & 319 & Joimville \\
\hline 57 & 1 & 0 & 309 & Joimville \\
\hline 58 & 1 & 0 & 264 & Joinville \\
\hline 59 & 1 & 0 & 364 & Joimville \\
\hline 60 & 1 & 0 & 501 & Joimville \\
\hline 61 & 1 & 0 & 341 & Joimville \\
\hline 62 & 1 & 0 & 333 & Joinville \\
\hline 63 & 1 & 0 & 424 & Joimville \\
\hline 64 & 1 & 0 & 333 & Joimville \\
\hline 65 & 1 & 0 & 319 & Joimville \\
\hline 66 & 1 & 0 & 347 & Joimville \\
\hline 67 & 1 & 0 & 306 & Joimville \\
\hline 68 & 1 & 0 & 299 & Joimville \\
\hline
\end{tabular}

Legenda:

Eliminados

Sorteados

Situaçlo do setor:

Situação urbana:

1. Área urbanizada de cidade ou vila

2. Área näo urbanizada de cidade ou vila

3. Área urbanizada isolada

Situaçăo rural:

4. Aglomerado rural de extensão urbana

5. Aglomerado rural isolado - povoado

6. Aglomerado rural isolado - núcleo

7. Aglomerado rural isolado - outros agiomerados

8. Zona rural exclusive aglomerado rural

Tipo do setor:

0. Comum ou não especial

6. Especial de penitenciárias, colônias penais, presídios, cadeias, etc.

7. Especial de asilos, orfanatos, conventos,

Total $=\mathbf{4 2}$ setores censitirioc. 
Continuação Tabela 3.

\begin{tabular}{|c|c|c|c|c|c|c|c|c|c|}
\hline $\begin{array}{c}\text { Sotar } \\
\text { conniatario }\end{array}$ & Situeglio & Tipo & $\begin{array}{c}\text { Domiolios } \\
\text { perticulares couppedos. } \\
\text { tres urbana }\end{array}$ & Nome do Distrito & $\begin{array}{c}\text { Setor } \\
\text { consitario }\end{array}$ & Situeglio & Tipo & $\begin{array}{c}\text { Domicílios } \\
\text { perticularces couppodos. } \\
\text { troe urbana }\end{array}$ & Nome do Distrito \\
\hline 69 & 1 & 0 & 279 & Joimille & 137 & 1 & $\overline{0}$ & 462 & Joimville \\
\hline 70 & 1 & 0 & 251 & Joimville & 138 & 1 & 0 & 289 & Joinville \\
\hline 71 & 1 & 0 & 350 & Joimville & 139 & 1 & 0 & 424 & Joinville \\
\hline 72 & 1 & 0 & 271 & Joinville & 140 & 1 & 0 & 341 & Joimville \\
\hline 73 & 1 & 0 & 214 & Joimville & 141 & 1 & 0 & 375 & Joinville \\
\hline 74 & 1 & 0 & 313 & Joinville & 142 & 1 & 0 & 394 & Joimville \\
\hline 75 & 1 & 0 & 324 & Joinville & 143 & 1 & 0 & 314 & Joinville \\
\hline 76 & 1 & 0 & 255 & Joinville & 144 & 1 & 0 & 323 & Joimville \\
\hline 77 & 1 & 0 & 340 & Joinville & 145 & 1 & 0 & 406 & Joinville \\
\hline 78 & 1 & 0 & 295 & Jaimville & 146 & 1 & $\mathbf{0}$ & 335 & Jaimille \\
\hline 79 & 1 & o & 196 & Joimville & 147 & 1 & 0 & 339 & Jaimville \\
\hline 80 & 1 & 0 & 304 & Joinville & 148 & 1 & $\mathbf{0}$ & 372 & Joinville \\
\hline 81 & 1 & $\mathbf{0}$ & 284 & Joinville & 149 & 1 & $\mathbf{0}$ & 293 & Joimville \\
\hline 82 & 1 & 0 & 294 & Joimville & 150 & 1 & 0 & 284 & Joimille \\
\hline 83 & 1 & 0 & 365 & Joimville & 151 & 1 & o & 341 & Joimville \\
\hline 84 & 1 & 0 & 346 & Jainville & 152 & 1 & $\mathbf{0}$ & 438 & Jaimville \\
\hline 85 & 1 & 0 & 328 & Jainville & 153 & 1 & 0 & 372 & Joimville \\
\hline 86 & 1 & $\mathbf{0}$ & 302 & Joimville & 154 & 1 & 0 & 299 & Joimville \\
\hline 87 & 1 & 0 & 332 & Joimville & 155 & 1 & $\mathbf{0}$ & 462 & Joimville \\
\hline 88 & 1 & 0 & 227 & Joimville & 156 & 1 & 0 & 269 & Joimville \\
\hline 89 & 1 & 0 & 348 & Joimville & 157 & 1 & 0 & 350 & Joimville \\
\hline 90 & 1 & $\mathbf{0}$ & 338 & Joimville & 158 & 1 & $\mathbf{0}$ & 338 & Jaimville \\
\hline 91 & 1 & $\mathbf{0}$ & 199 & Joimville & 159 & 1 & 0 & 531 & Joimille \\
\hline 92 & 1 & 0 & 339 & Joinville & 160 & 1 & 0 & 392 & Joimville \\
\hline 93 & 1 & $\mathbf{0}$ & 320 & Joirville & 161 & 1 & o & 349 & Jairville \\
\hline 94 & 1 & 0 & 276 & Joinville & 162 & 1 & 0 & 315 & Joimville \\
\hline 95 & 1 & 0 & 346 & Joimville & 163 & 1 & 0 & 171 & Joimville \\
\hline 96 & 1 & o & 351 & Joimville & 164 & 1 & o & 270 & Joimville \\
\hline 97 & 1 & 0 & 552 & Joimville & 165 & 1 & 0 & 310 & Joirville \\
\hline 98 & 1 & 0 & 327 & Joimville & 166 & 1 & 0 & 373 & Joimville \\
\hline 99 & 1 & 0 & 213 & Joimville & 167 & 1 & 0 & 330 & Joimville \\
\hline 100 & 1 & 0 & 382 & Joimville & 168 & 1 & 0 & 320 & Joimville \\
\hline 101 & 1 & 0 & 296 & Joimville & 169 & 1 & o & 349 & Joinville \\
\hline 102 & 1 & 0 & 328 & Jaimville & 170 & 1 & 0 & 369 & Joimville \\
\hline 103 & 1 & o & 305 & Joimville & 171 & 1 & 0 & 313 & Joimville \\
\hline 104 & 1 & 0 & 263 & Joinville & 172 & 1 & o & 347 & Joimville \\
\hline 105 & 1 & 0 & 248 & Joinville & 173 & 1 & 0 & 322 & Joimville \\
\hline 106 & 1 & o & 336 & Joimville & 174 & 1 & 0 & 251 & Joinville \\
\hline 107 & 1 & 0 & 363 & Joimville & 175 & 1 & 0 & 283 & Jaimille \\
\hline 108 & 1 & 0 & 286 & Joimville & 176 & 1 & 0 & 364 & Joinville \\
\hline 109 & 1 & 0 & 296 & Joimville & 17 & 1 & 0 & 356 & Jaimille \\
\hline 110 & 1 & 0 & 334 & Joinville & 178 & 1 & 0 & 315 & Joimville \\
\hline 111 & 1 & o & 320 & Joimville & 179 & 1 & o & 315 & Joinville \\
\hline 112 & 1 & 0 & 344 & Joimille & 180 & 1 & 0 & 355 & Joimville \\
\hline 113 & 1 & 0 & 319 & Joimville & 181 & 1 & o & 306 & Joinville \\
\hline 114 & 1 & 0 & 274 & Joimville & 182 & 1 & 0 & 367 & Joimville \\
\hline 115 & 1 & 0 & 363 & Joimville & 183 & 1 & 0 & 294 & Jaimville \\
\hline 116 & 1 & 0 & 269 & Joimville & 184 & 1 & o & 275 & Joimville \\
\hline 117 & 1 & 0 & 318 & Joimville & 185 & 1 & 0 & 359 & Joimville \\
\hline 118 & 1 & 0 & 335 & Joimville & 186 & 1 & 0 & 435 & Joinville \\
\hline 119 & 1 & 0 & 113 & Joimville & 187 & 1 & 0 & 279 & Joimville \\
\hline 120 & 1 & 0 & 376 & Joimville & 188 & 1 & 0 & 419 & Joimville \\
\hline 121 & 1 & 0 & 245 & Joimville & 189 & 1 & 0 & 274 & Jainville \\
\hline 122 & 1 & 0 & 201 & Jaimville & 190 & 1 & 0 & 308 & Joimville \\
\hline 123 & 1 & 0 & 408 & Joimille & 191 & 1 & 0 & 254 & Jaimville \\
\hline 124 & 1 & 0 & 323 & Joimville & 192 & 1 & 0 & 278 & Joimville \\
\hline 125 & 1 & 7 & 285 & Joinville & 193 & 1 & 0 & 332 & Jaimville \\
\hline 126 & 1 & 0 & 336 & Joimville & 194 & 1 & 0 & 210 & Joimville \\
\hline 127 & 1 & 0 & 266 & Joinville & 195 & 1 & 0 & 304 & Joimville \\
\hline 128 & 1 & o & 247 & Joimville & 196 & 1 & 0 & 374 & Joimville \\
\hline 129 & 1 & 0 & 286 & Joimville & 197 & 1 & 0 & 302 & Joimville \\
\hline 130 & 1 & 0 & 289 & Joimville & 198 & 1 & 0 & 330 & Joimville \\
\hline 131 & 1 & 0 & 381 & Joimville & 199 & 1 & 0 & 529 & Joimville \\
\hline 132 & 1 & 0 & 297 & Joimville & 200 & 1 & 0 & 307 & Joimville \\
\hline 133 & 1 & o & 345 & Joimille & 201 & 1 & 0 & 355 & Joimville \\
\hline 134 & 1 & 0 & 393 & Jaimville & 202 & 1 & 0 & 286 & Joinville \\
\hline 135 & 1 & 0 & 426 & Joimville & 203 & 1 & 0 & 393 & Joimville \\
\hline 136 & 1 & 0 & 370 & Jaimille & 204 & 1 & 0 & 355 & Joimille \\
\hline
\end{tabular}


Continuação Tabela 3.

\begin{tabular}{|c|c|c|c|c|c|c|c|c|c|}
\hline $\begin{array}{c}\text { Setor } \\
\text { censitánio }\end{array}$ & Situą̧̃o & Tipo & $\begin{array}{c}\text { Dorrićlios } \\
\text { particulares ocupados. } \\
\text { area urbana }\end{array}$ & Nome do Distrito & $\begin{array}{c}\text { Setor } \\
\text { censitário }\end{array}$ & Situaç̆o & Tipo & $\begin{array}{c}\text { Domicilios } \\
\text { perticulares ocupados. } \\
\text { area urbana }\end{array}$ & Nome do Distrito \\
\hline 205 & $T$ & 0 & 376 & Joimille & 273 & $\overline{1}$ & $\overline{0}$ & 276 & Joinville \\
\hline 206 & 1 & 0 & 340 & Joinville & 274 & 1 & 0 & 406 & Joimville \\
\hline 207 & 1 & $\mathbf{0}$ & 373 & Joimville & 275 & 1 & $\mathbf{0}$ & 17 & Joimville \\
\hline 208 & 1 & 0 & 353 & Joimville & 276 & 1 & 0 & 293 & Jaiaville \\
\hline 209 & 1 & 0 & 380 & Joimville & 277 & 1 & $\mathbf{0}$ & 321 & Joimville \\
\hline 210 & 1 & 0 & 485 & Joimille & 278 & 1 & 0 & 308 & Joirville \\
\hline 211 & 1 & 0 & 310 & Joinville & 279 & 1 & 0 & 313 & Joimville \\
\hline 212 & 1 & o & 356 & Joimville & 280 & 1 & 0 & 308 & Joinville \\
\hline 213 & 1 & 0 & 294 & Joimille & 281 & 1 & 0 & 403 & Joimville \\
\hline 214 & 1 & $\mathbf{0}$ & 452 & Joimville & 282 & 1 & $\mathbf{0}$ & 295 & Joinville \\
\hline 215 & 1 & $\mathbf{0}$ & 307 & Joimville & 283 & 1 & 0 & 318 & Joinville \\
\hline 216 & 1 & 0 & 275 & Joimville & 284 & 1 & 0 & 311 & Joimville \\
\hline 217 & 1 & $\mathbf{0}$ & 364 & Joimville & 283 & 1 & 0 & 301 & Joimville \\
\hline 218 & 1 & $\mathbf{0}$ & 541 & Joimville & 286 & 1 & 0 & 335 & Joinville \\
\hline 219 & 1 & 0 & 870 & Joimville & 287 & 1 & 0 & 328 & Joimville \\
\hline 220 & 1 & 0 & 366 & Jaimville & 288 & 1 & 0 & 391 & Joinville \\
\hline 221 & 1 & 0 & 566 & Joimville & 289 & 1 & 0 & 305 & Joimville \\
\hline 222 & 1 & 0 & 284 & Joimville & 290 & 1 & 0 & 276 & Joimville \\
\hline 223 & 1 & 0 & 319 & Joimville & 291 & 1 & 0 & 258 & Joinville \\
\hline 224 & 1 & $\mathbf{0}$ & 397 & Joimville & 292 & 1 & 0 & 440 & Joinville \\
\hline 225 & 1 & 0 & 307 & Joimville & 293 & 1 & 0 & 396 & Joimville \\
\hline 226 & 1 & 0 & 437 & Joinville & 294 & 1 & 0 & 276 & Joinville \\
\hline 227 & 1 & o & 359 & Joimville & 295 & 1 & 0 & 333 & Joimville \\
\hline 228 & 1 & 0 & 372 & Joimille & 296 & 1 & o & 298 & Joimville \\
\hline 229 & 1 & 0 & 352 & Joimville & 297 & 1 & o & 297 & Joimville \\
\hline 230 & 1 & 0 & 230 & Joimville & 298 & 1 & o & 300 & Joimville \\
\hline 231 & 1 & 0 & 329 & Joimville & 299 & 1 & 0 & 329 & Joimville \\
\hline 232 & 1 & 0 & 295 & Joimville & 300 & 1 & 0 & 368 & Joimville \\
\hline 233 & 1 & 0 & 281 & Joimville & 301 & 1 & 0 & 359 & Joimville \\
\hline 234 & 1 & 0 & 169 & Joimville & 302 & 1 & 0 & 333 & Joimville \\
\hline 235 & 1 & 0 & 397 & Joinville & 303 & 1 & 0 & 409 & Joimville \\
\hline 236 & 1 & 0 & 367 & Joinville & 304 & 1 & 0 & 445 & Joimville \\
\hline 237 & 1 & 0 & 277 & Joimville & 305 & 1 & 0 & 335 & Joinville \\
\hline 238 & 1 & 0 & 341 & Joinville & 306 & 1 & 0 & 354 & Joinville \\
\hline 239 & 1 & 0 & 297 & Joimille & 307 & 1 & o & 522 & Joimville \\
\hline 240 & 1 & 0 & 398 & Joimville & 308 & 1 & 0 & 437 & Joimville \\
\hline 241 & 1 & 0 & 272 & Joimville & 309 & 1 & 0 & 424 & Joimville \\
\hline 242 & 1 & 0 & 346 & Joimville & 310 & 1 & o & 478 & Joinville \\
\hline 243 & 1 & 0 & 426 & Joimville & 311 & 1 & 0 & 336 & Joimille \\
\hline 244 & 1 & o & 366 & Joimville & 312 & 1 & 0 & 300 & Joimille \\
\hline 245 & 1 & 0 & 348 & Joimville & 313 & 1 & 0 & 483 & Joimville \\
\hline 246 & 1 & 0 & 358 & Joimville & 314 & 1 & 0 & 268 & Joimville \\
\hline 247 & 1 & 0 & 327 & Joimville & 315 & 1 & 0 & 282 & Joinville \\
\hline 248 & 1 & 0 & 310 & Joimville & 316 & 1 & $\mathbf{0}$ & 333 & Joimville \\
\hline 249 & 1 & o & 371 & Joimville & 317 & 1 & 0 & 417 & Joimville \\
\hline 250 & 1 & 0 & 321 & Joimville & 318 & 1 & 0 & 390 & Joimville \\
\hline 251 & 1 & o & 360 & Joimville & 319 & 1 & 0 & 321 & Joinville \\
\hline 252 & 1 & 0 & 317 & Joimville & 320 & 1 & o & 314 & Joimville \\
\hline 253 & 1 & 0 & 243 & Joimville & 321 & 1 & 0 & 324 & Joinville \\
\hline 254 & 1 & 0 & 307 & Joimville & 322 & 1 & 0 & 214 & Joimville \\
\hline 255 & 1 & 0 & 288 & Joinville & 323 & 1 & 0 & 261 & Joimville \\
\hline 256 & 1 & 0 & 316 & Joimille & 324 & 1 & 0 & 407 & Joimville \\
\hline 257 & 1 & 0 & 346 & Joimville & 325 & 1 & 0 & 339 & Joimville \\
\hline 258 & 1 & 0 & 314 & Joimville & 326 & 1 & 0 & 338 & Joimville \\
\hline 259 & 1 & 0 & 350 & Joimville & 327 & 1 & 0 & 364 & Joimville \\
\hline 260 & 1 & 0 & 285 & Joimville & 328 & 1 & 0 & 351 & Joinville \\
\hline 261 & 1 & 0 & 278 & Joimville & 329 & 1 & 0 & 341 & Joinville \\
\hline 262 & 1 & 0 & 325 & Joimville & 330 & 1 & 0 & 227 & Joimville \\
\hline 263 & 1 & 0 & 335 & Joirville & 331 & 1 & 0 & 267 & Joimville \\
\hline 264 & 1 & 0 & 321 & Joinville & 332 & 1 & 0 & 327 & Joimville \\
\hline 265 & 1 & 0 & 272 & Joimville & 333 & 1 & 0 & 386 & Joimville \\
\hline 266 & 1 & 0 & 323 & Joimville & 334 & 1 & 0 & 240 & Joimville \\
\hline 267 & 1 & 0 & 388 & Joimille & 335 & 1 & 0 & 286 & Jainville \\
\hline 268 & 1 & 0 & 289 & Joimville & 336 & 1 & 6 & 1 & Joimville \\
\hline 269 & 1 & 0 & 334 & Joinville & 337 & 1 & 0 & 808 & Joimville \\
\hline 270 & 1 & 0 & 281 & Joimville & 338 & 1 & 0 & 448 & Joinville \\
\hline 271 & 1 & 0 & 322 & Joinville & 339 & 1 & 0 & 388 & Joimville \\
\hline 272 & 1 & 0 & 276 & Joimille & 340 & 1 & 0 & 369 & Joimville \\
\hline
\end{tabular}


Continuação Tabela 3.

\begin{tabular}{|c|c|c|c|c|}
\hline $\begin{array}{c}\text { Setor } \\
\text { censitánio }\end{array}$ & Situagâo & Tipo & $\begin{array}{c}\text { Domicilios } \\
\text { particulares cocupados - } \\
\text { áree urbana }\end{array}$ & Nome do Distrito \\
\hline 341 & 1 & 0 & 411 & Jainville \\
\hline 342 & 1 & 0 & 318 & Joimville \\
\hline 343 & 1 & $\mathbf{0}$ & 314 & Joimville \\
\hline 344 & 1 & 0 & 354 & Joimville \\
\hline 345 & 1 & 0 & 344 & Joimville \\
\hline 346 & 1 & 0 & 333 & Joimille \\
\hline 347 & 1 & 0 & 283 & Joimville \\
\hline 348 & 1 & 0 & 346 & Joinville \\
\hline 349 & 1 & $\mathbf{0}$ & 352 & Joimville \\
\hline 350 & 1 & 0 & 341 & Joinville \\
\hline 351 & 1 & $\mathbf{0}$ & 357 & Joinville \\
\hline 352 & 1 & 0 & 350 & Joinville \\
\hline 353 & 1 & $\mathbf{0}$ & 426 & Joinville \\
\hline 354 & 1 & $\mathbf{0}$ & 302 & Joimville \\
\hline 355 & 1 & $\mathbf{0}$ & 297 & Joimville \\
\hline 356 & 3 & 0 & 316 & Joinville \\
\hline 357 & 3 & 0 & 333 & Joimville \\
\hline 358 & 3 & 0 & 744 & Joimville \\
\hline 359 & 3 & $\mathbf{0}$ & 363 & Joinville \\
\hline 360 & 3 & 0 & 363 & Joimville \\
\hline 361 & 3 & $\mathbf{0}$ & 404 & Joinville \\
\hline 362 & 3 & 0 & 444 & Joimville \\
\hline 363 & 3 & 0 & 378 & Jcimille \\
\hline 364 & 3 & 0 & 333 & Joimville \\
\hline 365 & 3 & $\mathbf{0}$ & 401 & Joimville \\
\hline 366 & 3 & 0 & 492 & Joimville \\
\hline 367 & 3 & $\mathbf{0}$ & 381 & Joinville \\
\hline 368 & 3 & 0 & 360 & Joimville \\
\hline 369 & 3 & 0 & 322 & Joinville \\
\hline 370 & 3 & 0 & 269 & Joimville \\
\hline 371 & 1 & $\mathbf{0}$ & 343 & Joimille \\
\hline 372 & 3 & 0 & 337 & Joimville \\
\hline 373 & 3 & $\mathbf{0}$ & 403 & Joimville \\
\hline 374 & 3 & 0 & 322 & Joimville \\
\hline 375 & 3 & $\mathbf{0}$ & 352 & Joimville \\
\hline 376 & 8 & 0 & 0 & Joimville \\
\hline 377 & 8 & 0 & 0 & Joimville \\
\hline 378 & 8 & 0 & 0 & Joimville \\
\hline 379 & 8 & 0 & 0 & Joimville \\
\hline 380 & 8 & 0 & 0 & Joimville \\
\hline 381 & 8 & 0 & 0 & Jaimville \\
\hline 382 & 8 & 0 & 0 & Joinville \\
\hline 383 & 8 & 0 & 0 & Joimville \\
\hline 384 & 8 & 0 & 0 & Joimville \\
\hline 385 & 8 & 0 & 0 & Joimville \\
\hline 386 & 4 & 0 & 0 & Joimville \\
\hline 387 & 4 & 0 & 0 & Joimville \\
\hline 1 & 1 & 0 & 329 & Pirabeiraba \\
\hline 2 & 1 & 7 & 7 & Pirabeiraba \\
\hline 3 & 1 & $\mathbf{0}$ & 413 & Pirabeiraba \\
\hline 4 & 1 & 0 & 230 & Pirabeiraba \\
\hline 5 & 1 & 0 & 206 & Pirabeiraba \\
\hline 6 & 1 & $\mathbf{0}$ & 39 & Pirabeiraba \\
\hline 7 & 1 & $\mathbf{0}$ & 453 & Pirabeiraba \\
\hline 8 & 1 & $\mathbf{0}$ & 137 & Pirabeiraba \\
\hline 9 & 1 & 0 & 469 & Pirabeiraba \\
\hline 10 & 1 & 0 & 395 & Pirabeiraba \\
\hline 11 & 4 & 0 & 0 & Pirabeiraba \\
\hline 12 & 4 & 0 & 0 & Pirabeiraba \\
\hline 13 & 4 & 0 & 0 & Pirabeiraba \\
\hline 14 & 4 & 0 & 0 & Pirabeiraba \\
\hline 15 & 8 & 0 & 0 & Pirabeiraba \\
\hline 16 & 8 & 0 & 0 & Pirabeiraba \\
\hline 17 & 8 & 0 & 0 & Pirabeiraba \\
\hline 18 & 8 & 0 & 0 & Pirabeiraba \\
\hline 19 & 8 & 0 & 0 & Pirabeiraba \\
\hline 20 & 8 & 0 & 0 & Pirabeiraba \\
\hline
\end{tabular}


A partir dos 385 setores censitários urbanos dos distritos de Joinville e Pirabeiraba, que representaram o município de Joinville, foram mantidos apenas 382 setores, classificados como "comum ou não especial", em "situação urbana", e contendo "domicílios particulares ocupados", segundo Fundação IBGE (2002). Destes, foram sorteados 42 setores censitários (Tabela 3), mediante sorteio sistemático com probabilidade proporcional ao número de domicílios (KISH 1965).

Para o sorteio de moradias no segundo estágio, procedeu-se a contagem de moradias por quadra de cada setor, e a seguir, sortearam-se as 100 moradias $(95,24$ arredondados para 100 moradias). Em cada quadra, todos os domicílios sorteados foram visitados, identificando-se aqueles nos quais residiam idosos, e solicitando-os a participar do estudo.

A fração global de amostragem $(f)$ foi calculada pela expressão representada na Figura 6, onde $D j$ é o numero de moradias existentes em cada setor, contadas pelo censo demográfico do ano 2000 .

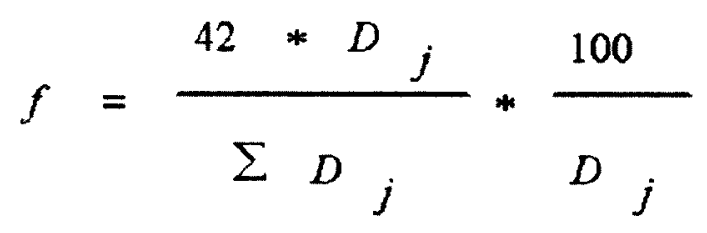

Figura 6. Cálculo da fração global de amostragem $(f)$ utilizada para o estudo.

Para ilustrar o formato de um setor censitário, na Figura 7 está representado o setor censitário Bom Retiro - 186, com suas respectivas quadras e ruas, um dos 42 setores que fizeram parte da amostra. 


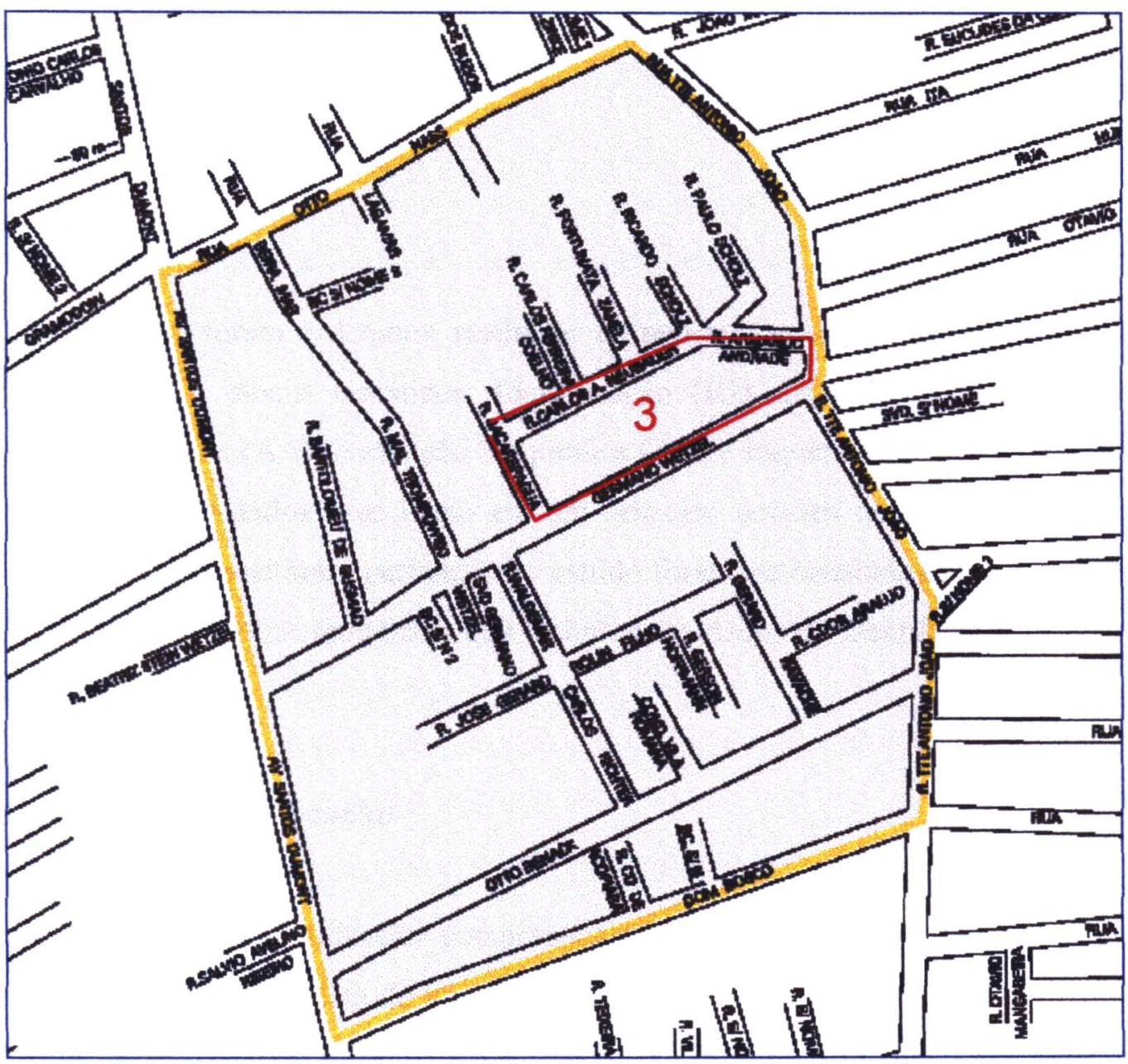

Figura 7. Representação do setor censitário urbano Bom Retiro - 186, da cidade de Joinville, segundo malha setorial do censo de 2000 (Fundação IBGE 2000a). Em vermelho, destaca-se a quadra de número 3.

\subsection{Treinamento}

Para garantir a homogeneidade na coleta de dados entre os entrevistadores, desenvolveu-se treinamento de 20 horas ministrado pela Profa. Dra. Maria de Fátima Nunes Marucci, orientadora do estudo, abrangendo avaliação antropométrica e inquérito alimentar. Todos os entrevistadores participaram deste treinamento, incluindo uma nutricionista, três estagiárias do curso de Farmácia Bioquímica e seis estagiários do curso de Educação Física da Univille. O treinamento serviu, também, para efetuar algumas modificações no Formulário de Registro de Dados - FRD 
(Anexo 1) de forma a torná-lo mais didático, tanto para o entrevistador como para o participante no momento da entrevista.

\subsection{Coleta de dados}

Os dados foram coletados mediante entrevista, registrando-se em FRD e dividido em cinco blocos temáticos: Identificação (ID); Dados sócio-econômicos (DS); Antropometria (AA); Avaliação bioquímica (AB) e Inquérito alimentar (IA).

A coleta de dados teve início em um primeiro contato no domicílio. Nesta fase, os idosos que aceitaram participar do estudo foram entrevistados para obtenção dos dois primeiros blocos temáticos, que incluíram os dados de identificação e sócioeconômicos.

\subsubsection{Dados de identificação}

Os dados de identificação compreenderam: nome, endereço, nacionalidade, naturalidade, estado civil, data de nascimento, cor ou grupo étnico relatado, sexo, se faz uso de suplementação vitamínica. Os dados de identificação e sócio-econômicos foram definidos seguindo-se metodologia aplicada no Censo 2000 pela Fundação IBGE (Fundação IBGE 2000b):

- Nome: nome completo do participante.

- Logradouro: endereço completo, incluindo número de telefone.

- Nacionalidade/Naturalidade: neste item, o participante relatou a cidade, estado e país de origem. Foram sugeridas três alternativas para resposta:

1. brasileiro nato: para a pessoa que nasceu no Brasil ou em país estrangeiro e foi registrada como brasileira; 
2. naturalizado brasileiro: para a pessoa que nasceu em país estrangeiro e obteve a nacionalidade brasileira por meio de título de naturalização ou valendo-se de dispositivo da legislação brasileira;

3. estrangeiro: para a pessoa nasceu fora do Brasil ou aquela que nasceu no Brasil e se registrou em representação estrangeira, e não se naturalizou brasileira.

- Estado civil: foi solicitada a natureza da última união, segundo cinco alternativas para resposta:

1. solteiro(a): para a pessoa que nunca viveu em companhia de cônjuge ou companheiro(a);

2. casado(a): para a pessoa que vivia em companhia de cônjuge com quem é casada no civil ou religioso ou ambos;

3. união consensual: para a pessoa que vivia em companhia de cônjuge com quem não contraiu casamento civil ou religioso;

4. desquitado(a) ou separado(a) judicialmente: para a pessoa que declarava ser desquitada ou separada, homologada por decisão judicial;

5. viúvo(a): para a pessoa que declarava ser viúva.

- Cor ou grupo étnico: foi solicitado ao voluntário o relato de sua cor ou grupo étnico, segundo cinco alternativas:

1. branca: para a pessoa que se autoreferiu como branca;

2. negra: para a pessoa que se autoreferiu de cor preta;

3. amarela: para a pessoa que se enquadrou possuir origem japonesa, chinesa, coreana;

4. parda: para a pessoa que se enquadrou como parda, mulata, cabocla, cafuza, mameluca ou mestiça;

5. indigena: para a pessoa que se declarou como índia. 
- Uso de suplementação vitaminica: caso afirmativo, fez-se o registro do tipo de vitamina que estava ingerindo.

\subsubsection{Dados sócio-econômicos}

- Escolaridade: os dados de escolaridade foram obtidos a partir do relato do grau mais elevado que freqüentou, seguindo-se oito categorias:

I. não alfabetizado: para a pessoa que nunca aprendeu a ler e escrever ou que, embora tenha aprendido, esqueceu. Foram considerados, também, àqueles que só eram capazes de escrever o próprio nome;

2. alfabetizado: para a pessoa que foi capaz de ler e escrever, mas que nunca freqüentou qualquer tipo de curso escolar;

3. ensino fundamental incompleto: para a pessoa que freqüentou, mas não concluiu o ensino fundamental, ou antigo $1^{\circ}$ Grau $\left(1^{\mathrm{a}}\right.$ a $8^{\mathrm{a}}$ série);

4. ensino fundamental completo: para a pessoa que freqüentou e concluiu o ensino fundamental, ou antigo $1^{\circ}$ Grau $\left(1^{\mathrm{a}}\right.$ a $8^{\mathrm{a}}$ série);

5. ensino médio incompleto: para a pessoa que freqüentou, mas não concluiu o ensino médio, ou antigo $2^{\circ}$ Grau ( $1^{\circ}$ ao $3^{\circ}$ colegial);

6. ensino médio completo: para a pessoa que freqüentou e concluiu o ensino médio, ou antigo $2^{\circ}$ Grau $\left(1^{\circ}\right.$ ao $3^{\circ}$ colegial);

7. ensino superior incompleto: para a pessoa que freqüentou, mas não concluiu o ensino superior, ou curso de graduação universitária;

8. ensino superior completo: para a pessoa que freqüentou, e concluiu o ensino superior, ou curso de graduação universitária.

- Renda por idoso: em salário mínimo (SM), registrado como sendo $\mathrm{R} \$ 200,00$.

De forma a obter-se maior veracidade dos dados relativos à renda, optou-se por perguntar aos voluntários na forma de categorias, obedecendo a metodologia utilizada pela Fundação IBGE (Fundação IBGE 2000b), ao invés de solicitar 
exatamente o quanto cada individuo recebia. As categorias utilizadas no estudo foram:

1. Dependente: para a pessoa que não recebia renda, e vivia do auxílio de parentes;

2. Até 2 (SM): para a pessoa que recebia até $\mathrm{R} \$ 400,00$;

3. De 2-3 (SM): para a pessoa que recebia entre $\mathrm{R} \$ 401,00$ e $\mathrm{R} \$ 600,00$;

4. De 3-5 (SM): para a pessoa que recebia entre $\mathrm{R} \$ 601,00$ e $\mathrm{R} \$ 1000,00$;

5. De 5-6 (SM): para a pessoa que recebia entre $\mathrm{R} \$ 1001,00$ e $\mathrm{R} \$ 1200,00$;

6. De 6-8 (SM): para a pessoa que recebia entre $\mathrm{R} \$ 1201,00$ e $\mathrm{R} \$ 1600,00$;

7. De 8-10 (SM): para a pessoa que recebia entre $\mathrm{R} \$ 1601,00$ e $\mathrm{R} \$ 2000,00$;

8. Dez ou mais (SM): para a pessoa que recebia acima de $\mathrm{R} \$ 2001,00$.

Na segunda fase da coleta de dados, um novo contato com os voluntários cadastrados foi estabelecido por telefone. Àqueles que não possuíam telefone, o contato foi estabelecido pessoalmente, na residência do idoso. Neste contato, os idosos foram convidados a comparecer nos locais previamente estabelecidos junto à Secretaria de Saúde, de forma a dar prosseguimento à coleta dos dados antropométricos, bioquímicos e dietéticos. Somente participaram desta fase os idosos capazes de se locomover até o local da coleta, que incluiu postos de saúde, salão de festas de igrejas e Centro Social Urbano, devido ao fato de estes estabelecimentos serem bem conhecidos da população de estudo.

\subsubsection{Dados antropométricos}

Os dados antropométricos utilizados para estudo foram: peso, estatura, perímetro do braço e prega cutânea tricipital.

Peso

Os idosos foram pesados em balança digital da marca Soehnle, com capacidade de $150 \mathrm{~kg}$ e divisão de $100 \mathrm{~g}$. No momento da mensuração, o idoso 
estava vestindo o mínimo de roupas possível (com os bolsos vazios, sem casaco, shapéu, boné, cinto, xale e demais acessórios que acarretem aumento do peso), sem calçados, e posicionado no centro da balança, de forma a distribuir o peso do corpo entre os pés, conforme técnica de Gordon e col. (1988). Foram efetuadas duas medições.

\section{Estatura}

Para a mensuração da estatura, utilizou-se estadiômetro portátil da marca Seca com capacidade para até $200 \mathrm{~cm}$, de acordo com a técnica de Gordon e col. (1988). No momento da mensuração, o idoso estava desprovido de calçados e casacos, jaquetas ou similares, mantendo seu posicionamento bem visualizado pelo entrevistador. O voluntário foi posicionado logo abaixo do estadiômetro, distribuindo seu peso de forma equilibrada em ambos os pés e mantendo olhar fixo para frente. Neste momento, o voluntário manteve a linha da visão perpendicular ao corpo, com a cabeça em plano de Frankfurt. Os braços permaneceram relaxados ao lado do tronco, com as palmas das mãos voltadas para o mesmo. Procurou-se manter os calcanhares, as nádegas, a escápula e a parte posterior do crânio tocando, ao mesmo tempo, a parede (na posição vertical) onde estava fixado o estadiômetro. Quando não foi possivel, o voluntário foi posicionado de forma que somente as nádegas e os calcanhares, ou as nádegas e a parte posterior do crânio, permanecessem tocando, ao mesmo tempo, a parede. Os calcanhares foram dispostos paralelamente e juntos. A parte móvel do estadiômetro foi, então, direcionada até parte superior da cabeça, efetuando-se pressão suficiente para comprimir o cabelo e registrar a medida. Duas medições foram efetuadas.

\section{Perimetro do braço}

O perímetro do braço foi medido com fita métrica inextensível da marca Cardiomed, com capacidade para até $150 \mathrm{~cm}$, segundo as técnicas de Callaway e col. (1988). 
No momento da mensuração, o voluntário foi posicionado em pé, de forma ereta, com os braços soltos ao lado do tronco, as palmas das mãos voltadas para o mesmo, e vestindo camisa sem mangas. A tomada da medida foi realizada com o entrevistador marcando o ponto médio do braço direito da pessoa, posicionado paralelo ao lado do tronco (Figura 8). O ponto médio foi localizado através da flexão do cotovelo, de forma que a palma da mão ficasse voltada para cima, formando um ângulo de $90^{\circ}$ no cotovelo. Neste momento, o entrevistador se posicionou atrás do voluntário e localizou o acrômio (osso localizado na parte posterior do ombro) e o olécrano (osso do cotovelo), marcando um ponto na extremidade de cada osso, conforme demonstrado na Figura 8.

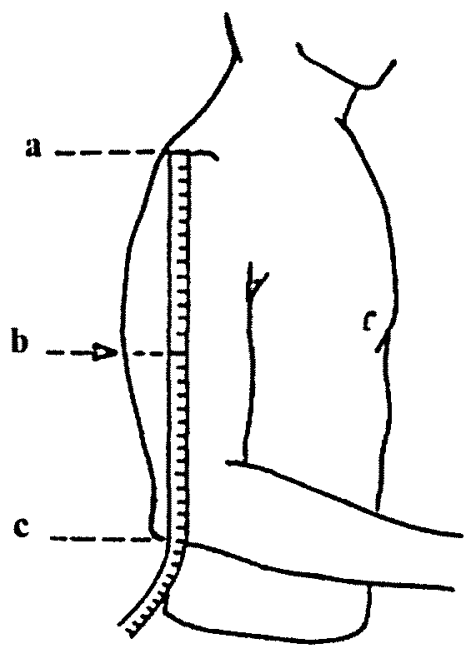

Figura 8. Representação da localização do ponto médio do braço: a) acrômio; b) ponto médio do braço; c) olécrano.

Em seguida, registrou-se um ponto exatamente entre as duas marcações anteriores, sendo este, o ponto médio entre o acrômio e o olécrano (Figura 9). Foram efetuadas duas medições. 


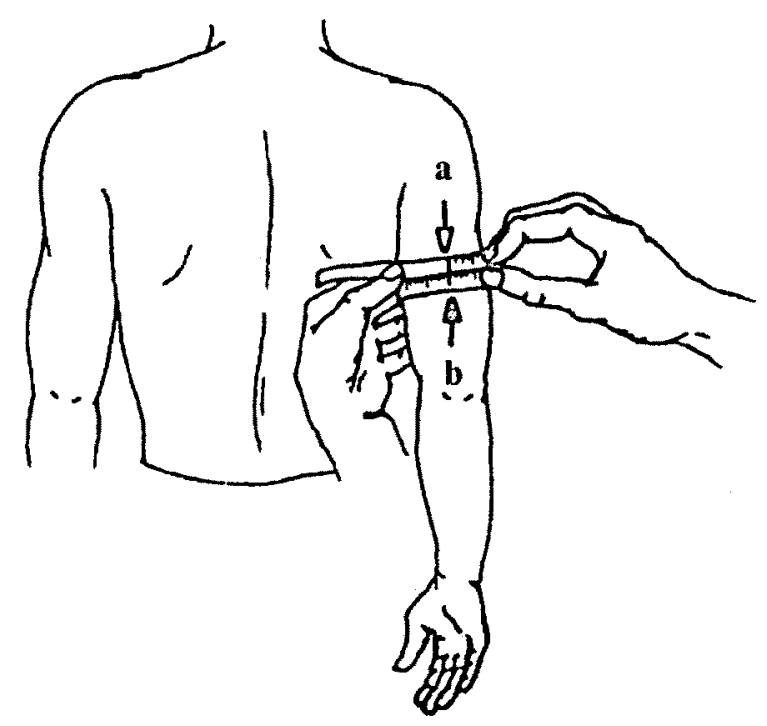

Figura 9. Representação da medida do perímetro do braço: a) zero da fita métrica; b) valor observado.

\section{Prega cutânea tricipital}

A prega cutânea tricipital foi mensurada utilizando-se um compasso de dobras cutâneas da marca Cescorf com variação de $0,1 \mathrm{~mm}$, seguindo as técnicas de Harrison e col. (1988). A medida foi realizada com o voluntário vestindo camisa sem mangas e posicionado de forma ereta, confortavelmente, com os braços soltos ao lado do tronco e as palmas das mãos voltadas para o mesmo. Para a tomada da medida, o entrevistador localizou o ponto médio do braço esquerdo, identificado anteriormente e utilizado para a mensuração do perímetro do braço. $O$ entrevistador então, posicionou-se atrás do voluntário e, com o dedo polegar $\mathrm{e} o$ indicador, pinçou a pele a, aproximadamente, $1 \mathrm{~cm}$ acima do ponto médio, efetuando a medida com $\mathrm{o}$ compasso exatamente sobre o ponto médio, conforme demonstrado na Figura 10. Três medições foram registradas. 


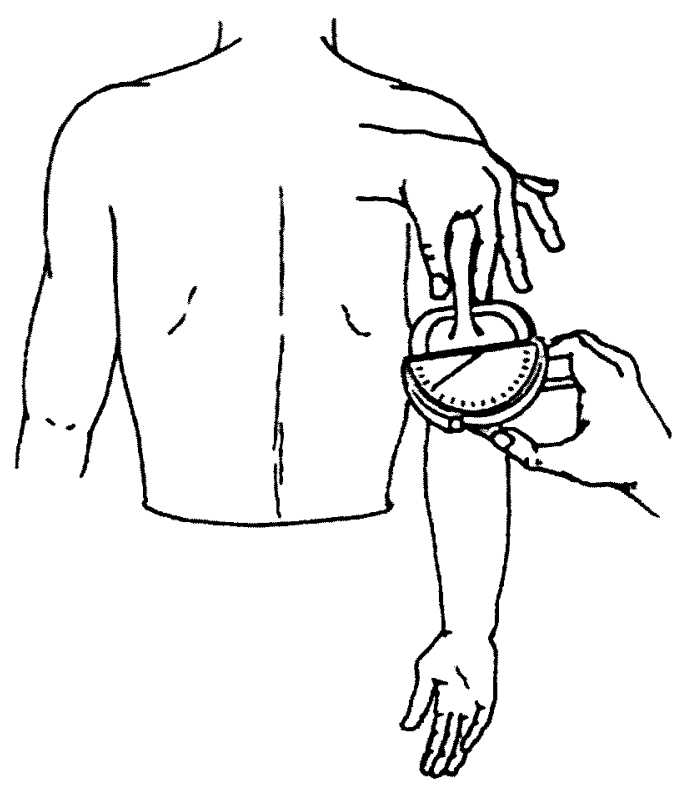

Figura 10. Representação da medida da prega cutânea tricipital.

\subsubsection{Dados bioquímicos}

Os dados bioquímicos utilizados neste estudo foram: glicose, colesterol total, triglicerideos, lipoproteina de alta densidade (HDL-c), lipoproteina de baixa densidade (LDL-c) e lipoproteína de muito baixa densidade (VLDL-c).

Para a avaliação bioquímica, o sangue foi coletado em jejum, uma vez, através de seringa e agulha estéreis e descartáveis. A punção venosa foi feita após o participante permanecer na mesma posição, sentado, por cerca de 5 minutos. De maneira a evitar a êstase venosa prolongada, o torniquete foi utilizado sempre por tempo inferior a 1 minuto. A coleta do sangue foi efetuada por uma farmacêuticabioquimica, obedecendo às normas de biossegurança preconizadas pelos CDC (1999) e BRASIL (2001). Após a coleta, o sangue foi imediatamente colocado em tubos a vácuo siliconizados, fluoretados, estéreis, devidamente identificados, numerados e armazenados temporariamente em recipiente refrigerado, fechado, até o transporte para o laboratório conveniado. No laboratório, o sangue foi centrifugado durante 10 
minutos $/ 2.000 \mathrm{~g}$, em centrífuga da marca BIOENG, modelo $B E-4000^{\circledast}$, para a separação do soro.

Glicose

A glicose foi dosada no plasma, empregando-se o método enzimático colorimétrico Glicose Oxidase/Peroxidase AA, da marca BIOSYSTEMS (BioSystems 2003).

Colesterol total, triglicerideos e HDL-c

As concentrações de colesterol total, HDL-c e triglicerídeos séricos foram determinadas pelos métodos enzimáticos Colestat enzimático AA, HDL Colesterol Reativo Precipitante e $T G$ Color GPO/PAP, respectivamente (Wiener lab. 1994), utilizando o autoanalisador bioquímico da marca WIENER, modelo $\operatorname{AIRONE}^{\circledR} 200$, software Crony Airone 2000 (Rosário - Argentina).

$L D L-c$

A partir dos valores de colesterol total, triglicerídeos e HDL-c dosados, foi determinado o valor da LDL-c, através da fórmula de Friedewald, quando os valores de triglicerídeos foram inferiores a $400 \mathrm{mg} / \mathrm{dL}$ (Friedewald e col. 1972), descrita a seguir:

LDL-c $=$ colesterol total $-(\mathrm{HDL}-\mathrm{c}+\mathrm{VLDL}-\mathrm{c})$

$V L D L-c$

Para o cálculo da VLDL-c, foi utilizada a seguinte equação da Sociedade Brasileira de Cardiologia (2001):

$\mathrm{VLDL}-\mathrm{c}=$ triglicerídeos $/ 5$. 


\subsubsection{Dados do consumo de macronutrientes e energia}

A verificação do consumo de macronutrientes e energia foi realizada pelo método recordatório de 24 horas, que consistiu na identificação e quantificação dos alimentos e preparações ingeridos durante o dia anterior à entrevista, desde o café da manhã até a última refeição do dia. As entrevistas foram realizadas no período da manhã, de acordo com a disponibilidade de local para a coleta, sempre nos dias compreendidos entre segunda e sexta-feira, inclusive. Como o método recordatório de 24 horas registra o consumo realizado no dia anterior a entrevista, os dados de consumo obtidos foram referentes ao período entre domingo e quinta-feira, inclusive.

Salienta-se a não utilização dos finais de semana (sábados e domingos) para a coleta dos dados antropométricos, bioquímicos e dietéticos, em virtude do não funcionamento dos postos de saúde nesses dias.

Todos os dados referentes ao consumo alimentar foram registrados em formulário específico (Anexo 2), para posterior cálculo de macronutrientes através do software Virtual Nutri, versão 1.0 (Philippi e col. 1996).

No momento do inquérito alimentar, foi solicitado aos voluntários relatar, com o máximo de detalhes possível, os alimentos sólidos e líquidos ingeridos no dia anterior, a hora em que foram ingeridos e a forma de cocção utilizada. Para facilitar a resposta, o entrevistador orientou quanto ao tamanho das medidas (Tabela 4).

Tabela 4. Relação das medidas e respectivos tamanhos adotados no inquérito alimentar Recordatório de 24 horas.

\begin{tabular}{ll}
\hline \multicolumn{1}{c}{ Medida } & \multicolumn{1}{c}{ Tamanho } \\
\hline Colher & Café, chá, sobremesa, sopa, servir \\
Concha & Rasa, cheia \\
Escumadeira & Rasa, cheia \\
Caneca & Pequena, média, grande \\
Copo & Pequeno, médio, grande \\
Prato & Raso, fundo \\
Pires & Café, chá \\
Xícara & Café, chá \\
Pedaço/fatia/unidade & Pequeno, médio, grande \\
\hline
\end{tabular}




\subsection{Variáveis de estudo}

\subsubsection{Variáveis demográficas}

As variáveis relacionadas à identificação dos participantes utilizadas para este estudo foram: estado civil, idade e sexo.

\subsubsection{Variáveis sócio-econômicas}

Para as variáveis sócio-econômicas, utilizaram-se: escolaridade e renda.

\subsubsection{Variáveis antropométricas}

As variáveis antropométricas utilizados neste estudo foram: peso, estatura, índice de massa corporal, perímetro do braço e prega cutânea tricipital.

Vários autores têm descrito padrões antropométricos específicos para pessoas idosas: Burr e Phillips (1984), Chumlea e col. (1987), Delarue e col. (1994), Perissinotto e col. (2002) e Kuczmarski e col. (2000).

Para este estudo, optou-se adotar o padrão de referência de Kuczmarski e col. (2000), visto que estes autores apresentaram resultados antropométricos referentes a indivíduos com idade igual ou superior a 50 anos, ao contrário dos demais autores, que analisaram indivíduos com idade igual ou superior a 65 anos.

O padrão adotado foi utilizado para análise do IMC, perímetro do braço e prega cutânea tricipital, sendo os valores apresentados nos percentis $10,15,25,50$, 75,85 e 90. Como critério de análise para cada uma dessas variáveis, adotou-se:

- Inadequado (insuficiente): valores $<$ P25

- Adequado: valores entre P25 e P75

- Inadequado (elevado): valores >P75.

Para IMC, os valores considerados como adequados foram os compreendidos entre: 
$.22,4-27,1 \mathrm{~kg} / \mathrm{m}^{2}$ para homens, $\mathrm{e}$ $.21,7-28,4 \mathrm{~kg} / \mathrm{m}^{2}$ para mulheres.

Para perímetro do braço, os valores considerados como adequados foram os compreendidos entre:

$.27,3-31,5 \mathrm{~cm}$ para homens, $\mathrm{e}$

$.25,5-31,5 \mathrm{~cm}$ para mulheres.

Para prega cutânea tricipital, os valores considerados como adequados foram os compreendidos entre:

$.8,7-13,8 \mathrm{~mm}$ para homens, $\mathrm{e}$

$.13,1-23,3 \mathrm{~mm}$ para mulheres.

\subsubsection{Avaliação bioquímica}

As variáveis bioquímicas utilizadas e seus valores de referência encontram-se descritos na Tabela 5. Para o valor de referência de glicose, utilizou-se a classificação da American Diabetes Association (2001). Em relação aos valores de colesterol total, HDL-c, LDL-c e triglicerídeos, seguiu-se a classificação laboratorial da "III Diretrizes Brasileira sobre Dislipidemias e Diretriz de Prevenção da Aterosclerose do Departamento de Aterosclerose da Sociedade Brasileira de Cardiologia" (Sociedade Brasileira de Cardiologia 2001). 
Tabela 5. Valores de referência, em jejum, para as variáveis bioquímicas analisadas.

\begin{tabular}{lcl}
\hline \multicolumn{1}{c}{ Variáveis } & Valores de referência $(\mathbf{m g} / \mathrm{dL})$ & Categoria \\
\hline Glicose & $70-110$ & Desejável \\
& $\geq 126$ & Aumentado \\
Colesterol total & $<200$ & Ótimo \\
& $200-239$ & Limítrofe \\
& $\geq 240$ & Alto \\
HDL-c & $<40$ & \\
& $>60$ & Baixo \\
& & Alto \\
LDL-c & $<100$ & \\
& $100-129$ & Ótimo \\
& $130-159$ & Desejável \\
& $160-189$ & Limítrofe \\
& $\geq 190$ & Alto \\
& & Muito alto \\
& $<150$ & Ótimo \\
& $150-200$ & Limítrofe \\
& $200-499$ & Alto \\
& $\geq 500$ & Muito alto \\
& &
\end{tabular}

\subsubsection{Avaliação dietética}

Para a análise diária da energia, utilizou-se a referência do National Research Council (1989), que estabelece $2.300 \mathrm{kcal}$ para homens e $1.900 \mathrm{kcal}$ para mulheres. Em relação aos macronutrientes, utilizou-se a referência de Trumbo e col. (2002), cujos valores são:

- Lipídios: $20-35 \%$

- Carboidratos: $45-65 \%$

- Proteínas: 10-35\% 


\subsection{Processamento e análise dos dados}

Todos os dados foram digitados em planilha eletrônica, Microsoft Office Excel, versão 2000. Os dados de inquérito alimentar foram registrados no programa Virtual Nutri, versão 1.0 (Philippi e col. 1996). A análise estatística foi realizada com o auxílio do programa estatístico Stata Statistical Software: Release 7 (Statacorp 2001), disponível no Departamento de Epidemiologia da Faculdade de Saúde Pública, Universidade de São Paulo.

\subsection{Análise estatística}

Os dados foram analisados utilizando-se o módulo "survey", cujos procedimentos foram precedidos do código "svy" do software STATA 7.0 (STATA for Windows Copryght 1984-2002), que incluiu efeito do plano de amostragem por conglomerados sobre as estimativas e respectivos intervalos de confiança.

A análise dos resultados da amostra de examinados, coletados na segunda etapa do estudo, foi corrigida através da ponderação, mediante uso de pesos estatísticos. A ponderação é um tratamento estatístico freqüentemente utilizado em inquéritos com baixas taxas de resposta ou cobertura (Korn e Graubard 1995, Lemeshow e col. 1998, Pfeffermann 1996).

Em cada setor censitário, procedeu-se ao cálculo dos pesos "w1", obtidos mediante a relação: número de indivíduos entrevistados/número de indivíduos examinados, em cada conglomerado. Os pesos " $\mathrm{w} 2 \mathrm{~h}$ " foram calculados para calibrar os resultados da amostra segundo sexo e idade, utilizando-se dados do Censo 2000 (Tabela 6). O peso final (w3), adicionado a cada registro do arquivo final da amostra, foi obtido por (w1 $\times$ w2). A Tabela 7 ilustra um exemplo do procedimento adotado, utilizando-se 10 indivíduos distribuídos em quatro setores censitários. 
Tabela 6. Distribuição dos pesos para correção da variação das taxas de examinados em 221 idosos da área urbana de Joinville-SC, segundo sexo e grupo etário. 2002.

\begin{tabular}{clcccccc}
\hline Sexo & Grupo etário & $\mathbf{h}$ & $\mathbf{N}_{\mathbf{h}}$ & $\mathbf{W}_{\mathbf{h}}$ & $\mathbf{n}_{\mathbf{h}}$ & $\mathbf{w}_{\mathbf{h}}$ & $\mathbf{w} \mathbf{2}_{\mathbf{h}}=\mathbf{W}_{\mathbf{h}} / \mathbf{w}_{\mathbf{h}}$ \\
\hline \multirow{4}{*}{ Masculino } & 60 a 69 anos & 1 & 8.125 & 0,27 & 55 & 0,25 & 1,09 \\
& 70 a 79 anos & 2 & 3.604 & 0,12 & 28 & 0,13 & 0,95 \\
& 80 anos ou mais & 3 & 1.057 & 0,04 & 7 & 0,03 & 1,12 \\
\hline \multirow{3}{*}{ Feminino } & 60 a 69 anos & 4 & 9.597 & 0,32 & 81 & 0,37 & 0,88 \\
& 70 a 79 anos & 5 & 5.348 & 0,18 & 43 & 0,19 & 0,92 \\
& 80 anos ou mais & 6 & 2.094 & 0,07 & 7 & 0,03 & 2,22 \\
\hline & Total & - & $\mathbf{2 9 . 8 2 5}$ & - & $\mathbf{2 2 1}$ & - & - \\
\hline
\end{tabular}

Onde:

- $\mathrm{h}=\mathrm{um}$ dos seis estratos;

- $\mathrm{N}_{\mathrm{h}}=$ tamanho da população do h-ésimo estrato;

- $\quad W_{h}=$ proporção da população do h-ésimo estrato;

- $\mathrm{n}_{\mathbf{h}}=$ tamanho da amostra do h-ésimo estrato;

- $\quad \mathrm{w}_{\mathrm{h}}=$ proporção da amostra do h-ésimo estrato;

- $\quad w 2_{h}$ : é o peso do h-ésimo estrato, ou seja, a razão entre a proporção do hésimo grupo etário e a mesma proporção na amostra.

Tabela 7. Distribuição dos pesos para correção da variação das taxas de examinados em 221 idosos da área urbana de Joinville-SC, segundo sexo e grupo etário. 2002.

\begin{tabular}{cccccc}
\hline \multirow{2}{*}{$\begin{array}{c}\text { Setor } \\
\text { censitário }\end{array}$} & $\begin{array}{c}\text { Idade } \\
\text { (anos) }\end{array}$ & Sexo & \multicolumn{3}{c}{ Pesos } \\
\cline { 4 - 6 } & 63 & 2 & w1 & w2 & w3 \\
\hline 7 & 65 & 1 & 4,67 & 0,88 & 4,11 \\
7 & 62 & 2 & 4,67 & 1,09 & 5,09 \\
7 & 65 & 1 & 9,00 & 1,09 & 9,88 \\
16 & 67 & 2 & 9,00 & 0,88 & 7,92 \\
16 & 82 & 1 & 9,00 & 1,12 & 10,08 \\
16 & 70 & 2 & 10,00 & 0,92 & 9,20 \\
25 & 74 & 2 & 1,67 & 0,92 & 1,53 \\
34 & 78 & 2 & 1,67 & 0,92 & 1,53 \\
34 & 76 & 1 & 1,67 & 0,95 & 1,58 \\
34 & & & & &
\end{tabular}


A análise estatística para variáveis categóricas (estado civil, grupo etário, escolaridade, renda e IMC), consistiu em testes de associação segundo o sexo. Intervalos de confiança (95\%) foram calculados para as estimativas de proporções. Ainda, os valores estimados para níveis de significância foram comparados ao valor padrão de 0,05 para o nível de significância.

As variáveis quantitativas foram avaliadas pela comparação de médias e respectivos intervalos de confiança (95\%), usando o teste t-Student com nível de significância igual a 0,05 .

\subsection{Aspectos éticos}

Como o projeto de pesquisa analisou seres humanos, a identificação dos participantes foi sigilosa, sendo os dados armazenados na instituição de pesquisa sob a tutela do pesquisador responsável do estudo. Quando houve concordância de participação, os mesmos assinaram o Termo de Consentimento Informado (Anexo 3), elaborado de acordo com as normas da Resolução $n^{\circ} 196 / 1996$, do Conselho Nacional de Saúde (BRASIL 2000), sendo fornecida uma cópia a cada participante do estudo. Quaisquer dúvidas surgidas ao longo do estudo foram esclarecidas pelo doutorando, pesquisador responsável do estudo. Para o desenvolvimento do estudo, o projeto foi submetido ao Comitê de Ética em Pesquisa da FSP/USP e obteve aprovação em dezembro de 2000 (Anexo 4). 


\section{RESULTADOS}

\subsection{Sorteio dos setores censitários}

Dos 407 setores censitários que compõem o município de Joinville, apenas 382 fizeram parte do cadastro das unidades primárias para o sorteio de primeiro estágio. Destes, 42 setores censitários foram sorteados para obtenção da amostra (Tabela 3), conforme representado na Figura 11.

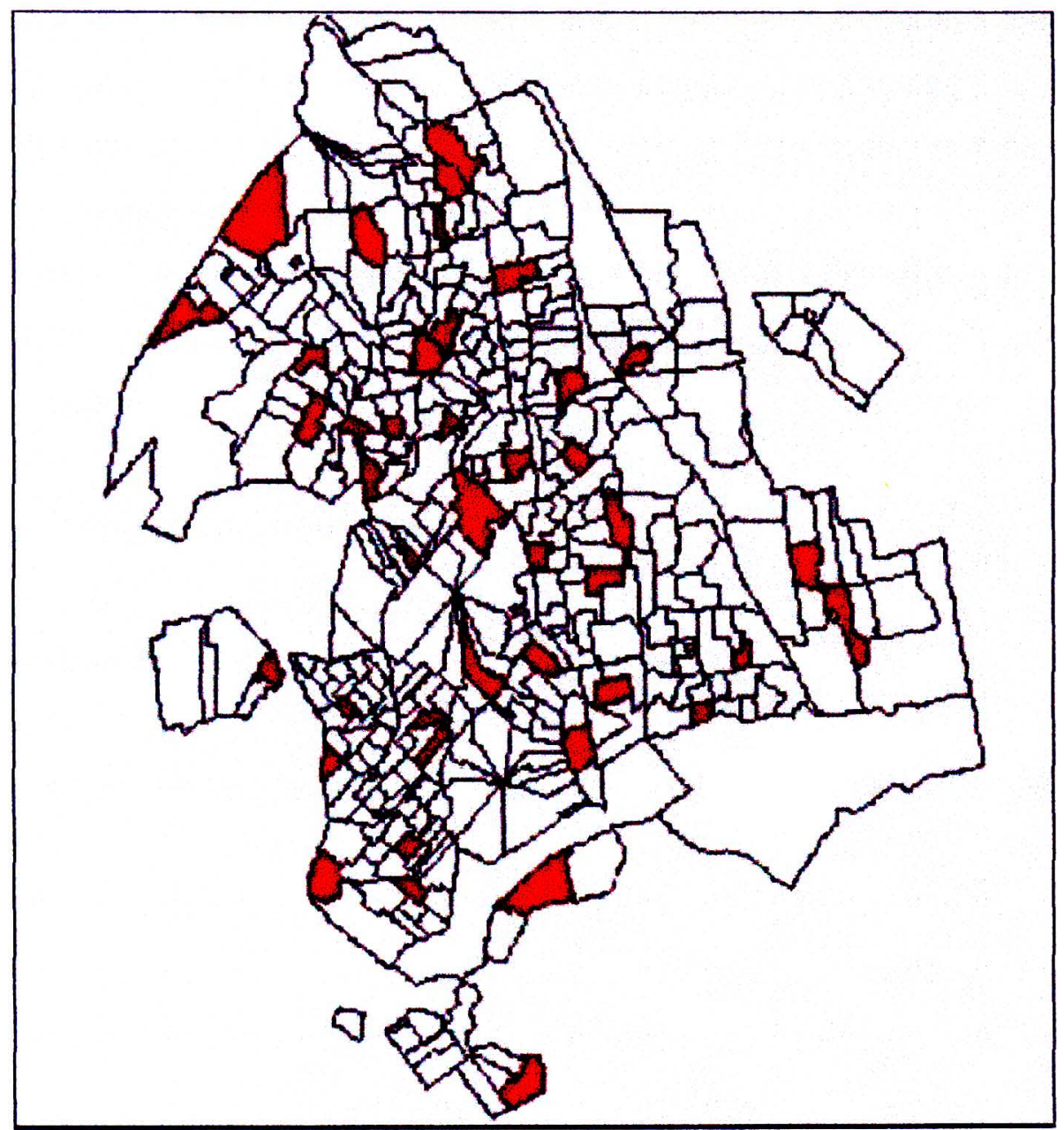

Figura 11. Representação dos 42 setores censitários sorteados (em vermelho) sobre o mapa da cidade de Joinville. 


\subsection{Amostra}

Na primeira etapa do estudo, que consistiu da coleta de dados em domicílio, 660 idosos foram entrevistados, representando 78,5\% da amostra probabilística. Nesta fase, foram coletados os seguintes dados: nome, logradouro, nacionalidade/naturalidade, estado civil, cor ou grupo étnico, uso de suplementação vitamínica, escolaridade e renda.

$\mathrm{Na}$ segunda etapa do estudo, realizada nos postos de saúde, foram coletados os dados antropométricos, bioquímicos e dietéticos, comparecendo 221 idosos, aproximadamente $33,5 \%$ da amostra.

A Tabela 8 descreve a distribuição do número de moradias sorteadas no processo amostral, o número esperado de idosos, o número de moradias visitadas, o número de idosos obtidos após a visita em domicílio, o número de idosos entrevistados nos postos de saúde e a taxa de resposta, para cada setor censitário investigado. A taxa de resposta foi definida como sendo o número de entrevistas realizadas sobre o número de idosos esperados em cada setor. Para valores de taxa de resposta acima de 1,0, o número de entrevistas realizadas superou o número de entrevistas esperadas.

\subsection{Etapa 1: domicílio, 660 idosos}

\subsubsection{Descrição dos dados}

Os dados obtidos na primeira etapa do estudo encontram-se descritos na Tabela 9. 
Tabela 8. Distribuição do número de moradias sorteadas, número esperado de idosos, número de moradias visitadas, número de idosos obtidos, número de idosos entrevistados e taxa de resposta, segundo o setor censitário.

\begin{tabular}{|c|c|c|c|c|c|c|}
\hline $\begin{array}{c}\text { Setor } \\
\text { censitário }\end{array}$ & $\begin{array}{l}\text { Moradias } \\
\text { sorteadas }\end{array}$ & $\begin{array}{c}\text { Idosos } \\
\text { esperados }\end{array}$ & $\begin{array}{l}\text { Moradias } \\
\text { visitadas }\end{array}$ & $\begin{array}{c}\text { Idosos } \\
\text { obtidos }\end{array}$ & $\begin{array}{c}\text { Idosos } \\
\text { entrevistados }\end{array}$ & $\begin{array}{l}\text { Taxa de } \\
\text { resposta }\end{array}$ \\
\hline 5 & 108 & 21,6 & 5 & 5 & 1 & 0,05 \\
\hline 7 & 114 & 22,8 & 12 & 14 & 14 & 0,61 \\
\hline 16 & 129 & 25,8 & 18 & 27 & 27 & 1,05 \\
\hline 25 & 115 & 23,0 & 9 & 10 & 10 & 0,43 \\
\hline 34 & 125 & 25,0 & 4 & 5 & 5 & 0,20 \\
\hline 46 & 123 & 24,6 & 17 & 26 & 26 & 1,06 \\
\hline 55 & 123 & 24,0 & 20 & 30 & 30 & 1,25 \\
\hline 64 & 111 & 20,0 & 9 & 13 & 13 & 0,65 \\
\hline 74 & 114 & 20,0 & 18 & 25 & 25 & 1,25 \\
\hline 84 & 109 & 21,8 & 17 & 23 & 23 & 1,06 \\
\hline 94 & 114 & 22,8 & 13 & 16 & 15 & 0,66 \\
\hline 104 & 125 & 25,0 & 13 & 15 & 15 & 0,60 \\
\hline 112 & 129 & 25,8 & 19 & 26 & 27 & 1,05 \\
\hline 123 & 112 & 22,4 & 8 & 8 & 7 & 0,31 \\
\hline 134 & 105 & 21,0 & 15 & 21 & 21 & 1,00 \\
\hline 141 & 107 & 21,4 & 7 & 9 & 9 & 0,42 \\
\hline 150 & 117 & 23,4 & 9 & 13 & 13 & 0,56 \\
\hline 159 & 98 & 19,6 & 8 & 11 & 11 & 0,56 \\
\hline 168 & 106 & 21,2 & 9 & 12 & 12 & 0,57 \\
\hline 177 & 109 & 21,8 & 28 & 39 & 39 & 1,79 \\
\hline 186 & 104 & 20,8 & 12 & 13 & 13 & 0,63 \\
\hline 196 & 106 & 21,2 & 9 & 9 & 9 & 0,42 \\
\hline 205 & 126 & 22,4 & 14 & 20 & 19 & 0,85 \\
\hline 213 & 99 & 20,0 & 9 & 10 & 10 & 0,50 \\
\hline 220 & 106 & 21,2 & 7 & 8 & 8 & 0,38 \\
\hline 228 & 115 & 23,0 & 11 & 11 & 11 & 0,48 \\
\hline 239 & 115 & 23,0 & 17 & 36 & 36 & 1,57 \\
\hline 246 & 106 & 21,2 & 21 & 26 & 26 & 1,23 \\
\hline 256 & 120 & 24,0 & 7 & 8 & 9 & 0,38 \\
\hline 265 & 112 & 22,4 & 11 & 16 & 16 & 0,71 \\
\hline 276 & 115 & 24,2 & 9 & 11 & 11 & 0,46 \\
\hline 285 & 112 & 22,4 & 12 & 18 & 17 & 0,76 \\
\hline 294 & 121 & 24,2 & 21 & 31 & 31 & 1,28 \\
\hline 303 & 113 & 22,6 & 16 & 25 & 25 & 1,11 \\
\hline 311 & 113 & 22,6 & 9 & 10 & 10 & 0,44 \\
\hline 319 & 116 & 23,2 & 3 & 3 & 3 & 0,13 \\
\hline 329 & 137 & 27,4 & 5 & 5 & 5 & 0,18 \\
\hline 338 & 112 & 22,4 & 10 & 11 & 11 & 0,49 \\
\hline 346 & 111 & 22,2 & 17 & 24 & 25 & 1,13 \\
\hline 355 & 102 & 22,4 & 2 & 2 & 2 & 0,09 \\
\hline 363 & 123 & 24,6 & 8 & 10 & 10 & 0,41 \\
\hline 371 & 111 & 20,0 & 8 & 10 & 10 & 0,50 \\
\hline Total & 4788 & 950,4 & 496 & 665 & 660 & 0,69 \\
\hline
\end{tabular}


Tabela 9. Distribuição das freqüências absoluta (n) e relativa (\%) de 660 idosos da área urbana de Joinville-SC, segundo dados sócio-econômicos, demográficos e sexo. 2002.

\begin{tabular}{|c|c|c|c|c|c|c|}
\hline \multirow{3}{*}{$\begin{array}{c}\text { Dados sócio-econômicos e } \\
\text { demográficos }\end{array}$} & \multicolumn{4}{|c|}{ Sexo } & \multirow{2}{*}{\multicolumn{2}{|c|}{ Total }} \\
\hline & \multicolumn{2}{|c|}{ Masculino } & \multicolumn{2}{|c|}{ Feminino } & & \\
\hline & n & $\%$ & $\mathbf{n}$ & $\%$ & $\mathbf{n}$ & $\%$ \\
\hline \multicolumn{7}{|l|}{ Local de origem } \\
\hline Santa Catarina (SC) & 229 & 81,8 & 328 & 86,3 & 557 & 84,5 \\
\hline Rio Grande do Sul (RS) & 13 & 4,6 & 13 & 3,4 & 26 & 3,9 \\
\hline Paraná (PR) & 11 & 3,9 & 11 & 2,9 & 22 & 3,3 \\
\hline São Paulo (SP) & 5 & 1,8 & 9 & 2,4 & 14 & 2,1 \\
\hline Demais estados & 20 & 7,1 & 18 & 4,7 & 38 & 5,7 \\
\hline Estrangeiros & 2 & 0,8 & 1 & 0,3 & 3 & 0,5 \\
\hline \multicolumn{7}{|l|}{ Estado civil } \\
\hline Solteiro & 5 & 1,8 & 7 & 1,8 & 12 & 1,8 \\
\hline Casado & 221 & 78,9 & 166 & 43,7 & 387 & 58,6 \\
\hline União consensual & 13 & 4,7 & 9 & 2,4 & 22 & 3,4 \\
\hline Desquitado ou separado & 7 & 2,5 & 14 & 3,7 & 21 & 3,2 \\
\hline Viúvo & 34 & 12,1 & 184 & 48,4 & 218 & 33,0 \\
\hline \multicolumn{7}{|l|}{ Grupo etário (anos) } \\
\hline $60-69$ & 158 & 56,5 & 204 & 53,8 & 362 & 54,8 \\
\hline $70-79$ & 93 & 33,2 & 127 & 33,4 & 220 & 33,3 \\
\hline $80+$ & 29 & 10,3 & 49 & 12,8 & 78 & 11,9 \\
\hline \multicolumn{7}{|l|}{ Cor ou grupo étnico } \\
\hline Branca & 244 & 87,1 & 347 & 91,3 & 591 & 89,5 \\
\hline Negra & 6 & 2,1 & 2 & 0,5 & 8 & 1,2 \\
\hline Parda & 29 & 10,4 & 31 & 8,2 & 60 & 9,1 \\
\hline Amarela & 1 & 0,4 & 0 & 0 & 1 & 0,2 \\
\hline Indígena & 0 & 0 & 0 & 0 & 0 & 0 \\
\hline \multicolumn{7}{|l|}{ Escolaridade } \\
\hline Não alfabetizado & 13 & 4,6 & 48 & 12,6 & 61 & 9,2 \\
\hline Alfabetizado & 30 & 10,7 & 22 & 5,8 & 52 & 7,9 \\
\hline Ensino fundamental incompleto & 201 & 71,7 & 280 & 73,7 & 481 & 72,8 \\
\hline Ensino fundamental complcto & 15 & 5,4 & 16 & 4,2 & 31 & 4,7 \\
\hline Ensino médio incompleto & 1 & 0,4 & 4 & 1,1 & 5 & 0,8 \\
\hline Ensino médio completo & 15 & 5,4 & 5 & 1,3 & 20 & 3,0 \\
\hline Ensino superior incompleto & 1 & 0,4 & 0 & & 1 & 0,2 \\
\hline Ensino superior completo & 4 & 1,4 & 5 & 1,3 & 9 & 1,4 \\
\hline \multicolumn{7}{|l|}{ Renda $(S M=R \$ 200,00)$} \\
\hline Dependente & 26 & 9,3 & 191 & 50,3 & 217 & 32,8 \\
\hline Até 2 SM & 145 & 51,7 & 156 & 41,1 & 301 & 45,6 \\
\hline $2-3 \mathrm{SM}$ & 57 & 20,4 & 23 & 6,1 & 80 & 12,1 \\
\hline 3-5 SM & 38 & 13,6 & 6 & 1,6 & 44 & 6,7 \\
\hline 5-6 SM & 4 & 1,4 & 1 & 0,3 & 5 & 0,8 \\
\hline 6-8 SM & 3 & 1,1 & 1 & 0,3 & 4 & 0,6 \\
\hline 8-10 SM & 2 & 0,7 & 0 & & 2 & 0,3 \\
\hline $10+\mathrm{SM}$ & 5 & 1,8 & 2 & 0,5 & 7 & 1,1 \\
\hline Total & 280 & 100 & 380 & 100 & 660 & 100 \\
\hline
\end{tabular}




\subsubsection{Representatividade da etapa $2: 221$ idosos}

Para verificar se houve semelhança entre o grupo de idosos que não participou da segunda etapa do estudo (439 idosos, não examinados) e o grupo que participou (221 idosos, examinados), ambos foram analisados quanto às variáveis: sexo, estado civil, grupo etário, cor ou grupo étnico, escolaridade e renda (Tabela 10). O teste do qui-quadrado para proporcionalidade mostrou que a variável grupo etário apresentou diferença estatisticamente significante $(p<0,05)$ entre os dois grupos (Tabela 10).

Tabela 10. Distribuição das freqüências absoluta (n) e relativa (\%) de idosos em duas amostras da área urbana de Joinville-SC, segundo dados sócio-econômicos e demográficos. 2002.

\begin{tabular}{|c|c|c|c|c|c|c|c|}
\hline \multirow[t]{2}{*}{$\begin{array}{c}\text { Dados sócio-econômicos e } \\
\text { demográficos }\end{array}$} & \multicolumn{2}{|c|}{$\begin{array}{c}\text { Não } \\
\text { examinados } \\
n=439 \\
\end{array}$} & \multicolumn{2}{|c|}{$\begin{array}{c}\text { Examinados } \\
n=221\end{array}$} & \multicolumn{2}{|c|}{$\begin{array}{c}\text { Total } \\
n=660\end{array}$} & \multirow[t]{2}{*}{$p$} \\
\hline & $\mathbf{n}$ & $\%$ & $\mathbf{n}$ & $\%$ & $\mathbf{n}$ & $\%$ & \\
\hline Sexo & & & & & & & 0,4737 \\
\hline Masculino & 190 & 43,3 & 90 & 40,7 & 280 & 42,4 & \\
\hline Feminino & 249 & 56,7 & 131 & 59,3 & 380 & 57,6 & \\
\hline Estado civil & & & & & & & 0,8549 \\
\hline Solteiro & 9 & 2,1 & 3 & 1,4 & 12 & 1,8 & \\
\hline Casado/União consensual & 267 & 60,8 & 142 & 64,2 & 409 & 62,0 & \\
\hline Desquitado/Separado & 14 & 3,2 & 7 & 3,2 & 21 & 3,2 & \\
\hline Viúvo & 149 & 33,9 & 69 & 31,2 & 218 & 33,0 & \\
\hline Grupo etário (anos)* & & & & & & & 0,0055 \\
\hline $60-69$ & 226 & 51,5 & 136 & 61,4 & 362 & 54,8 & \\
\hline $70-79$ & 149 & 33,9 & 71 & 32,0 & 220 & 33,3 & \\
\hline $80+$ & 64 & 14,6 & 14 & 6,6 & 78 & 11,9 & \\
\hline Escolaridade & & & & & & & 0,3784 \\
\hline Não alfabetizado & 39 & 8,9 & 22 & 10,0 & 61 & 9,2 & \\
\hline Alfabetizado & 39 & 8,9 & 13 & 5,9 & 52 & 7,9 & \\
\hline Ensino fundamental incompleto & 323 & 73,6 & 158 & 71,4 & 481 & 72,8 & \\
\hline Ensino fundamental completo & 16 & 3,6 & 15 & 6,8 & 31 & 4,7 & \\
\hline Ensino médio e superior & 22 & 5,0 & 13 & 5,9 & 35 & 5,4 & \\
\hline Renda $(S M=R \$ 200,00)$ & & & & & & & 0,6893 \\
\hline Dependente & 142 & 32,3 & 75 & 33,9 & 217 & 32,8 & \\
\hline Até 2 SM & 203 & 46,2 & 98 & 44,4 & 301 & 45,6 & \\
\hline $2-3 \mathrm{SM}$ & 55 & 12,5 & 25 & 11,3 & 80 & 12,1 & \\
\hline 3-5 SM & 26 & 5,9 & 18 & 8,1 & 44 & 6,7 & \\
\hline $5+S M$ & 13 & 3,1 & 5 & 2,3 & 18 & 2,8 & \\
\hline
\end{tabular}

${ }^{*} \mathrm{p}<0,05$. 
As médias de idade das amostras foram diferentes, conforme descrito na Tabela 11, a partir do modo estimado para proporcionalidade e da comparação entre os resultados obtidos para os respectivos intervalos de confiança.

Tabela 11. Médias, erros-padrão e intervalos de confiança (I.C.) dos grupos de examinados e de não examinados de uma amostra de idosos da área urbana de Joinville-SC, segundo idade. 2002.

\begin{tabular}{llcccc}
\hline \multirow{2}{*}{ Variável } & & \multicolumn{2}{c}{ Grupo } & \multirow{2}{*}{ Total } & \multirow{2}{*}{$p$} \\
\cline { 2 - 4 } & & Examinados & Não examinados & & \\
\cline { 2 - 5 } Idade (anos) & Média & 621 & 439 & 660 & \\
& Erro Padrão & 0,41 & 70,5 & 69,8 & \multirow{2}{*}{0,0000} \\
& I.C. $95 \%$ & {$[67,5 ; 69,2]$} & {$[69,6 ; 71,4]$} & {$[69,0 ; 70,5]$} & \\
\hline
\end{tabular}
$\mathrm{p}<0,05$.

Para as demais variáveis: sexo, estado civil, escolaridade e renda, não houve diferença estatisticamente significante $(p<0,05)$ entre os dois grupos (Tabela 10).

A Tabela 12 mostra a distribuição de grupo etário de idosos segundo três grupos: amostra de examinados, Censo 2000 para o Município de Joinville, e Censo 2000 para os idosos do Brasil. É possivivel verificar a semelhança das freqüências percentuais entre os três grupos.

Tabela 12. Distribuição de idosos segundo a amostra de examinados, segundo o Censo 2000 para o Município de Joinville, e segundo o Censo 2000 para os idosos do Brasil, considerando-se grupo etário.

\begin{tabular}{|c|c|c|c|c|c|c|}
\hline \multirow{3}{*}{ População/Grupo etário } & \multicolumn{6}{|c|}{ Sexo } \\
\hline & \multicolumn{2}{|c|}{ Masculino } & \multicolumn{2}{|c|}{ Feminino } & \multicolumn{2}{|c|}{ Total } \\
\hline & $\mathbf{n}$ & $\%$ & $\mathbf{n}$ & $\%$ & $\mathbf{n}$ & $\%$ \\
\hline \multicolumn{7}{|l|}{ Amostra } \\
\hline 60-69 anos & 55 & 40 & 81 & 60 & 136 & 100 \\
\hline $70-79$ anos & 28 & 39 & 43 & 61 & 71 & 100 \\
\hline 80 anos e mais & 7 & 50 & 7 & 50 & 14 & 100 \\
\hline Total & 90 & 41 & 131 & 59 & 221 & 100 \\
\hline \multicolumn{7}{|l|}{ Joinville } \\
\hline 60-69 anos & 7.692 & 46 & 9.086 & 54 & 16.778 & 100 \\
\hline $70-79$ anos & 3.412 & 40 & 5.063 & 60 & 8.475 & 100 \\
\hline 80 anos e mais & 1.001 & 34 & 1.982 & 66 & 2.983 & 100 \\
\hline Total & 12.105 & 43 & 16.131 & 57 & 28.236 & 100 \\
\hline \multicolumn{7}{|l|}{ Brasil } \\
\hline $60-69$ anos & 3.792 .534 & 46 & 4.389 .501 & 54 & 8.182 .035 & 100 \\
\hline $70-79$ anos & 2.009 .900 & 44 & 2.511 .989 & 56 & 4.521 .889 & 100 \\
\hline 80 anos e mais & 731.350 & 40 & 1.100 .755 & 60 & 1.832 .105 & 100 \\
\hline Total & 6.533 .784 & 45 & 8.002 .245 & 55 & 14.536.029 & 100 \\
\hline
\end{tabular}




\subsection{Etapa 2: postos de saúde, 221 idosos}

Para que os dados obtidos na etapa 2 do estudo, coletados nos postos de saúde, fossem considerados representativos da etapa 1, procedeu-se ao tratamento estatístico levando-se em conta, a ponderação dos dados. Os resultados não ponderados encontram-se descritos no Anexo 5. Os pesos calculados para cada setor censitário investigado encontram-se descritos na Tabela 13.

Tabela 13. Distribuição dos pesos para correção da variação das taxas de examinados em 221 idosos da área urbana de Joinville-SC, segundo setor censitário.

\begin{tabular}{|c|c|c|c|c|}
\hline \multirow{2}{*}{$\begin{array}{c}\text { Setor } \\
\text { censitário }\end{array}$} & \multirow{2}{*}{$\begin{array}{c}\text { Idosos } \\
\text { entrevistados }\end{array}$} & \multicolumn{2}{|c|}{ Idosos examinados } & \multirow{2}{*}{$w 1_{i}=\frac{\text { Idosos entrevistado }}{\text { Idosos examinados }}$} \\
\hline & & $\mathbf{n}$ & $\%$ & \\
\hline 5 e 7 & 15 & 3 & 20,0 & 5,0 \\
\hline 16 & 27 & 3 & 11,1 & 9,0 \\
\hline 25 & 10 & 1 & 10,0 & 10,0 \\
\hline 34 & 5 & 3 & 60,0 & 1,7 \\
\hline 46 & 26 & 6 & 23,1 & 4,3 \\
\hline 55 & 30 & 14 & 46,7 & 2,1 \\
\hline 64 & 13 & 2 & 15,4 & 6,5 \\
\hline 74 & 25 & 8 & 32,0 & 3,1 \\
\hline 84 & 23 & 15 & 65,2 & 1,5 \\
\hline 94 & 15 & 3 & 20,0 & 5,0 \\
\hline 104 & 15 & 7 & 46,7 & 2,1 \\
\hline 112 & 27 & 16 & 59,3 & 1,7 \\
\hline 123 & 7 & 1 & 14,3 & 7,0 \\
\hline 134 & 21 & 5 & 23,8 & 4,2 \\
\hline 141 & 9 & 4 & 44,4 & 2,3 \\
\hline 150 & 13 & 6 & 46,2 & 2,2 \\
\hline 159 & 11 & 2 & 18,2 & 5,5 \\
\hline 168 & 12 & 5 & 41,7 & 2,4 \\
\hline 177 & 39 & 6 & 15,4 & 6,5 \\
\hline 186 & 13 & 7 & 53,8 & 1,9 \\
\hline 196 & 9 & 3 & 33,3 & 3,0 \\
\hline 205 & 19 & 6 & 31,6 & 3,2 \\
\hline 213 & 10 & 1 & 10,0 & 10,0 \\
\hline 220 & 8 & 4 & 50,0 & 2,0 \\
\hline 228 & 11 & 7 & 63,6 & 1,6 \\
\hline 239 & 36 & 11 & 30,6 & 3,3 \\
\hline 246 & 26 & 11 & 42,3 & 2,4 \\
\hline 256 & 9 & 2 & 22,2 & 4,5 \\
\hline 265 & 16 & 6 & 37,5 & 2,7 \\
\hline 276 & 11 & 5 & 45,5 & 2,2 \\
\hline 285 & 17 & 6 & 35,3 & 2,8 \\
\hline 294 & 31 & 13 & 41,9 & 2,4 \\
\hline 303 & 25 & 9 & 36,0 & 2,8 \\
\hline 311 & 10 & 1 & 10,0 & 10,0 \\
\hline 319 & 3 & 1 & 33,3 & 3,0 \\
\hline 329 & 5 & 3 & 60,0 & 1,7 \\
\hline 338 & 11 & 4 & 36,4 & 2,8 \\
\hline 346 & 25 & 6 & 24,0 & 4,2 \\
\hline 355 & 2 & 0 & 0,0 & 0,0 \\
\hline 363 & 10 & 1 & 10,0 & 10,0 \\
\hline 371 & 10 & 4 & 40,0 & 2,5 \\
\hline Total & 660 & 221 & 33,5 & \\
\hline
\end{tabular}




\subsubsection{Análise das variáveis}

As variáveis e respectivos números de idosos analisados na etapa 2 foram:

- naturalidade (local de nascimento), estado civil, grupo etário, sexo, escolaridade e renda: 221 ;

- IMC: 217;

- perímetro do braço e prega cutânea tricipital: 218;

- concentrações de glicose, colesterol total, triglicerídeos e HDL-c: 218;

- concentração de LDL-c: 214;

- energia e macronutrientes: 221.

Os dados sócio-econômicos e demográficos dos 221 idosos encontram-se descritos na Tabela 14. As variáveis sócio-econômicas e demográficas utilizadas encontram-se descritas na Tabela 15

Em relação à naturalidade (local de origem), a maioria $(77,7 \%)$ dos homens $\mathrm{e}$ das mulheres $(83,3 \%)$ nasceram em Santa Catarina. O segundo e terceiro Estado mais freqüente foram, respectivamente, Minas Gerais e Rio Grande do Sul (Tabela 14).

Quanto ao estado civil, a maioria $(85,6 \%)$ dos homens relatou ser casado ou viver em união consensual, mostrando diferença estatisticamente significante $(\mathrm{p}<0,05)$ em relação às mulheres (Tabela 15). Para os idosos viúvos, as mulheres foram cerca de quatro vezes mais $(45,0 \%)$ freqüentes em relação aos homens $(11,1 \%)$, havendo diferença estatisticamente significante $(p<0,05)$ entre os sexos (Tabela 15, Figura 12).

As idades máxima e mínima encontradas foram 87 e 60 anos, respectivamente, sendo que a média de idade para homens e mulheres foi, respectivamente, 68,5 e 68,3 anos. Da mesma forma que para os idosos participantes da primeira etapa, na segunda etapa o grupo etário de 60-69 anos foi o que apresentou maior $(61,4 \%)$ freqüência de idosos (Tabela 10), tanto para o sexo masculino como para o feminino, conforme demonstrado na Figura 12. 
Tabela 14. Distribuição das freqüências absoluta (n) e relativa (\%) de 221 idosos da área urbana de Joinville-SC, segundo dados sócio-econômicos, demográficos e sexo. 2002.

\begin{tabular}{|c|c|c|c|c|c|c|}
\hline \multirow{3}{*}{$\begin{array}{c}\text { Dados sócio-econômicos e } \\
\text { demográficos }\end{array}$} & \multicolumn{4}{|c|}{ Sexo } & \multirow{2}{*}{\multicolumn{2}{|c|}{ Total }} \\
\hline & \multicolumn{2}{|c|}{ Masculino } & \multicolumn{2}{|c|}{ Feminino } & & \\
\hline & n & $\%$ & n & $\%$ & $\mathbf{n}$ & $\%$ \\
\hline \multicolumn{7}{|l|}{ Local de origem } \\
\hline Santa Catarina (SC) & 70 & 77,7 & 109 & 83,3 & 179 & 81,0 \\
\hline Minas Gerais (MG) & 5 & 5,6 & 6 & 4,6 & 11 & 5,0 \\
\hline Rio Grande do Sul (RS) & 5 & 5,6 & 5 & 3,8 & 10 & 4,5 \\
\hline Paraná (PR) & 5 & 5,6 & 4 & 3,0 & 9 & 4,1 \\
\hline São Paulo (SP) & 3 & 3,3 & 3 & 2,3 & 6 & 2,7 \\
\hline Demais estados & 2 & 2,2 & 4 & 3,0 & 6 & 2,7 \\
\hline \multicolumn{7}{|l|}{ Estado civil } \\
\hline Solteiro & 1 & 1,1 & 2 & 1,5 & 3 & 1,4 \\
\hline Casado & 72 & 80,0 & 64 & 48,8 & 136 & 61,5 \\
\hline União consensual & 5 & 5,6 & 1 & 0,8 & 6 & 2,7 \\
\hline Desquitado ou separado & 2 & 2,2 & 5 & 3,8 & 7 & 3,2 \\
\hline Viúvo & 10 & 11,1 & 59 & 45,1 & 69 & 31,2 \\
\hline \multicolumn{7}{|l|}{ Grupo etário (anos) } \\
\hline $60-69$ & 55 & 61,1 & 81 & 61,8 & 136 & 61,4 \\
\hline $70-79$ & 28 & 31,1 & 43 & 32,8 & 71 & 32,0 \\
\hline $80+$ & 7 & 7,8 & 7 & 5,3 & 14 & 6,6 \\
\hline \multicolumn{7}{|l|}{ Cor ou grupo étnico } \\
\hline Branca & 75 & 83,3 & 115 & 87,8 & 190 & 86,0 \\
\hline Negra & 1 & 1,1 & 1 & 0,8 & 2 & 0,9 \\
\hline Parda & 14 & 15,6 & 15 & 11,4 & 29 & 13,1 \\
\hline Amarela & 0 & 0 & 0 & 0 & 0 & 0 \\
\hline Indígena & 0 & 0 & 0 & 0 & 0 & 0 \\
\hline \multicolumn{7}{|l|}{ Escolaridade } \\
\hline Não alfabetizado & 6 & 6,7 & 16 & 12,2 & 22 & 10,0 \\
\hline Alfabetizado & 8 & 8,9 & 5 & 3,8 & 13 & 5,9 \\
\hline Ensino fundamental incompleto & 59 & 65,6 & 99 & 75,6 & 158 & 71,4 \\
\hline Ensino fundamental completo & 10 & 11,1 & 5 & 3,8 & 15 & 6,8 \\
\hline Ensino médio incompleto & 0 & 0 & 1 & 0,8 & 1 & 0,5 \\
\hline Ensino médio completo & 6 & 6,6 & 3 & 2,3 & 9 & 4,0 \\
\hline Ensino superior incompleto & 0 & 0 & 0 & 0 & 0 & 0 \\
\hline Ensino superior completo & 1 & 1,1 & 2 & 1,5 & 3 & 1,4 \\
\hline \multicolumn{7}{|l|}{ Renda (SM = RS 200,00) } \\
\hline Dependente & 5 & 5,6 & 70 & 53,4 & 75 & 33,9 \\
\hline Até $2 \mathrm{SM}$ & 46 & 51,1 & 52 & 39,7 & 98 & 44,4 \\
\hline $2-3 \mathrm{SM}$ & 18 & 20,0 & 7 & 5,3 & 25 & 11,3 \\
\hline 3-5 SM & 17 & 18,9 & 1 & 0,8 & 18 & 8,1 \\
\hline 5-6 SM & 2 & 2,2 & 0 & 0 & 2 & 0,9 \\
\hline 6-8 SM & 2 & 2,2 & 0 & 0 & 2 & 0,9 \\
\hline 8-10 SM & 0 & 0 & 0 & 0 & 0 & 0 \\
\hline $10+\mathrm{SM}$ & 0 & 0 & 1 & 0,8 & 1 & 0,5 \\
\hline Total & 90 & 100 & 131 & 100 & 221 & 100 \\
\hline
\end{tabular}


Tabela 15. Distribuição das freqüências absoluta (n) e relativa (\%) de 221 idosos da área urbana de Joinville-SC, segundo variáveis sócio-econômicas, demográficas e sexo. 2002.

\begin{tabular}{|c|c|c|c|c|c|c|}
\hline \multirow{3}{*}{$\begin{array}{c}\text { Variáveis sócio-econômicas e } \\
\text { demográficas }\end{array}$} & \multicolumn{4}{|c|}{ Sexo } & \multirow{3}{*}{$X^{2}$} & \multirow{3}{*}{$p$} \\
\hline & \multicolumn{2}{|c|}{ Masculino } & \multicolumn{2}{|c|}{ Feminino } & & \\
\hline & $\mathbf{n}$ & $\%$ & $\mathbf{n}$ & $\%$ & & \\
\hline \multicolumn{7}{|l|}{ Estado civil* } \\
\hline Casado/União consensual & 77 & 85,6 & 65 & 49,6 & \multirow{3}{*}{30,86} & \multirow{3}{*}{0,0000} \\
\hline Solteiro/Desquitado/Separado & 3 & 3,3 & 7 & 5,4 & & \\
\hline Viúvo & 10 & 11,1 & 59 & 45,0 & & \\
\hline
\end{tabular}

\section{Grupo etário (anos)}

$\begin{array}{lrrrrrr}60-69 & 55 & 61,1 & 81 & 61,8 & 0,55 & 0,7728 \\ 70-79 & 28 & 31,1 & 43 & 32,8 & & \\ 80+ & 7 & 7,8 & 7 & 5,3 & & \end{array}$

\section{Escolaridade*}

Não alfabetizado

Alfabetizado

$\begin{array}{llll}6 & 6,7 & 16 & 12,2\end{array}$

Ensino fundamental incompleto

$\begin{array}{llll}8 & 8,9 & 5 & 3,8\end{array}$

$59 \quad 65,6 \quad 99 \quad 75,6$

Ensino fundamental completo

$\begin{array}{llll}10 & 11,1 & 5 & 3,8\end{array}$

Ensino médio e superior

$\begin{array}{llll}7 & 7,7 & 6 & 4,6\end{array}$

Renda (SM = RS 200,00) *

Dependente

Atć 2 SM

$\begin{array}{rrrrrr}5 & 5,6 & 70 & 53,4 & & \\ 46 & 51,1 & 52 & 39,7 & 72,11 & 0,0000 \\ 18 & 20,0 & 7 & 5,3 & & \\ 21 & 23,3 & 2 & 1,6 & & \end{array}$

2-3 SM

$\begin{array}{llll}21 & 23,3 & 2 & 1,6\end{array}$

$3+\mathrm{SM}$

${ }^{*} \mathrm{p}<0,05$. 


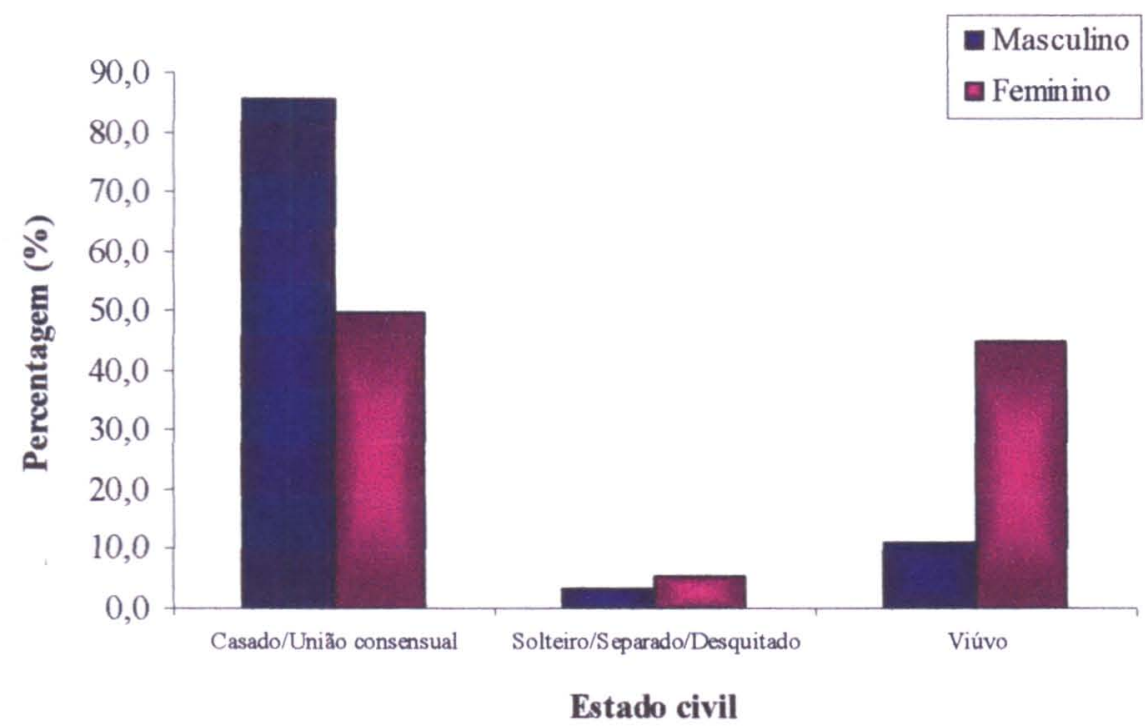

Figura 12. Distribuição de idosos da área urbana de Joinville-SC, segundo estado civil e sexo. 2002.

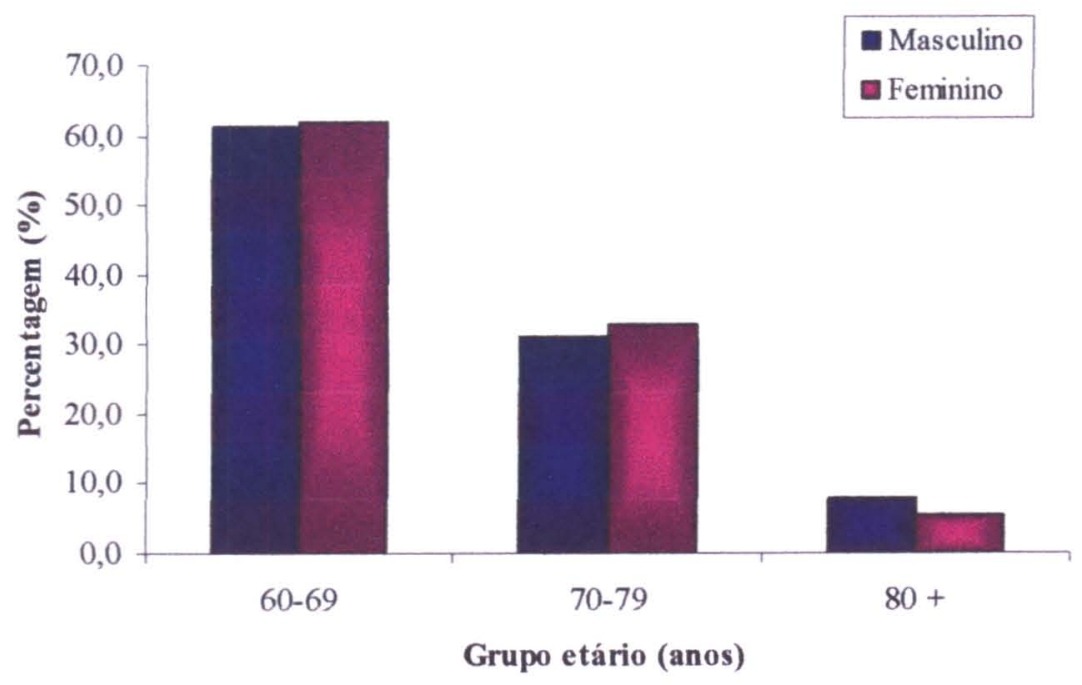

Figura 13. Distribuição de idosos da área urbana de Joinville-SC, segundo grupo etário e sexo. 2002. 
Para escolaridade, excetuando-se a categoria de não alfabetizados e ensino fundamental incompleto, os homens relataram maior freqüência nas demais categorias (Tabela 15). A categoria que apresentou maior freqüência relatada para ambos os sexos foi ensino fundamental incompleto, sendo $65,6 \%$ para homens e $75,6 \%$ para mulheres (Tabela 15, Figura 14). Houve diferença estatisticamente significante $(\mathrm{p}<0,05)$ entre os sexos para escolaridade (Tabela 15).

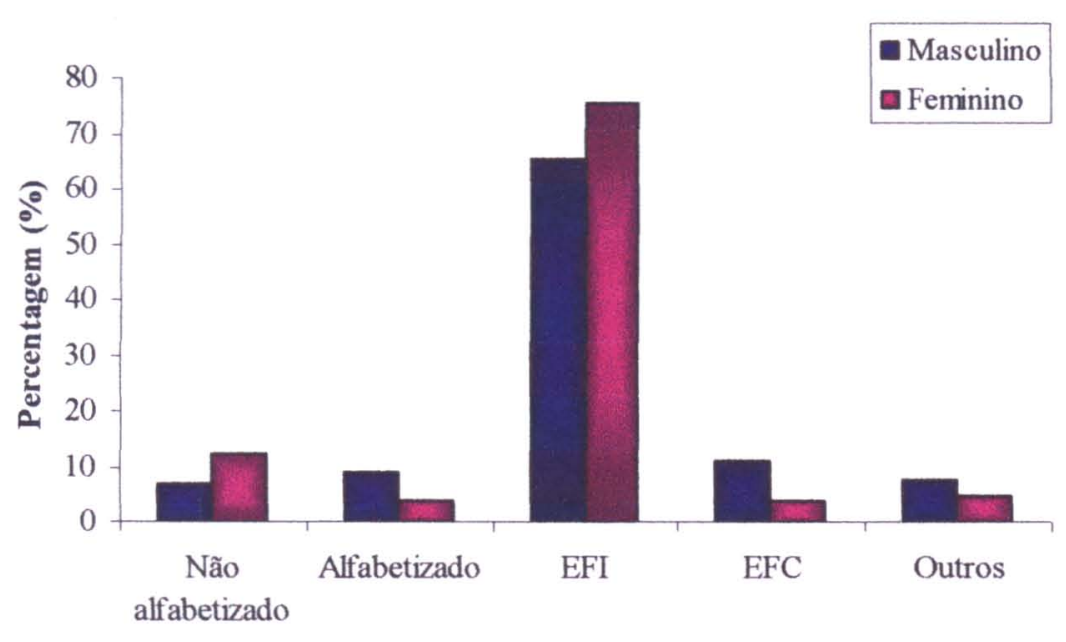

Escolaridade

Figura 14. Distribuição de idosos da área urbana de Joinville-SC, segundo escolaridade e sexo. 2002. EFI: Ensino Fundamental Incompleto, EFC: Ensino Fundamental Completo.

A renda também mostrou diferença significante $(\mathrm{p}<0,05)$ entre os sexos (Tabela 15). As mulheres relataram serem dependentes em maior freqüência do que os homens. O contrário ocorreu para os que recebiam até dois salários mínimos, sendo os homens os mais $(51,1 \%)$ freqüentes (Tabela 15 , Figura 15$)$. 


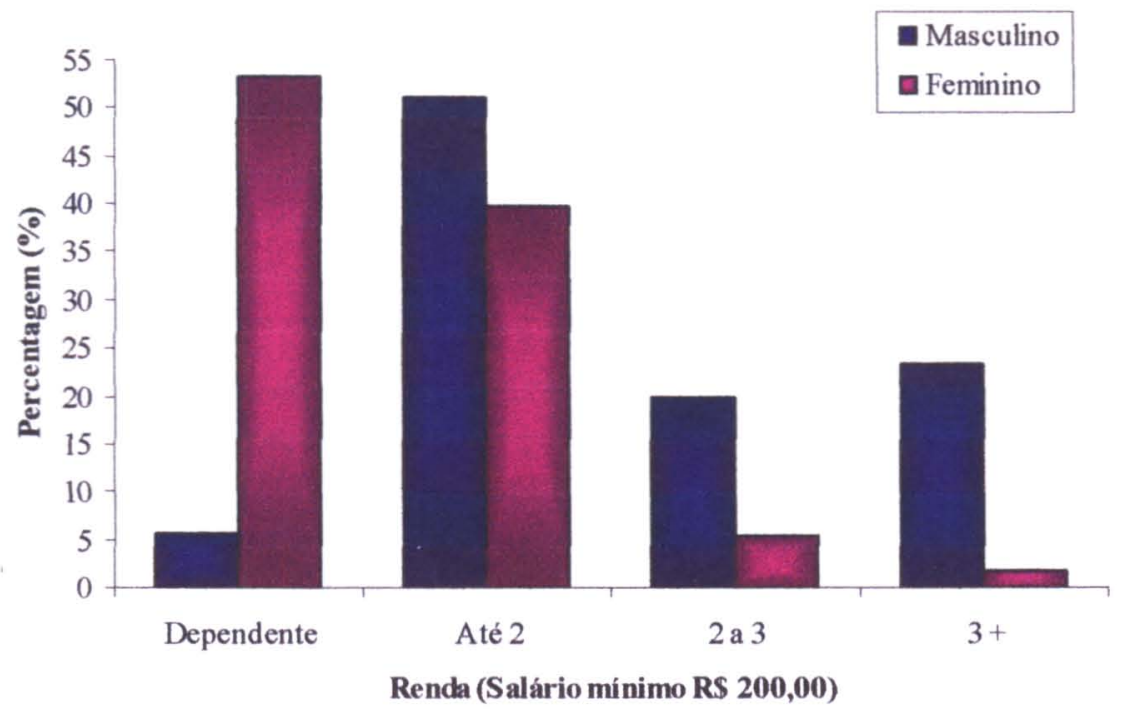

Figura 15. Distribuição dos idosos da área urbana de Joinville-SC, segundo renda e sexo. 2002.

\subsubsection{Variáveis antropométricas}

As variáveis antropométricas avaliadas foram: peso, estatura, $\mathrm{IMC}$, perímetro do braço e prega cutânea tricipital.

A Tabela 16 mostra que homens e mulheres não apresentaram diferença em relação ao peso, mas os homens apresentaram maior média de estatura $(166,3 \mathrm{~cm})$ em relação às mulheres $(155,1 \mathrm{~cm})$, havendo diferença estatisticamente significante $(\mathrm{p}<0,05)$ entre os sexos.

A média do IMC dos voluntários examinados foi $26,8 \mathrm{~kg} / \mathrm{m}^{2}$, onde as mulheres apresentaram média de IMC significativamente $(\mathrm{p}<0,05)$ superior $(28,1$ $\left.\mathrm{kg} / \mathrm{m}^{2}\right)$ a dos homens $\left(25,2 \mathrm{~kg} / \mathrm{m}^{2}\right)$ (Tabela 16$)$.

Para perímetro do braço, as mulheres apresentaram média de perímetro significativamente $(\mathrm{p}<0,05)$ maior $(31,3 \mathrm{~cm})$ que os homens $(29,9 \mathrm{~cm})$ (Tabela 16).

Quanto à prega cutânea tricipital, as mulheres também apresentaram valores médios bem superiores $(21,9 \mathrm{~mm})$ aos dos homens $(10,7 \mathrm{~mm})$, havendo diferença estatisticamente significante $(\mathrm{p}<0,05)$ (Tabela 16). 
Tabela 16. Médias, erros-padrão e intervalos de confiança de variáveis antropométricas dos idosos que compareceram na segunda etapa do estudo, segundo sexo. 2002.

\begin{tabular}{|c|c|c|c|c|c|}
\hline \multirow{2}{*}{$\begin{array}{l}\text { Variáveis } \\
\text { antropométricas }\end{array}$} & & \multicolumn{2}{|c|}{ Sexo } & \multirow{2}{*}{ Total } & \multirow{2}{*}{$p$} \\
\hline & & Masculino & Feminino & & \\
\hline \multirow{3}{*}{ Peso (kg) } & Média & 69,8 & 67,8 & 68,7 & \multirow{3}{*}{0,2980} \\
\hline & Erro Padrão & 1,62 & 1,44 & 1,24 & \\
\hline & I.C. $95 \%$ & {$[66.9 ; 73.5]$} & {$[64.3 ; 70.1]$} & {$[66.2 ; 71.2]$} & \\
\hline \multirow{3}{*}{ Estatura $(\mathrm{cm})^{*}$} & Média & 166,3 & 155,1 & 160 & \multirow{3}{*}{0,0000} \\
\hline & Erro Padrão & 1,08 & 0,78 & 0,94 & \\
\hline & I.C. $95 \%$ & {$[164.1 ; 168.4]$} & {$[153.5 ; 156.7]$} & {$[158.1 ; 161.9]$} & \\
\hline \multirow{3}{*}{$\operatorname{IMC}\left(\mathrm{kg} / \mathrm{m}^{2}\right)^{*}$} & Média & 25,2 & 28,1 & 26,8 & \multirow{3}{*}{0,0000} \\
\hline & Erro Padrão & 0,41 & 0,55 & 0,41 & \\
\hline & I.C. $95 \%$ & {$[24.4 ; 26.0]$} & {$[26.9 ; 29.2]$} & {$[25.9 ; 27.7]$} & \\
\hline \multirow{3}{*}{$\begin{array}{l}\text { Perimetro do braço } \\
(\mathrm{cm})^{*}\end{array}$} & Média & 29,9 & 31,3 & 30,7 & \multirow{3}{*}{0,0490} \\
\hline & Erro Padrão & 0,52 & 0,52 & 0,38 & \\
\hline & I.C. $95 \%$ & {$[28.9 ; 30.9]$} & {$[30.3 ; 32.4]$} & {$[29.9 ; 31.5]$} & \\
\hline \multirow{3}{*}{$\begin{array}{l}\text { Prega cutânea } \\
\text { tricipital (mm)* }\end{array}$} & Média & 10,7 & 21,9 & 16,9 & \multirow{3}{*}{0,0000} \\
\hline & Erro Padrão & 0,41 & 0,83 & 0,68 & \\
\hline & I.C. $95 \%$ & {$[9.9 ; 11.6]$} & {$[20.2 ; 23.6]$} & {$[15.5 ; 18.3]$} & \\
\hline
\end{tabular}

$*_{\mathrm{p}}<0,05$.

Quando separados em relação aos percentis de referência para IMC, segundo Kuczmarski e col. (2000), apesar da maioria dos homens e das mulheres terem apresentado valores médios de IMC normais, uma grande parcela $(32,8 \%)$ dos idosos apresentou valores médios de IMC elevados (Tabela 17, Figura 16), havendo diferença estatisticamente significante $(p<0,05)$ dos percentis de IMC entre os sexos. Nota-se que a diferença ocorreu para percentis de IMC inadequado (Tabela 17).

Quando separados em relação aos percentis de referência para perimetro do braço, segundo Kuczmarski e col. (2000), apesar da maioria dos homens e das mulheres terem apresentado valores médios de perímetro do braço adequados, uma grande parcela $(32,4 \%)$ indivíduos apresentou valores médios elevados (Tabela 18 , Figura 17), havendo diferença estatisticamente significante $(p<0,05)$ dos percentis de perímetro do braço entre os sexos. Nota-se que esta diferença também ocorreu para percentis de IMC inadequado (Tabela 18). 
Tabela 17. Freqüências relativas (\%) dos percentis IMC de 217 idosos da área urbana de Joinville-SC, segundo proposto por Kuczmarski e col. (2000) por sexo. 2002.

\begin{tabular}{|c|c|c|c|c|c|}
\hline \multirow[b]{2}{*}{ IMC } & \multicolumn{2}{|c|}{ Sexo } & \multirow{2}{*}{$\begin{array}{l}\text { Total } \\
(\%)\end{array}$} & \multirow[b]{2}{*}{$\chi^{2}$} & \multirow[b]{2}{*}{$p$} \\
\hline & $\begin{array}{c}\text { Masculino } \\
(\%)\end{array}$ & $\begin{array}{c}\text { Feminino } \\
(\%)\end{array}$ & & & \\
\hline $\begin{array}{l}\text { Inadequado } \\
\text { (insuficiente): valores } \\
<\mathrm{P} 25\end{array}$ & 16,0 & 5,2 & 10,0 & & \\
\hline $\begin{array}{l}\text { Adequado: } \\
\text { valores entre P25 e P75 }\end{array}$ & 60,0 & 55,0 & 57,2 & 3,82 & 0,0270 \\
\hline $\begin{array}{l}\text { Inadequado (elevado): } \\
\text { valores }>\text { P75 }\end{array}$ & 24,0 & 39,8 & 32,8 & & \\
\hline Total & 100,0 & 100,0 & 100,0 & & \\
\hline
\end{tabular}

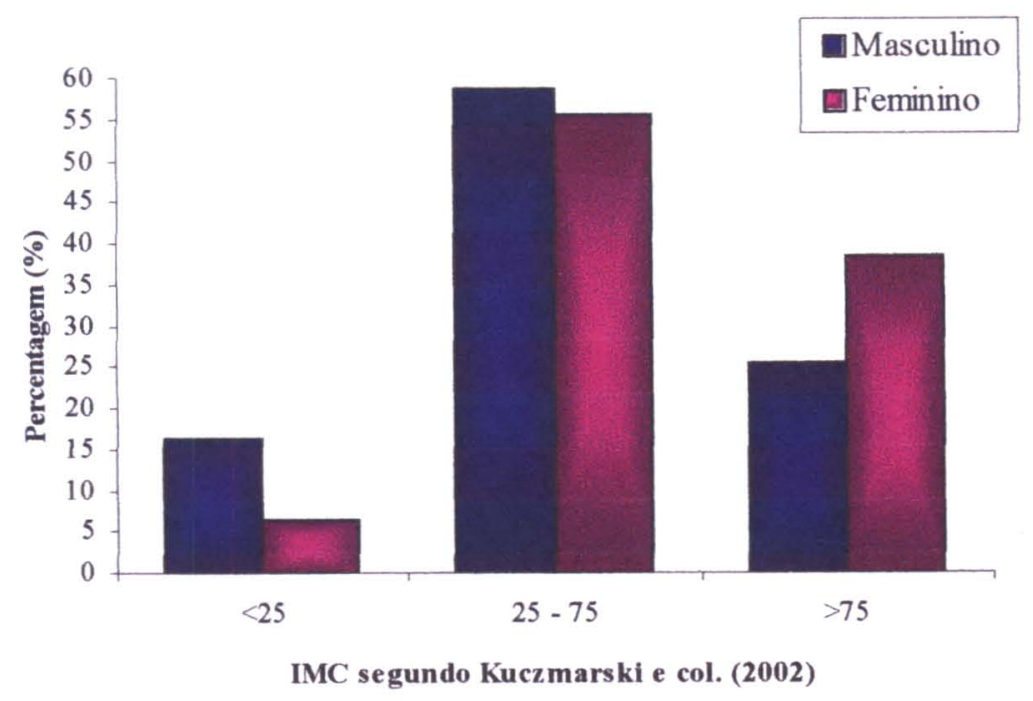

Figura 16. Distribuição de 217 idosos da área urbana de Joinville-SC, segundo os percentis de IMC, proposto por Kuczmarski e col. (2000), e sexo. 2002. 
Tabela 18. Frequências relativas (\%) dos percentis de perímetro do braço de 218 idosos da área urbana de Joinville-SC, segundo proposto por Kuczmarski e col. (2000), por sexo. 2002.

\begin{tabular}{|c|c|c|c|c|c|}
\hline \multirow[b]{2}{*}{ Perímetro do braço } & \multicolumn{2}{|c|}{ Sexo } & \multirow{2}{*}{$\begin{array}{c}\text { Total } \\
(\%)\end{array}$} & \multirow[b]{2}{*}{$\chi^{2}$} & \multirow[b]{2}{*}{$p$} \\
\hline & $\begin{array}{c}\text { Masculino } \\
(\%)\end{array}$ & $\begin{array}{c}\text { Feminino } \\
(\%)\end{array}$ & & & \\
\hline $\begin{array}{l}\text { Inadequado } \\
\text { (insuficiente): valores } \\
<\text { P25 }\end{array}$ & 20,9 & 4,3 & 11,7 & & \\
\hline $\begin{array}{l}\text { Adequado: } \\
\text { valores entre P25 e P75 }\end{array}$ & 58,6 & 53,8 & 55,9 & 6,63 & 0,0024 \\
\hline $\begin{array}{l}\text { Inadequado (elevado): } \\
\text { valores }>\text { P75 }\end{array}$ & 20,5 & 41,9 & 32,4 & & \\
\hline Total & 100,0 & 100,0 & 100,0 & & \\
\hline
\end{tabular}

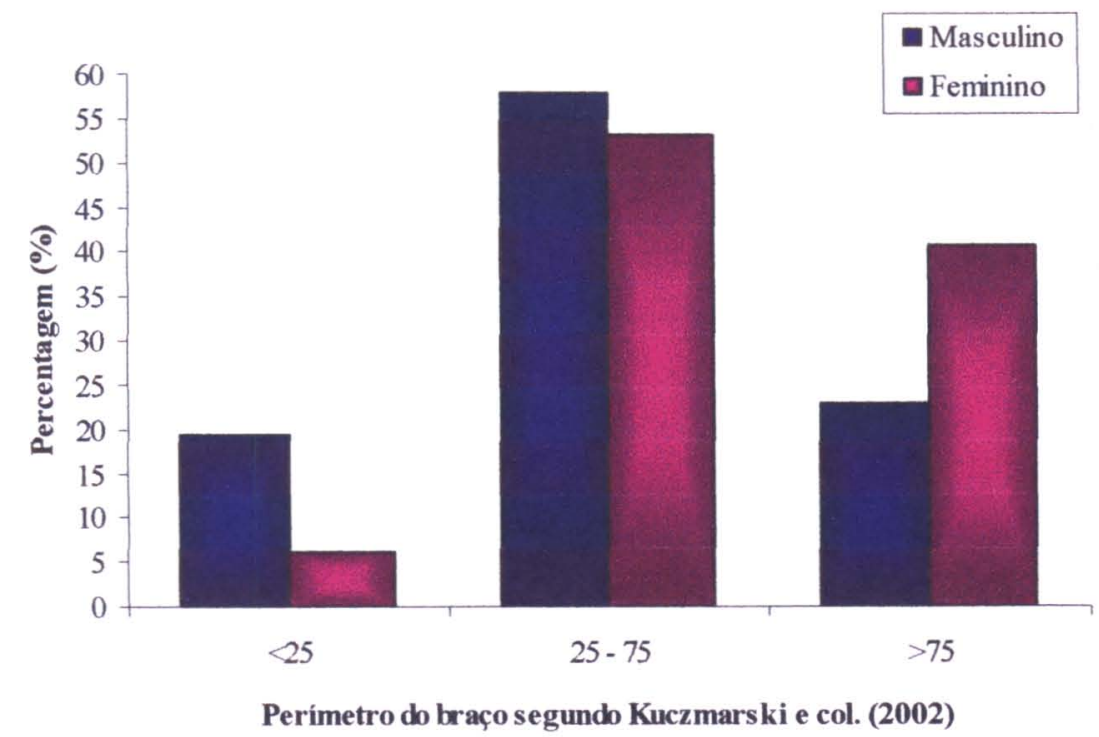

Figura 17. Distribuição de 218 idosos da área urbana de Joinville-SC, segundo os percentis de perímetro do braço, proposto por Kuczmarski e col. (2000), e sexo. 2002. 
Quando separados em relação aos percentis de referência para prega cutânea tricipital, segundo Kuczmarski e col. (2000), apesar de 44,3\% dos homens e 45,4\% das mulheres terem apresentado valores médios de prega cutânea tricipital adequados, uma grande parcela $(33,4 \%)$ dos indivíduos apresentou valores médios elevados (Tabela 19, Figura 18), havendo diferença estatisticamente significante $(p<0,05)$ dos percentis de prega cutânea tricipital entre os sexos. Nota-se que esta diferença também ocorreu para percentis de prega cutânea tricipital inadequado (Tabela 19).

Tabela 19. Distribuição das freqüências absoluta (n) e relativa (\%) dos percentis de prega cutânea tricipital de 218 idosos da área urbana de Joinville-SC, segundo proposto por Kuczmarski e col. (2000), e sexo. 2002.

\begin{tabular}{|c|c|c|c|c|c|}
\hline \multirow[b]{2}{*}{$\begin{array}{l}\text { Prega cutânea } \\
\text { tricipital }\end{array}$} & \multicolumn{2}{|c|}{ Sexo } & \multirow{2}{*}{$\begin{array}{l}\text { Total } \\
(\%)\end{array}$} & \multirow[b]{2}{*}{$\chi^{2}$} & \multirow[b]{2}{*}{$p$} \\
\hline & $\begin{array}{c}\text { Masculino } \\
(\%)\end{array}$ & $\begin{array}{c}\text { Feminino } \\
(\%)\end{array}$ & & & \\
\hline $\begin{array}{l}\text { Inadequado } \\
\text { (insuficiente): valores } \\
<\text { P25 }\end{array}$ & 32,9 & 9,4 & 19,9 & & \\
\hline $\begin{array}{l}\text { Adequado: } \\
\text { valores entre P25 e P75 }\end{array}$ & 46,5 & 46,8 & 46,7 & 9,54 & 0,0003 \\
\hline $\begin{array}{l}\text { Inadequado (elevado): } \\
\text { valores }>\text { P75 }\end{array}$ & 20,6 & 43,8 & 33,4 & & \\
\hline Total & 100,0 & 100,0 & 100,0 & & \\
\hline
\end{tabular}




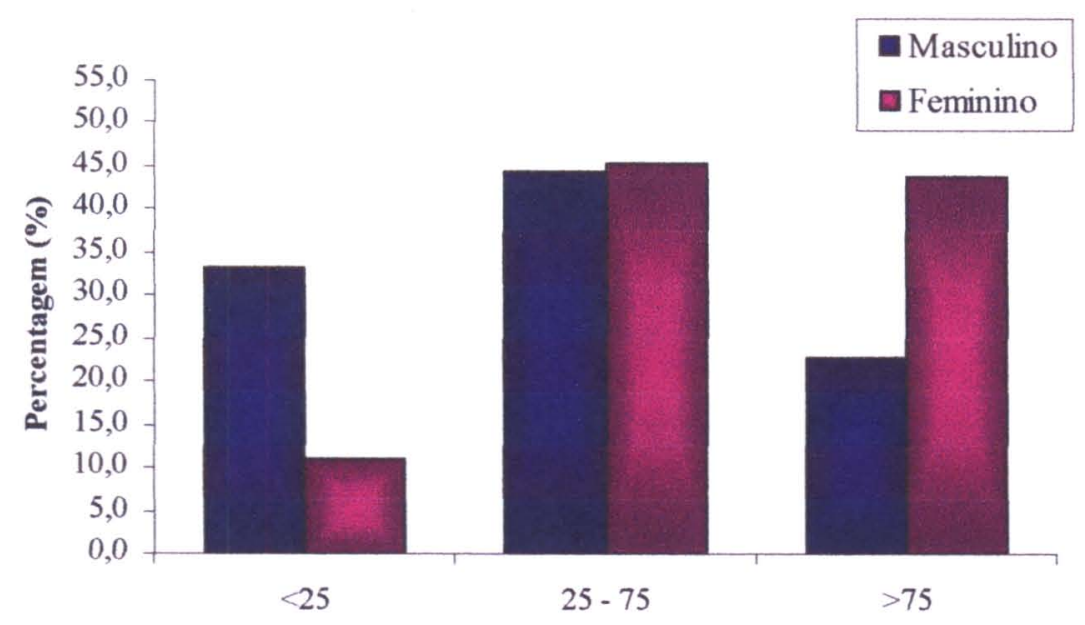

Prega cutâne a tricipital segundo Kucz marski e col. (2002)

Figura 18. Distribuição de 218 idosos da área urbana de Joinville-SC, segundo percentis de prega cutânea tricipital, proposto por Kuczmarski e col. (2000), e sexo. 2002.

\subsubsection{Associação de IMC com variáveis sócio-econômicas}

\subsubsection{IMC X Idade}

Para verificar se houve alteração do IMC com o aumento da idade, construiuse um gráfico mostrando a relação IMC X Idade, demonstrado na Figura 19. Na figura, é possível observar que o IMC dos idosos foi semelhante até, aproximadamente, 80 anos. Após essa idade, parece haver uma tendência dos indivíduos a não apresentar IMC superior a aproximadamente $30 \mathrm{~kg} / \mathrm{m}^{2}$. 


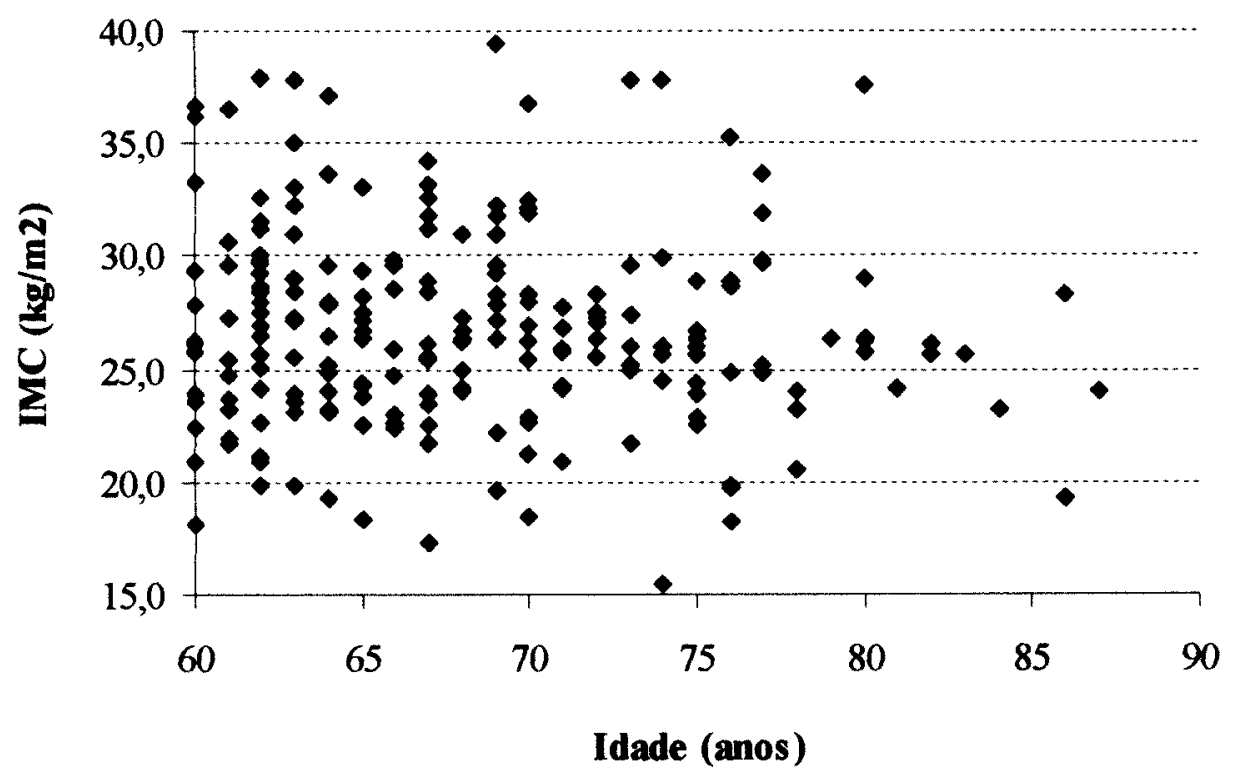

Figura 19. Idade de 221 idosos residentes na área urbana de Joinville-SC, segundo IMC. 2002.

\subsubsection{IMC X Renda}

A relação entre as três categorias de $\mathrm{IMC}$ e renda foi demonstrada na Tabela 20. Dos 87 homens examinados, a renda de até dois SM foi a mais freqüente nas três categorias de IMC consideradas. A maioria dos homens que relataram receber três ou mais SM, enquadrou-se como IMC adequado. Para as mulheres, a característica "dependente" em relação à renda mostrou ser a mais freqüente nas três categorias de IMC investigadas. Nenhuma mulher com IMC classificado como inadequado insuficiente relatou possuir renda maior do que $2 \mathrm{SM}$. 
Tabela 20. Relação entre IMC e renda em 221 idosos da área urbana de Joinville-SC, segundo o sexo. 2002.

\begin{tabular}{|c|c|c|c|c|c|}
\hline \multirow{3}{*}{$\begin{array}{c}\text { IMC } \\
\left(\mathrm{kg} / \mathrm{m}^{2}\right)\end{array}$} & \multirow{3}{*}{$\begin{array}{c}\text { Renda } \\
(\mathrm{SM}=\mathrm{R} \$ 200,00)\end{array}$} & \multicolumn{4}{|c|}{ Sexo } \\
\hline & & \multicolumn{2}{|c|}{$\begin{array}{c}\text { Masculino } \\
n=87\end{array}$} & \multicolumn{2}{|c|}{$\begin{array}{c}\text { Feminino } \\
n=130\end{array}$} \\
\hline & & $n$ & $\%$ & $n$ & $\%$ \\
\hline \multirow{5}{*}{$\begin{array}{l}\text { Inadequado } \\
\text { (insuficiente): } \\
\text { valores }<\text { P25 }\end{array}$} & Dependente & 0 & 0 & 4 & 3,1 \\
\hline & Até $2 \mathrm{SM}$ & 8 & 9,2 & 4 & 3,1 \\
\hline & $2-3 \mathrm{SM}$ & 4 & 4,6 & 0 & 0 \\
\hline & $3+\mathrm{SM}$ & 2 & 2,3 & 0 & 0 \\
\hline & Total & 14 & 16,1 & 8 & 6,2 \\
\hline \multirow{5}{*}{$\begin{array}{l}\text { Adequado: } \\
\text { valores entre } \\
\text { P25 e P75 }\end{array}$} & Dependente & 2 & 2,3 & 35 & 27,0 \\
\hline & Até $2 \mathrm{SM}$ & 26 & 30,0 & 28 & 21,5 \\
\hline & 2-3 SM & 8 & 9,1 & 5 & 3,8 \\
\hline & $3+\mathrm{SM}$ & 15 & 17,2 & 2 & 1,5 \\
\hline & Total & 51 & 58,6 & 70 & 53,8 \\
\hline \multirow{5}{*}{$\begin{array}{l}\text { Inadequado } \\
\text { (elevado): } \\
\text { valores >P75 }\end{array}$} & Dependente & 3 & 3,5 & 30 & 23,1 \\
\hline & Até $2 \mathrm{SM}$ & 10 & 11,5 & 20 & 15,4 \\
\hline & $2-3 \mathrm{SM}$ & 5 & 5,7 & 2 & 1,5 \\
\hline & $3+\mathrm{SM}$ & 4 & 4,6 & 0 & 0 \\
\hline & Total & 22 & 25,3 & 52 & 40,0 \\
\hline
\end{tabular}

\subsubsection{IMC X Escolaridade}

A relação entre as três categorias de IMC e escolaridade foi descrita na Tabela 21. Ensino Fundamental Incompleto foi a categoria de escolaridade mais freqüente para homens e mulheres nas três classes de IMC consideradas. Mulheres e homens que relataram ser alfabetizados ou não, foram mais freqüentes para as categorias de IMC classificadas como adequada e elevada. 
Tabela 21. Relação entre IMC e escolaridade em 221 idosos da área urbana de Joinville-SC, segundo o sexo. 2002.

\begin{tabular}{|c|c|c|c|c|c|}
\hline \multirow{3}{*}{$\begin{array}{c}\text { IMC } \\
\left(\mathrm{kg} / \mathrm{m}^{2}\right)\end{array}$} & \multirow{3}{*}{ Escolaridade $^{*}$} & \multicolumn{4}{|c|}{ Sexo } \\
\hline & & \multicolumn{2}{|c|}{$\begin{array}{c}\text { Masculino } \\
\mathrm{n}=87\end{array}$} & \multicolumn{2}{|c|}{$\begin{array}{c}\text { Feminino } \\
n=130\end{array}$} \\
\hline & & $\mathbf{n}$ & $\%$ & $\mathbf{n}$ & $\%$ \\
\hline \multirow{5}{*}{$\begin{array}{l}\text { Inadequado } \\
\text { (insuficiente): } \\
\text { valores }<\text { P25 }\end{array}$} & Alfabetizado ou não & 2 & 2,3 & 1 & 0,8 \\
\hline & EFI & 10 & 11,6 & 6 & 4,6 \\
\hline & EFC & 1 & 1,1 & 0 & 0 \\
\hline & EMe ES & 1 & 1,1 & 1 & 0,8 \\
\hline & Total & 14 & 16,1 & 8 & 6,2 \\
\hline \multirow{5}{*}{$\begin{array}{l}\text { Adequado: } \\
\text { valores entre } \\
\text { P25 e P75 }\end{array}$} & Alfabetizado ou não & 7 & 8,0 & 10 & 7,7 \\
\hline & EFI & 34 & 39,1 & 53 & 40,8 \\
\hline & EFC & 6 & 6,9 & 2 & 1,5 \\
\hline & EM e ES & 4 & 4,6 & 5 & 3,8 \\
\hline & Total & 51 & 58,6 & 70 & 53,8 \\
\hline \multirow{5}{*}{$\begin{array}{l}\text { Inadequado } \\
\text { (elevado): } \\
\text { valores >P75 }\end{array}$} & Alfabetizado ou não & 4 & 4,6 & 10 & 7,7 \\
\hline & EFI & 13 & 15,0 & 39 & 30,0 \\
\hline & EFC & 3 & 3,4 & 3 & 2,3 \\
\hline & EM e ES & 2 & 2,3 & 0 & 0 \\
\hline & Total & 22 & 25,3 & 52 & 40,0 \\
\hline
\end{tabular}

*Escolaridade: EFI: Ensino Fundamental Incompleto, EFC: Ensino Fundamental Completo; EM: Ensino Médio; ES: Ensino Superior.

\subsubsection{Variáveis bioquímicas}

As variáveis bioquímicas utilizadas neste estudo foram: glicose, colesterol total, HDL-c, LDL-c e triglicerídeos. As médias das variáveis bioquímicas analisadas, segundo o sexo, encontram-se descritas na Tabela 22. Os homens apresentaram concentrações médias de glicose $(103,2 \mathrm{mg} / \mathrm{dL})$ significativamente inferiores $(p<0,05)$ a das mulheres $(116,0 \mathrm{mg} / \mathrm{dL})$. Não houve diferença estatisticamente significante $(p<0,05)$ para colesterol total, HDL-c, LDL-c e triglicerídeos entre os sexos (Tabela 22).

Segundo a American Diabetes Association (2001), tanto a média da concentração de glicose para os 221 indivíduos $(110,3 \mathrm{mg} / \mathrm{dL})$ como para as 
mulheres $(116,0 \mathrm{mg} / \mathrm{dL})$, foram consideradas como acima do desejável $(110,0$ $\mathrm{mg} / \mathrm{dL}$ ).

Os valores para as concentrações médias de colesterol total da amostra $(213,4$ $\mathrm{mg} / \mathrm{dL})$, dos homens $(207,0 \mathrm{mg} / \mathrm{dL})$, e das mulheres $(218,6 \mathrm{mg} / \mathrm{dL})$, foram considerados como sendo limítrofes (200-239 mg/dL), segundo a "III Diretrizes Brasileiras sobre Dislipidemias e Diretriz de Prevenção da Aterosclerose do Departamento de Aterosclerose da Sociedade Brasileira de Cardiologia" (Sociedade Brasileira de Cardiologia 2001).

Tabela 22. Médias, erros-padrão e intervalos de confiança (I.C.) de variáveis bioquímicas de idosos da área urbana de Joinville-SC, segundo sexo. 2002.

\begin{tabular}{|c|c|c|c|c|c|}
\hline \multirow{2}{*}{$\begin{array}{l}\text { Variáveis } \\
\text { bioquímicas }\end{array}$} & & \multicolumn{2}{|c|}{ Sexo } & \multirow{2}{*}{ Total } & \multirow{2}{*}{$p$} \\
\hline & & Masculino & Feminino & & \\
\hline \multirow{3}{*}{ Glicose* } & Média & 103,2 & 116,0 & 110,3 & \multirow{3}{*}{0,0000} \\
\hline & Erro Padrão & 2,2 & 3,55 & 2,22 & \\
\hline & I.C. $95 \%$ & {$[98,8 ; 107,7]$} & {$[108,9 ; 123,2]$} & {$[105,8 ; 114,8]$} & \\
\hline \multirow{3}{*}{ Colesterol total } & Média & 207,0 & 218,6 & 213,4 & \multirow{3}{*}{0,1220} \\
\hline & Erro Padrão & 7 & 5,77 & 5,12 & \\
\hline & I.C. $95 \%$ & {$[192,9 ; 221,2]$} & {$[206,9 ; 230,2]$} & {$[203,0 ; 223,7]$} & \\
\hline \multirow{3}{*}{ HDL-c } & Média & 50,3 & 51,0 & 50,7 & \multirow{3}{*}{0,4690} \\
\hline & Erro Padrão & 0,89 & 0,46 & 0,49 & \\
\hline & I.C. $95 \%$ & {$[48,5 ; 52,1]$} & {$[50,1 ; 51,9]$} & {$[49,7 ; 51,7]$} & \\
\hline \multirow{3}{*}{ LDL-c** } & Média & 124,6 & 133,4 & 129,5 & \multirow{3}{*}{0,1130} \\
\hline & Erro Padrão & 5,14 & 5,16 & 4,34 & \\
\hline & I.C. $95 \%$ & {$[114,2 ; 135,0]$} & {$[123,0 ; 143,9]$} & {$[120,7 ; 138,3]$} & \\
\hline \multirow{3}{*}{ Triglicerídeos } & Média & 160,7 & 158,7 & 159,6 & \multirow{3}{*}{0,9110} \\
\hline & Erro Padrão & 14,26 & 11,78 & 9,56 & \\
\hline & I.C. $95 \%$ & {$[131,9 ; 189,6]$} & {$[134,9 ; 182,6]$} & {$[140,3 ; 179,0]$} & \\
\hline
\end{tabular}

${ }^{*} \mathrm{p}<0,05$.

**Para o cálculo do LDL-c, foram excluídos os indivíduos que apresentaram concentração de triglicerideos $>400 \mathrm{mg} / \mathrm{dL}$ : 3 homens e 1 mulher.

Para HDL-c, as médias dos valores encontrados para o sexo masculino $(50,3 \mathrm{mg} / \mathrm{dL})$, feminino $(51,0 \mathrm{mg} / \mathrm{dL})$ e amostra $(50,7 \mathrm{mg} / \mathrm{dL})$, foram classificadas como desejável (40-60 mg/dL). 
Em relação a média de LDL-c, apenas a encontrada para o sexo masculino $(124,6 \mathrm{mg} / \mathrm{dL})$ foi classificada como desejável (100-129 $\mathrm{mg} / \mathrm{dL})$. Para o sexo feminino $(133,4 \mathrm{mg} / \mathrm{dL})$ e para a amostra $(129,5 \mathrm{mg} / \mathrm{dL})$, os valores encontrados foram classificados como sendo limítrofes (130-159 mg/dL).

As médias dos valores encontrados para triglicerídeos de homens $(160,7$ $\mathrm{mg} / \mathrm{dL})$, mulheres $(158,7 \mathrm{mg} / \mathrm{dL})$ e amostra $(159,6 \mathrm{mg} / \mathrm{dL})$, também foram classificadas como sendo limítrofes (150-200 mg/dL).

Os valores de referência para cada variável bioquímica analisada, segundo a freqüência e o sexo, estão descritos na Tabela 23.

Tabela 23. Freqüência absoluta (n) e relativa (\%) de variáveis bioquímicas de 218 idosos residentes na área urbana de Joinville-SC, segundo valores de referência e sexo. 2002.

\begin{tabular}{|c|c|c|c|c|c|c|}
\hline \multirow{2}{*}{$\begin{array}{c}\text { Variáveis } \\
\text { bioquímicas }\end{array}$} & \multirow{2}{*}{$\begin{array}{l}\text { Valores de } \\
\text { referência } \\
(\mathrm{mg} / \mathrm{dL})\end{array}$} & \multirow[t]{2}{*}{ Categoria } & \multicolumn{2}{|c|}{$\begin{array}{c}\text { Masculino } \\
\mathrm{n}=89\end{array}$} & \multicolumn{2}{|c|}{$\begin{array}{c}\text { Feminino } \\
\mathrm{n}=129\end{array}$} \\
\hline & & & $\mathbf{n}$ & $\%$ & $\mathbf{n}$ & $\%$ \\
\hline \multirow[t]{3}{*}{ Glicose } & $70-110$ & Desejável & 70 & 78,6 & 83 & 64,4 \\
\hline & $110-126$ & Limítrofe & 8 & 9,0 & 23 & 17,8 \\
\hline & $\geq 126$ & Aumentado & 11 & 12,4 & 23 & 17,8 \\
\hline \multirow[t]{3}{*}{ Colesterol total } & $<200$ & Ótimo & 41 & 46,1 & 48 & 37,3 \\
\hline & $200-239$ & Limitrofe & 26 & 29,2 & 43 & 33,3 \\
\hline & $\geq 240$ & Alto & 22 & 24,7 & 38 & 29,4 \\
\hline \multirow[t]{3}{*}{ HDL-c } & $<40$ & Baixo & 1 & 1,1 & 1 & 0,8 \\
\hline & $40-60$ & Desejável & 85 & 95,6 & 121 & 93,8 \\
\hline & $>60$ & Alto & 3 & 3,3 & 7 & 5,4 \\
\hline \multirow[t]{5}{*}{ LDL-c* } & $<100$ & Ótimo & 23 & 26,7 & 17 & 13,3 \\
\hline & $100-129$ & Desejável & 25 & 29,1 & 36 & 28,1 \\
\hline & $130-159$ & Limítrofe & 22 & 25,6 & 49 & 38,4 \\
\hline & $160-189$ & Alto & 12 & 13,9 & 19 & 14,8 \\
\hline & $\geq 190$ & Muito alto & 4 & 4,7 & 7 & 5,4 \\
\hline \multirow[t]{4}{*}{ Triglicerídeos } & $<150$ & Ótimo & 58 & 65,3 & 78 & 60,4 \\
\hline & $150-200$ & Limitrofe & 14 & 15,7 & 22 & 17,1 \\
\hline & $200-499$ & Alto & 15 & 16,8 & 28 & 21,7 \\
\hline & $\geq 500$ & Muito alto & 2 & 2,2 & 1 & 0,8 \\
\hline
\end{tabular}

$*_{n}=214: 86$ homens e 128 mulheres. 
$\mathrm{Na}$ Tabela 23, é possível verificar que a maioria dos homens apresentou a média de todas as variáveis bioquímicas analisadas dentro dos valores de referência classificados como desejável e ótimo. Quanto às mulheres, estas apresentaram diferentes resultados em relação aos valores de referência. Para níveis de glicose, colesterol total, HDL-c e triglicerídeos, a média da maioria do sexo feminino foi classificada como desejável, mas, para LDL-c, a maioria foi classificada como limítrofe (Tabela 23).

A Tabela 24 mostra as médias das variáveis bioquímicas classificadas como: aumentada, alta e muito alta, segundo a freqüência e o sexo. Não houve diferença entre os sexos para as variáveis bioquímicas aumentadas avaliadas.

Tabela 24. Médias, erros-padrão e intervalos de confiança (I.C.) para classe de idosos com variáveis bioquímicas aumentada, alta ou muito alta, segundo sexo. 2002.

\begin{tabular}{|c|c|c|c|c|}
\hline \multirow{2}{*}{$\begin{array}{l}\text { Variáveis bioquimicas } \\
\text { (mg/dL) }\end{array}$} & & \multicolumn{2}{|c|}{ Sexo } & \multirow{2}{*}{ Total } \\
\hline & & Masculino & Feminino & \\
\hline \multirow{3}{*}{$\begin{array}{l}\text { Aumentada, } n=34 \\
\text { Glicose }>=126\end{array}$} & Média & 156,9 & 188,7 & 178,4 \\
\hline & Erro Padrão & 9,5 & 11,6 & 8,7 \\
\hline & I.C. $95 \%$ & {$[135,6 ; 178,2]$} & {$[164,6 ; 212,7]$} & {$[160,6 ; 196,2]$} \\
\hline \multirow{3}{*}{$\begin{array}{l}\text { Alta, } n=60 \\
\text { Colesterol Total }>=240\end{array}$} & Média & 256,6 & 268,3 & 264,0 \\
\hline & Erro Padrão & 2,7 & 4,9 & 3,3 \\
\hline & I.C. $95 \%$ & {$[250,9 ; 262,3]$} & {$[258,4 ; 278,3]$} & {$[257,4 ; 270,7]$} \\
\hline \multirow{3}{*}{$\begin{array}{l}\text { Alta/Muito alta, } n=42 \\
\text { LDL-C }>=160\end{array}$} & Média & 177,4 & 184,1 & 181,5 \\
\hline & Erro Padrão & 3,2 & 5,3 & 3,5 \\
\hline & I.C. $95 \%$ & {$[170,7 ; 184,2]$} & {$[173,1 ; 195,1]$} & {$[174,4 ; 188,7]$} \\
\hline \multirow{3}{*}{$\begin{array}{l}\text { Alta/Muito alta, } n=46 \\
\text { Triglicerideos }>=200\end{array}$} & Média & 302,4 & 275,1 & 285,2 \\
\hline & Erro Padrão & 28,9 & 17,8 & 15,4 \\
\hline & I.C. $95 \%$ & {$[41,0 ; 363,7]$} & {$[238,8 ; 311,5]$} & {$[254,2 ; 316,2]$} \\
\hline
\end{tabular}

Nenhum dos voluntários apresentou valores de concentração de glicose inferiores a $70 \mathrm{mg} / \mathrm{dL}$. Os casos em que a concentração de glicose foram igual ou superior a $126 \mathrm{mg} / \mathrm{dL}$ corresponderam a 34 indivíduos (15,6\% da amostra). 
A Figura 20 mostra a distribuição de 218 idosos segundo valores de referência de colesterol total e o sexo, apresentados na Tabela 23 . Destes, $60(27,5 \%)$ indivíduos apresentaram concentração de colesterol total aumentada ( $\geq 240,0 \mathrm{mg} / \mathrm{dL}$ ) (Tabela 24).

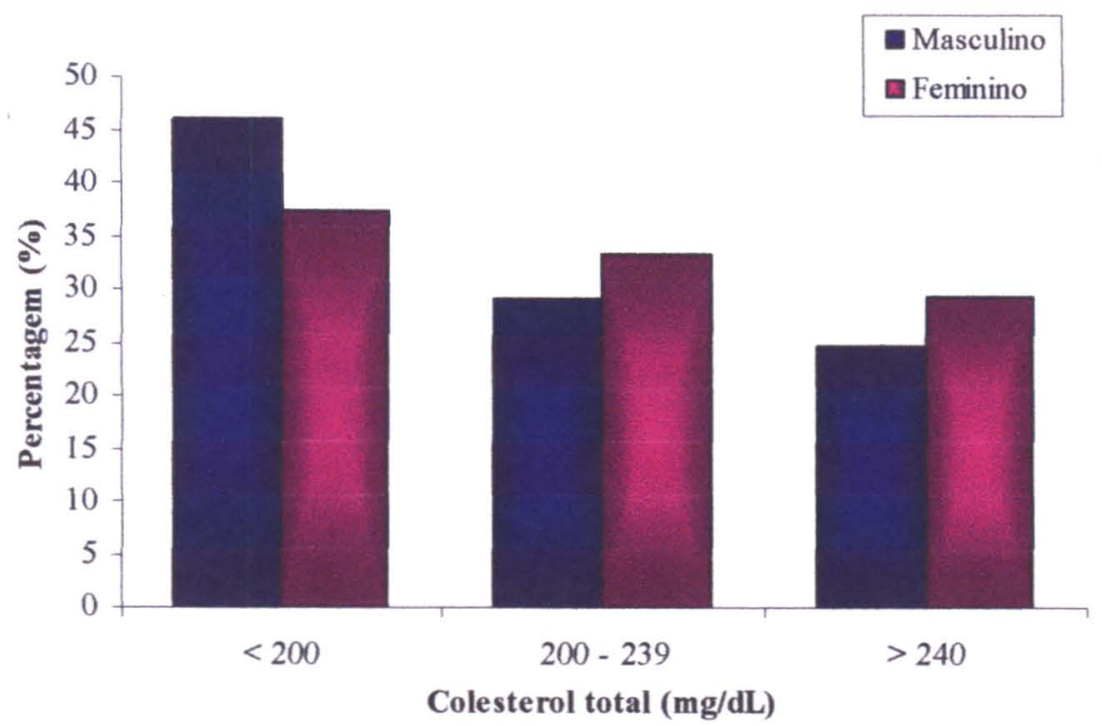

Figura 20. Distribuição de 218 idosos da área urbana de Joinville-SC, segundo valores de referência de colesterol total e o sexo. 2002.

A Figura 21 mostra a distribuição de 214 idosos segundo valores de referência de LDL-c e o sexo, apresentados na Tabela 23. Nesta figura, observa-se que grande parte $(42,7 \%)$ dos homens e, principalmente, a maioria $(58,6 \%)$ das mulheres, apresentarou concentrações de LDL-c superiores ao considerado limítrofe $(\geq 130,0 \mathrm{mg} / \mathrm{dL})$. 


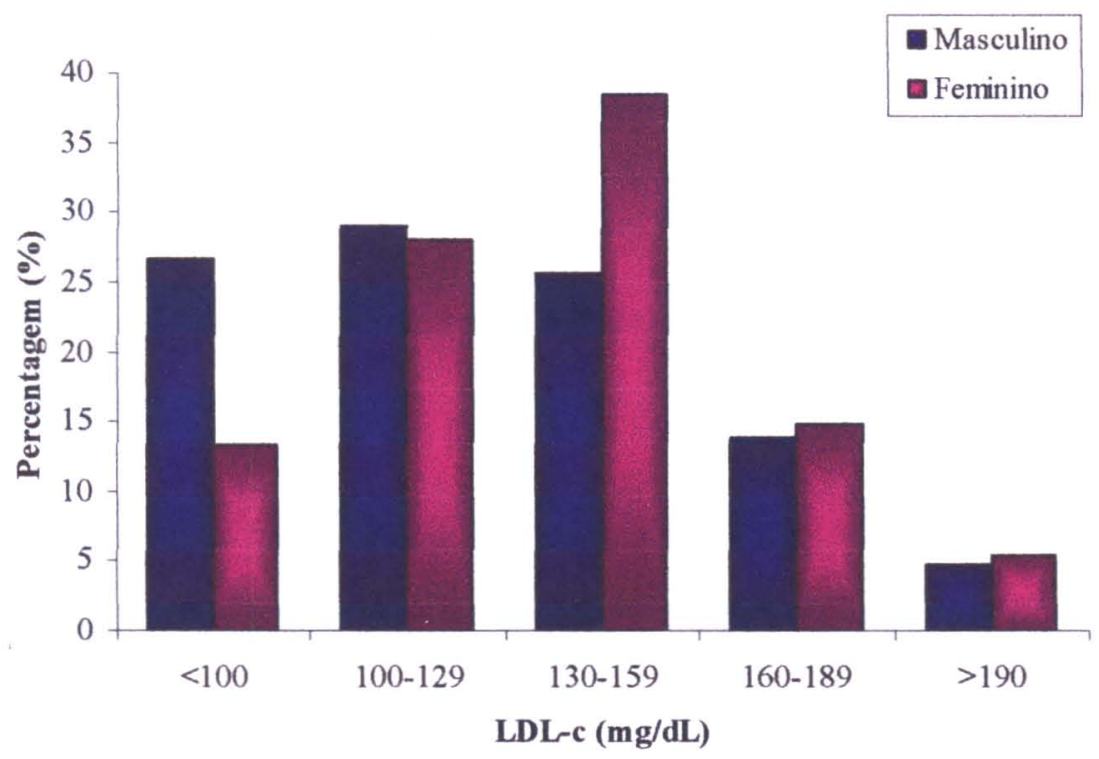

Figura 21. Distribuição de 214 idosos da área urbana de Joinville-SC, segundo valores de referência de LDL-c, e o sexo. 2002.

A Figura 22 mostra a distribuição de 218 idosos segundo valores de referência de triglicerídeos e o sexo, apresentados na Tabela 23. A maioria dos homens e das mulheres enquadraram-se como ótimo $(<150,0 \mathrm{mg} / \mathrm{dL})$, segundo os valores de referência utilizados.

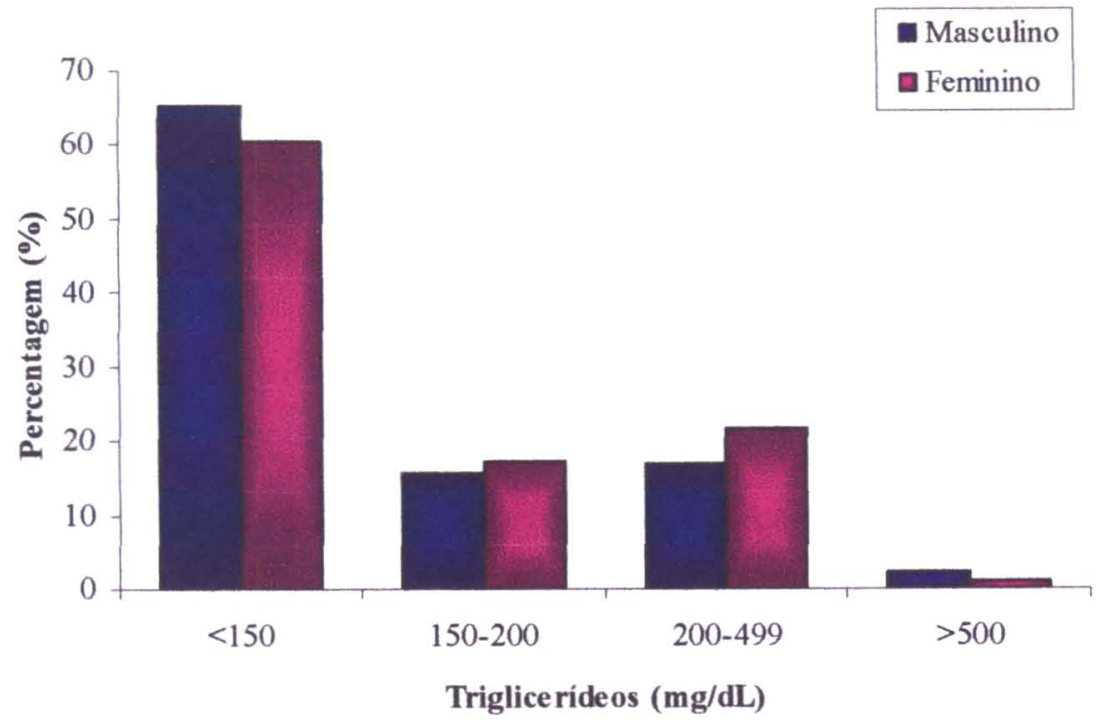

Figura 22. Distribuição de 218 idosos da área urbana de Joinville-SC, segundo valores de referência de triglicerídeos e o sexo. 2002. 
5.4.4.1. IMC X Perfil bioquímico alto (glicose $\geq 126 \mathrm{mg} / \mathrm{dL}$, colesterol total $\geq 240$ $\mathrm{mg} / \mathrm{dL}, \mathrm{LDL}-\mathrm{c} \geq 160 \mathrm{mg} / \mathrm{dL}$ e triglicerídeos $\geq 200 \mathrm{mg} / \mathrm{dL}$ )

A relação entre as três categorias de IMC e perfil bioquímico alto está descrita na Tabela 25.

Tabela 25. Relação entre IMC e perfil bioquímico alto em 221 idosos da área urbana de Joinville-SC, segundo o sexo. 2002.

\begin{tabular}{|c|c|c|c|c|c|}
\hline \multirow{3}{*}{$\begin{array}{c}\text { IMC } \\
\left(\mathrm{kg} / \mathrm{m}^{2}\right)\end{array}$} & \multirow{3}{*}{$\begin{array}{c}\text { Variável } \\
\text { bioquímica alta } \\
(\mathrm{mg} / \mathrm{dL})\end{array}$} & \multicolumn{4}{|c|}{ Sexo } \\
\hline & & \multicolumn{2}{|c|}{$\begin{array}{c}\text { Masculino } \\
n=87\end{array}$} & \multicolumn{2}{|c|}{$\begin{array}{c}\text { Feminino } \\
\mathbf{n}=128\end{array}$} \\
\hline & & $\mathbf{n}$ & $\%$ & $\mathbf{n}$ & $\%$ \\
\hline \multirow{4}{*}{$\begin{array}{l}\text { Inadequado } \\
\text { (insuficiente): } \\
\text { valores }<\text { P25 }\end{array}$} & Glicose & 3 & 3,4 & 1 & 0,8 \\
\hline & Colesterol total & 1 & 1,1 & 0 & 0 \\
\hline & LDL-c & 1 & 1,1 & 0 & 0 \\
\hline & Triglicerídeos & 0 & 0 & 1 & 0,8 \\
\hline \multirow{4}{*}{$\begin{array}{l}\text { Adequado: } \\
\text { valores entre } \\
\text { P25 e P75 }\end{array}$} & Glicose & 2 & 2,3 & 11 & 8,6 \\
\hline & Colesterol total & 14 & 16,1 & 22 & 17,1 \\
\hline & LDL-c & 11 & 12,6 & 13 & 10,1 \\
\hline & Triglicerídeos & 10 & 11,6 & 13 & 10,1 \\
\hline \multirow{4}{*}{$\begin{array}{l}\text { Inadequado } \\
\text { (elevado): } \\
\text { valores }>\text { P75 }\end{array}$} & Glicose & 5 & 5,7 & 10 & 7,8 \\
\hline & Colesterol total & 7 & 8,0 & 16 & 12,5 \\
\hline & LDL-c & 4 & 4,6 & 13 & 10,1 \\
\hline & Triglicerideos & 6 & 6,9 & 14 & 10,9 \\
\hline
\end{tabular}

Em relação ao sexo masculino, é possivel verificar que para as três categorias de IMC consideradas, a freqüência de indivíduos com concentração de glicose acima de $126 \mathrm{mg} / \mathrm{dL}$ foi semelhante. As mulheres foram cerca de 10 vezes mais freqüentes para glicose alta nas categorias de IMC consideradas como adequada e elevada, em relação à insuficiente.

Para colesterol total $\geq 240 \mathrm{mg} / \mathrm{dL}$, LDL-c $\geq 160 \mathrm{mg} / \mathrm{dL}$ e triglicerídeos $\geq 200$ $\mathrm{mg} / \mathrm{dL}$, tanto homens como mulheres que apresentaram IMC adequado, foram mais freqüentes do que os que apresentaram IMC inadequado (insuficiente ou elevado). 
Nenhuma mulher com IMC classificado como insuficiente apresentou coiesterol total $\geq 240 \mathrm{mg} / \mathrm{dL}$ e LDL-c $\geq 160 \mathrm{mg} / \mathrm{dL}$, e nenhum homem classificado como insuficiente apresentou triglicerídeos $\geq 200 \mathrm{mg} / \mathrm{dL}$.

\subsubsection{Variáveis dietéticas}

Além das avaliações antropométrica e bioquímica, uma terceira avaliação realizada foi o inquérito alimentar, através do método Recordatório de 24 horas. A partir deste método, e com o auxílio do software Virtual Nutri (Philippi e col. 1996), calculou-se o valor energético e de macronutrientes da dieta dos indivíduos (Tabela 26). O valor energético para o sexo masculino foi $1.515,1 \mathrm{kcal}$, sendo superior ao do sexo feminino, que foi de $1.339,6 \mathrm{kcal}$, não havendo diferença estatisticamente significante entre os sexos (Tabela 26).

Tabela 26. Médias, erros-padrão e intervalos de confiança (I.C.) de variáveis dietéticas de 221 idosos da área urbana de Joinville-SC, segundo o valor energético da dieta e de macronutrientes por sexo. 2002.

\begin{tabular}{|c|c|c|c|c|c|}
\hline \multirow{2}{*}{ Variáveis dietẻticas } & & \multicolumn{2}{|c|}{ Sexo } & \multirow{2}{*}{ Total } & \multirow{2}{*}{$p$} \\
\hline & & Masculino & Feminino & & \\
\hline \multirow{3}{*}{ Energia (kcal) } & Média & $1.515,1$ & $1.339,6$ & $1.418,2$ & \multirow{3}{*}{0,0500} \\
\hline & Erro Padrão & 71,74 & 61,86 & 49,62 & \\
\hline & I.C. $95 \%$ & {$[1.369,9 ; 1.660,2]$} & {$[1.214,5 ; 1.464,7]$} & {$[1.317,8 ; 1.518,6]$} & \\
\hline \multirow{3}{*}{ Carboidratos $(\%)^{*}$} & Média & 49,2 & 54,1 & 51,9 & \multirow{3}{*}{0,0380} \\
\hline & Erro Padrão & 1,9 & 1,25 & 1,12 & \\
\hline & I.C. $95 \%$ & {$[45,4 ; 53,1]$} & {$[51,5 ; 56,6]$} & {$[49,6 ; 54,2]$} & \\
\hline \multirow{3}{*}{ Proteinas $(\%)^{*}$} & Média & 19,6 & 17,0 & 18,2 & \multirow{3}{*}{0,0020} \\
\hline & Erro Padrão & 0,58 & 0,55 & 0,38 & \\
\hline & I.C. $95 \%$ & {$[18,5 ; 20,8]$} & {$[15,9 ; 18,1]$} & {$[17,4 ; 19,0]$} & \\
\hline \multirow{3}{*}{ Lipidios (\%) } & Média & 31,2 & 29,0 & 30,0 & \multirow{3}{*}{0,3030} \\
\hline & Erro Padrão & 1,9 & 0,94 & 1,03 & \\
\hline & I.C. $95 \%$ & {$[27,3 ; 35,0]$} & {$[27,1 ; 30,9]$} & {$[27,9 ; 32,0]$} & \\
\hline
\end{tabular}

${ }^{*} p<0,05$.

Para o consumo médio de macronutrientes, os homens apresentaram maior $(19,6 \%)$ consumo médio de proteinas em relação às mulheres $(17,0 \%)$, havendo 
diferença estatisticamente significante $(\mathrm{p}<0,05)$ entre os sexos. Em contrapartida, as mulheres relataram consumir significativamente mais $(54,1 \%)$ carboidratos do que os homens $(49,2 \%)$. Não houve diferença estatisticamente significante $(p<0,05)$ entre os sexos para o consumo médio de lipídios (Tabela 26).

A Figura 23 mostra a contribuição calórica média dos macronutrientes para homens e mulheres.

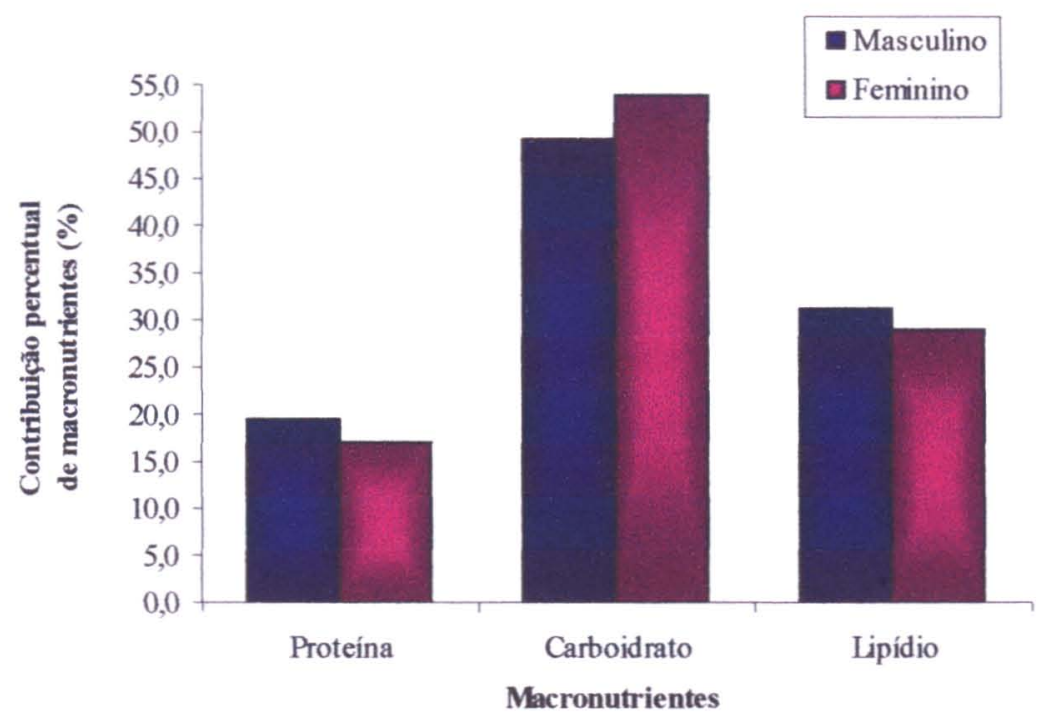

Figura 23. Contribuição percentual de macronutrientes da dieta de 221 idosos residentes na área urbana de Joinville-SC, segundo sexo. 2002.

De forma a verificar se houve alteração da contribuição calórica total com o aumento da idade, construiu-se um gráfico mostrando a relação Energia $\mathrm{X}$ Idade, demonstrado na Figura 24. Na figura, é possível observar uma sensível tendência da contribuição calórica total não exceder $2.000 \mathrm{kcal}$ para os indivíduos com 80 anos ou mais anos de idade. 


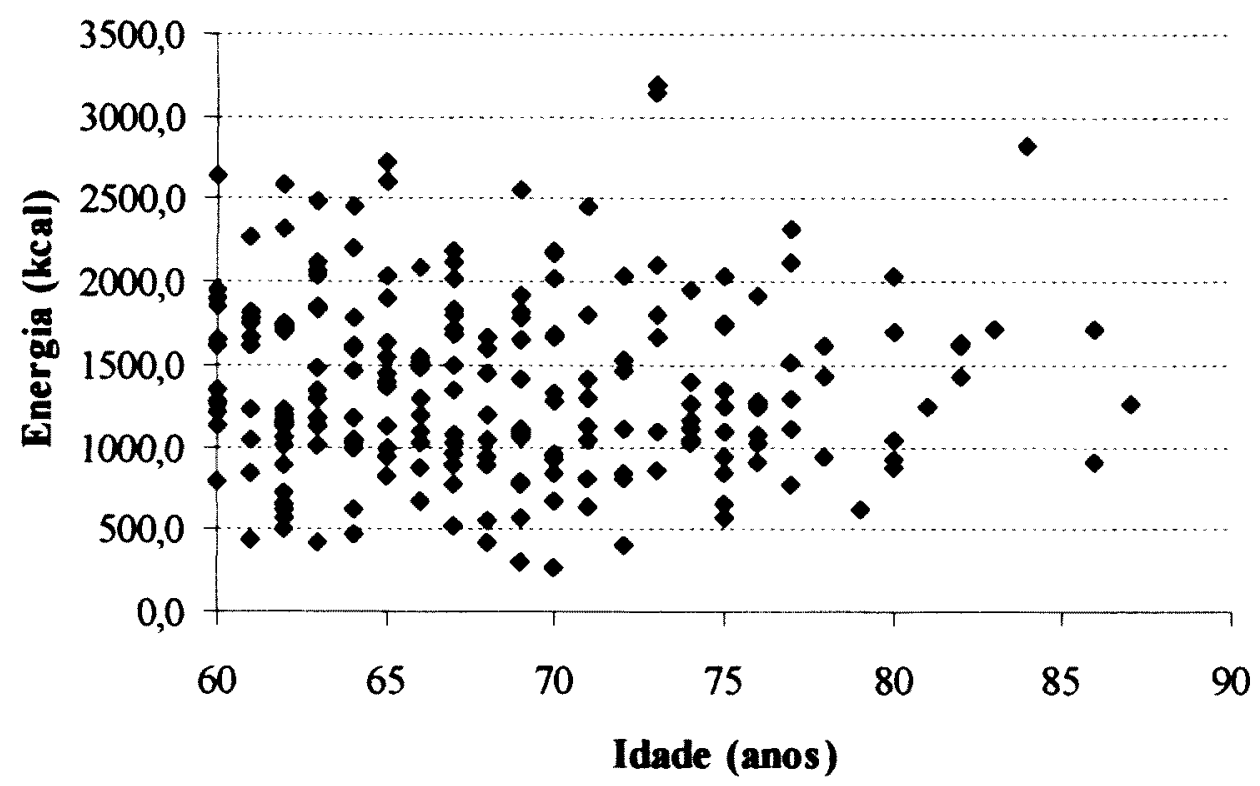

Figura 24. Contribuição calórica total (Energia) de 221 idosos residentes na área urbana de Joinville-SC, segundo idade. 2002.

Quando comparados aos valores recomendados para energia, tanto homens como mulheres apresentaram valores médios inferiores (Tabela 26) ao proposto pelo National Research Council - NRC (1989), que estabelece $2.300 \mathrm{kcal}$ para homens e $1.900 \mathrm{kcal}$ para mulheres.

Em relação à contribuição percentual média de macronutrientes, ambos os sexos enquadraram-se dentro dos valores aceitáveis (Trumbo e col. 2002), estabelecidos em: $45-65 \%$ para carboidratos, 10-35\% para proteínas e $20-35 \%$ para lipidios (Tabela 26).

A distribuição dos idosos segundo os valores recomendados para energia e macronutrientes encontra-se descrita na Tabela 27. Nesta tabela, é possível observar que a maioria dos homens e das mulheres apresentou valores médios de energia dentro do esperado, segundo os respectivos valores de consumo estabelecidos pelo $N R C$. Apesar da maioria dos indivíduos ter apresentado valores médios de macronutrientes considerados dentro dos valores aceitáveis segundo Trumbo e col. (2002), em uma grande parcela dos individuos a contribuição de macronutrientes mostrou valores médios abaixo e acima do desejável, tanto para o sexo masculino como para o feminino, e principalmente para carboidratos e lipídios (Tabela 27). 
Tabela 27. Distribuição de 221 idosos da área urbana de Joinville-SC, segundo a contribuição de macronutrientes referencial na dieta e sexo (NRC 1989; Trumbo e col. 2002).

\begin{tabular}{|c|c|c|c|c|c|c|}
\hline \multirow{3}{*}{$\begin{array}{l}\text { Variáveis } \\
\text { dietéticas }\end{array}$} & \multirow{3}{*}{$\begin{array}{c}\text { Valores de } \\
\text { referência (\%) }\end{array}$} & \multirow{3}{*}{ Categoria } & \multicolumn{4}{|c|}{ Sexo } \\
\hline & & & \multicolumn{2}{|c|}{$\begin{array}{c}\text { Masculino } \\
\mathrm{n}=90\end{array}$} & \multicolumn{2}{|c|}{$\begin{array}{c}\text { Feminino } \\
n=131\end{array}$} \\
\hline & & & $n$ & $\%$ & $\mathbf{n}$ & $\%$ \\
\hline \multirow{4}{*}{ Energia (kcal) } & $<2.300$ & Desejável & 80 & 88,9 & - & \\
\hline & $\geq 2.300$ & Alto & 10 & 11,1 & - & \\
\hline & $<1.900$ & Desejável & - & & 116 & 88,5 \\
\hline & $\geq 1.900$ & Alto & - & & 15 & 11,4 \\
\hline \multirow{3}{*}{ Carboidratos (\%) } & $<45$ & Baixo & 30 & 33,3 & 31 & 23,7 \\
\hline & $45-65$ & Desejável & 50 & 55,6 & 75 & 57,2 \\
\hline & $\geq 65$ & Alto & 10 & 11,1 & 25 & 19,1 \\
\hline \multirow{3}{*}{ Proteínas (\%) } & $<10$ & Baixo & 3 & 3,3 & 12 & 9,2 \\
\hline & $10-35$ & Desejável & 85 & 94,5 & 118 & 90,0 \\
\hline & $\geq 35$ & Alto & 2 & 2,2 & 1 & 0,8 \\
\hline \multirow{3}{*}{ Lipídios (\%) } & $<20$ & Baixo & 17 & 18,9 & 19 & 14,5 \\
\hline & $20-35$ & Desejável & 50 & 55,5 & 81 & 61,8 \\
\hline & $\geq 35$ & Alto & 23 & 25,6 & 31 & 23,7 \\
\hline
\end{tabular}

A freqüência de indivíduos que relataram consumir carboidratos e proteínas abaixo dos valores aceitáveis, segundo Trumbo e col. (2002), foi superior aos que relataram consumir acima dos valores aceitáveis, tanto para homens como para mulheres. $\mathrm{O}$ contrário ocorreu com a contribuição de lipídios na dieta, onde cerca de um quarto dos homens e um quarto das mulheres revelaram consumir mais do que $35 \%$ de lipídios na dieta, valor considerado alto segundo Trumbo e col. (2002).

\subsubsection{IMC X Contribuição calórica total (kcal)}

A relação entre IMC e contribuição calórica total pode ser verificada na Figura 25. É possível observar que a contribuição calórica total praticamente não foi alterada com o aumento do IMC. 


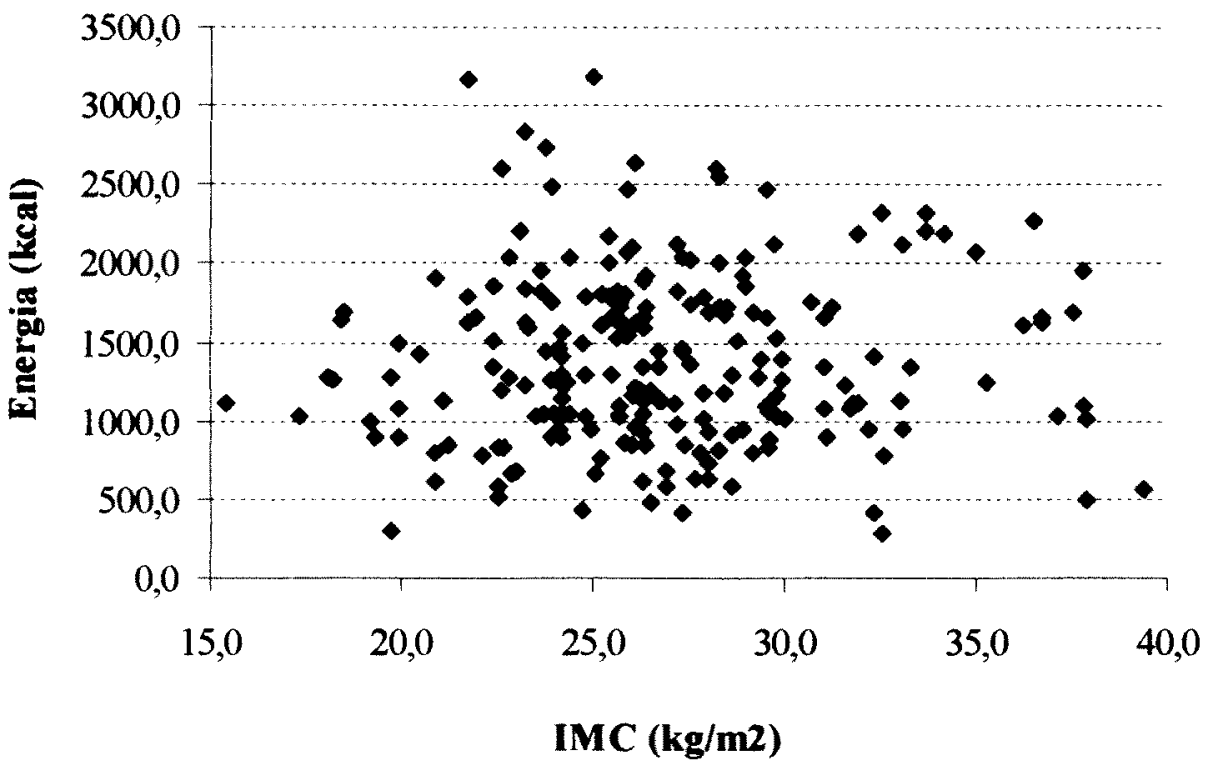

Figura 25. Contribuição calórica total (Energia) de 221 idosos residentes na área urbana de Joinville-SC, segundo IMC. 2002.

5.4.5.2. IMC $X$ Contribuição na dieta, com $\geq 65 \%$ de Carboidratos, $\geq 35 \%$ de Proteínas e $\geq 35 \%$ de Lipídios

A relação entre IMC e contribuição de macronutrientes na dieta acima do desejável pode ser verificada na Tabela 28. A tabela mostra que, tanto para o sexo masculino como para o feminino, a contribuição de proteínas na dieta não excedeu $35 \%$ para os indivíduos com IMC insuficiente. Nas três categorias de IMC consideradas, a contribuição acima do desejável de lipídios na dieta foi a mais freqüente para os homens. 
Tabela 28. Relação entre IMC e variáveis dietéticas acima do desejável (Trumbo e col. 2002), em 221 idosos da área urbana de Joinville-SC, segundo o sexo. 2002.

\begin{tabular}{|c|c|c|c|c|c|}
\hline \multirow{3}{*}{$\begin{array}{c}\text { IMC } \\
\left(\mathrm{kg} / \mathrm{m}^{2}\right)\end{array}$} & \multirow{3}{*}{$\begin{array}{l}\text { Variável dietética } \\
\text { acima do desejável } \\
(\%)\end{array}$} & \multicolumn{4}{|c|}{ Sexo } \\
\hline & & \multicolumn{2}{|c|}{$\begin{array}{c}\text { Masculino } \\
\mathbf{n}=87\end{array}$} & \multicolumn{2}{|c|}{$\begin{array}{c}\text { Feminino } \\
\mathbf{n}=130\end{array}$} \\
\hline & & n & $\%$ & n & $\%$ \\
\hline \multirow{3}{*}{$\begin{array}{l}\text { Inadequado } \\
\text { (insuficiente): } \\
\text { valores }<\text { P25 }\end{array}$} & Carboidratos & 0 & 0 & 2 & 1,5 \\
\hline & Proteinas & 0 & 0 & 0 & 0 \\
\hline & Lipídios & 3 & 3,4 & l & 0,8 \\
\hline \multirow{3}{*}{$\begin{array}{l}\text { Adequado: } \\
\text { valores entre } \\
\text { P25 e P75 }\end{array}$} & Carboidratos & 7 & 8,0 & 15 & 11,5 \\
\hline & Proteinas & 1 & 1,1 & 1 & 0,8 \\
\hline & Lipídios & 12 & 13,8 & 16 & 12,3 \\
\hline \multirow{3}{*}{$\begin{array}{l}\text { Inadequado } \\
\text { (elevado): } \\
\text { valores }>\text { P75 }\end{array}$} & Carboidratos & 2 & 2,3 & 8 & 6,1 \\
\hline & Proteinas & 1 & 1,1 & 0 & 0 \\
\hline & Lipidios & 7 & 8,0 & 12 & 9,2 \\
\hline
\end{tabular}

\subsubsection{Contribuição, na dieta, com $\geq 35 \%$ de lipídios $X$ colesterol total $\geq 240$ $\mathrm{mg} / \mathrm{dL}, \mathrm{LDL}-\mathrm{c} \geq 160 \mathrm{mg} / \mathrm{dL}$ e triglicerideos $\geq 200 \mathrm{mg} / \mathrm{dL}$}

A relação entre contribuição, na dieta, com $\geq 35 \%$ de lipídios, e perfil bioquímico alto, está descrita na Tabela 29.

Tabela 29. Relação entre contribuição na dieta com $\geq 35 \%$ de lipídios e colesterol total $\geq 240 \mathrm{mg} / \mathrm{dL}$, LDL-c $\geq 160 \mathrm{mg} / \mathrm{dL}$, triglicerideos $\geq 200 \mathrm{mg} / \mathrm{dL}$, em 221 idosos da área urbana de Joinville-SC, segundo o sexo. 2002.

\begin{tabular}{cccccccc}
\hline \multirow{2}{*}{$\begin{array}{c}\text { Variável } \\
\text { bioquímica alta } \\
(\mathbf{m g} / \mathbf{d L})\end{array}$} & \multicolumn{2}{c}{$\begin{array}{c}\text { Masculino } \\
\mathbf{n = 2 3}\end{array}$} & \multicolumn{2}{c}{$\begin{array}{c}\text { Feminino } \\
\mathbf{n = 3 1}\end{array}$} & & \multicolumn{2}{c}{$\begin{array}{c}\text { Total } \\
\mathbf{n = 5 4}\end{array}$} \\
\cline { 2 - 7 } & $\mathbf{n}$ & $\mathbf{\%}$ & $\mathbf{n}$ & $\mathbf{\%}$ & $\mathbf{n}$ & $\mathbf{\%}$ \\
\hline Colesterol total & 5 & 21,7 & 6 & 19,3 & 11 & 20,3 \\
LDL-c & 4 & 18,1 & 4 & 13,0 & 8 & 14,8 \\
Triglicerídeos & 5 & 21,7 & 3 & 9,7 & 8 & 14,8 \\
\hline
\end{tabular}




\section{DISCUSSÃO}

A situação nutricional da população idosa brasileira sinaliza a necessidade de buscar conhecer e compreender todas as peculiaridades que afetam o consumo alimentar do idoso, levando-se em consideração as características regionais nas quais estão inseridos (Campos e col. 2000). Estudos que caracterizam o estado nutricional da população, em especial a que apresenta idade igual ou superior a 60 anos, possibilita ao município o desenvolvimento de um planejamento preventivo às próximas gerações. $\mathrm{O}$ estabelecimento de programas educacionais em relação à dieta e estilo de vida ainda na fase infantil, fornecendo informações para que a população envelheça de forma saudável e economicamente ativa, proporciona inúmeras vantagens ao município, como: diminuição de gastos com medicamentos, principalmente para diabetes e hipertensão arterial; redução de encaminhamentos aos postos de saúde; diminuição do número de internações; liberação do cuidador, geralmente um membro da família que deixa de trabalhar para cuidar do idoso debilitado; entre outras, que desgastam o sistema único de saúde e impedem o crescimento de um município/Estado/País.

Este é o primeiro estudo desenvolvido em Santa Catarina de avaliação do estado nutricional de pessoas com idade igual ou superior a 60 anos, residentes na área urbana e não institucionalizadas.

Face ao rápido aumento do número de pessoas com 60 ou mais anos no mundo, inúmeros estudos têm sido desenvolvidos nos últimos 20 anos de forma a contribuir para a geração de informações que caracterizem esta população.

No Brasil, estudos utilizando dados primários, de pessoas com idade igual ou superior a 60 anos, também têm sido desenvolvidos, entre os quais pode-se destacar: Ramos e Goihman (1989) em São Paulo-SP, Veras e col. (1989) no Rio de JaneiroRJ, Marucci (1992) em São Paulo-SP, Ramos e col. (1993) em São Paulo-SP, Najas e col. (1994) em São Paulo-SP, Rio Grande do Sul (1997) em nove regiões do Rio Grande do Sul, Cervato e col. (1997) em Cotia-SP, Ramos e col. (1998) em São Paulo-SP, Coelho Filho e Ramos (1999) em Fortaleza-CE, Fornés e col. (2000) em Cotia-SP, Cabrera e Jacob Filho (2001) em Londrina-PR, Barreto e col. (2003) em Bambuí-MG, Lebrão e Duarte (2003) com o Projeto SABE em São Paulo. Outros 
estudos, não realizados com dados primários, mas que também investigaram o mesmo grupo etário, compreendem: Coitinho e col. (1991) em diferentes cidades do país, e Tavares e Anjos (1999) em 363 municípios brasileiros.

Neste estudo, um fator importante que prejudicou a coleta de dados em domicílio foi as eleições de 2002, que ocorreram na mesma época em que a pesquisa estava sendo desenvolvida: setembro, outubro e novembro. Por várias vezes, os idosos se recusaram a atender os entrevistadores, acreditando ser uma abordagem política, mesmo estando os entrevistadores devidamente identificados com o logotipo das universidades envolvidas no estudo. Ainda assim, foram cadastrados 660 idosos na primeira fase do estudo. A maior perda ocorreu na segunda fase da pesquisa com a coleta dos dados antropométricos, bioquímicos e dietéticos. Nesta fase, compareceram 221 voluntários. Atribuiu-se esta redução na participação dos idosos a vários fatores, entre eles:

- estar ausente no momento do contato (mesmo após dois contatos, seja por telefone ou na residência);

- impossibilidade de se deslocar até o posto de saúde devido a compromissos domiciliares, como ir ao mercado, cozinhar, cuidar de netos, etc;

- impossibilidade de se deslocar até o posto de saúde devido a problemas de saúde;

- não achar necessário por possuir plano de saúde;

- ter que se submeter a coleta de sangue,

- não querer participar por motivos pessoais;

- falecimento.

Devido a elevada ausência de resposta ocorrida na segunda etapa do estudo, optou-se por realizar a ponderação dos dados de forma a tratar o grupo de idosos examinados como sendo representativo da amostra. Esta questão foi principalmente evidenciada quando investigaram-se as caracteristicas sócio-demográficas do grupo de não examinados e do grupo de examinados. Apenas a característica "grupo etário" mostrou diferença estatisticamente significante $(p<0,05)$ entre os dois grupos, sendo 
o grupo de examinados cerca de dois anos mais novo, em média, que o grupo de não examinados. Acredita-se que essa diferença na média de idade entre os dois grupos tenha exercido forte influência no momento dos idosos se deslocarem até os postos de saúde para serem examinados. Esta é uma questão importante que deve ser levada em conta no planejamento de estudos com populações idosas, visto que o grupo etário em questão geralmente possui dificuldade para se deslocar. Ainda que o tempo para o desenvolvimento do estudo aumente consideravelmente, faz-se necessária a investigação do idoso na própria residência, reduzindo drasticamente desta forma, a ausência de resposta.

Assim como em outros estudos desenvolvidos no Brasil (Ramos e col. 1993; Rio Grande do Sul 1997; Cervato e col. 1997; Ramos e col. 1998; Coelho Filho e Ramos 1999; Tavares e Anjos 1999; Cabrera e Jacob Filho 2001; Lima Costa e col. 2000, Lebrão 2003), neste estudo a maior freqüência de idosos do sexo feminino também foi verificada.

Estudos desenvolvidos em outros paises também descreveram as mulheres como mais freqüentes na população (Vellas e col. 1997; Lasheras e col. 1999). A predominância do sexo feminino e também, nos três grupos etários avaliados: 60-69, 70-79 e 80+ anos, confirma a maior expectativa de vida deste grupo etário (Tavares e Anjos 1999). Esta característica tem sido atribuída a: menor exposição a determinados fatores de risco, notadamente no trabalho; menor prevalência de tabagismo e consumo de bebida alcoólica; diferenças quanto à atitude em relação a doenças e incapacidades e, por último, maior cobertura da assistência ginecoobstétrica (Coelho Filho e Ramos 1999). Segundo a Fundação IBGE 2002, a característica da mulher residir na cidade também pode beneficiar na maior expectativa de vida, especialmente as viúvas, devido a proximidade com seus filhos, dos serviços especializados de saúde e de outros facilitadores do cotidiano.

A maior freqüência de mulheres viúvas encontrada neste estudo, cerca de quatro vezes maior que a dos homens, coincide com os resultados descritos por outros autores (Lima Costa e col. 2000, Lebrão 2003). Lebrão e Duarte (2003), em estudo conduzido no Município de São Paulo no ano de 2000, também relataram a frequêencia quatro vezes maior de mulheres viúvas. Pesquisa realizada com idosos no Rio Grande do Sul mostrou que, além das mulheres apresentarem maior frequiência 
de viuvez, estas também predominaram na área urbana das cidades onde o estudo foi desenvolvido (Rio Grande do Sul 1997). Outro estudo realizado em Fortaleza-CE, também revelou a maior freqüência de mulheres viúvas (Coelho Filho e Ramos 1999).

Segundo a OPAS (1999), as mulheres e os homens envelhecem de maneira diferente. No que se refere à esperança de vida, a vantagem da mulher, em parte, é biológica. Longe de ser o sexo frágil, o sexo feminino parece ter mais capacidade de recuperação que o masculino, em todas as idades. É possível também que, na vida adulta, as mulheres, graças a hormônios que as protegem contra doenças do coração, por exemplo, tenham uma vantagem biológica. Schlenker (1998b) coloca que o fato de as mulheres superarem os homens em relação à expectativa de vida pode estar relacionado a fatores genéticos ou ambientais, ou uma combinação de ambos. Lebrão (2003), destaca o fato do estado conjugal ser a característica demográfica da população idosa com diferenciais por sexo mais expressivas, resultado, principalmente, da maior expectativa de vida da mulher.

Os dados da distribuição demográfica da população analisada mostraram o predomínio de uma população homogênea, sendo a maioria catarinense. Embora esta característica esteja sendo modificada ao longo dos anos, Santa Catarina ainda é um estado que sofre pouca influência migratória dos outros estados do Brasil. A caracteristica de uma população homogênea do estado e, conseqüentemente, de Joinville, também pode ser observada quando investigamos a cor ou grupo étnico relatado, onde poucos $(14,0 \%)$ relataram não ser de cor branca. Quanto a este tipo de informação, cor ou grupo étnico, alguns idosos, mesmo sendo visivelmente de cor negra, relataram se enquadrar na cor parda, revelando a indefinição ainda existente deste tema na sociedade. Apesar de ser a mesma definição utilizada pelo IBGE no último censo (Fundação IBGE 2000b), para obtenção de dados sobre etnia, no momento de relatar a qual grupo o idoso pertencia, parecia haver certo receio por parte de algumas pessoas em afirmar pertencer à raça negra. Essa baixa influência migratória dos estados vizinhos e o padrão étnico homogêneo observado sugerem que Joinville ainda mantém as características estabelecidas pela colonização européia. Esta é uma característica importante, pois reflete o estilo de vida da população. Por ainda manter hábitos antigos da colonização européia, como se 
deslocar para o trabalho de bicicleta e cultivar flores, a população idosa preserva um estilo de vida saudável.

A média de idade obtida de 69,8 anos mostrou que a população estudada foi constituída predominantemente por idosos "jovens" (60-69 anos), tendo como aspecto positivo o fato de grande parte $(62,0 \%)$ viver com o cônjuge; característica importante para o aumento da qualidade de vida do idoso. A característica de idoso "jovem" é facilmente verificada quando se analisa por grupo etário, onde a maioria $(54,8 \%)$ dos idosos relatou idade inferior a 70 anos. Apenas $11,9 \%$ dos idosos relataram possuir 80 ou mais anos de idade. Este perfil também foi verificado em outros estudos (Ramos e col. 1993, Rio Grande do Sul 1997, Ramos e col. 1998, Coelho Filho e Ramos 1999, Cabrera e Jacob Filho 2001).

O perfil do idoso descrito neste estudo, com baixa renda e escolaridade, coincide com o retratado por outros autores (Ramos 1987; Ramos e col. 1993, Coelho Filho e Ramos 1999, Lima Costa 2000, Cabrera e Jacob Filho 2001). A baixa escolaridade relatada, onde a maioria $(71,4 \%)$ da população revelou não ter completado o ensino fundamental, também era esperada. Apenas 5,9\% dos idosos conseguiram ingressar no ensino médio e no ensino superior. É importante colocar que, neste estudo, os dados de renda (individual) e escolaridade foram coletados como categóricos, sem discriminar anos de estudo e valor exato da renda. Nas décadas de 10-40 do século $\mathrm{XX}$, períodos nos quais se originou a maioria da população pesquisada, havia menor freqüência à escola, priorizando-se o trabalho em detrimento da educação. $\mathrm{Na}$ época, a maioria da população estudava até a quarta série do primário, visto que não havia exigência de maior escolaridade para conseguir melhores cargos e, conseqüentemente, melhor renda. Desta forma, embora não seja possível afirmar exatamente quantos anos de estudo os indivíduos desta pesquisa cursaram, é pertinente supor que a grande maioria também tenha concluído apenas a primeira parte do primário $\left(1^{\mathrm{a}}\right.$ a $4^{\mathrm{a}}$ série). Acredita-se que esta característica será substancialmente modificada para as próximas gerações, devido à maior possibilidade de freqüência à escola e, também, à grande competitividade do mercado de trabalho atual.

Quanto à renda, o fato das mulheres terem relatado substancialmente maior $(53,4 \%)$ dependência em relação aos homens $(5,6 \%)$, vem ao encontro do que foi 
comentado anteriormente, onde as mulheres nascidas até o começo do século passado desenvolviam atividades mais relacionadas ao lar, cuidando dos filhos, em relação aos homens, responsáveis pela busca do sustento familiar. Cabe colocar que, neste estudo, os dados de renda coletados referem-se aos indivíduos entrevistados, não sendo a renda familiar. Desta forma, não é possivel identificar a renda dos indivíduos que relataram ser dependentes, em sua maioria mulheres.

Segundo a Fundação IBGE (2002), quando o assunto é escolaridade e renda, as diferenças entre homens e mulheres são expressivas. Mesmo que ambos tenham a mesma média de anos de estudo, os homens ganham mais que as mulheres. Essa desigualdade de rendimentos se mantém em todos os estados e regiões, e em todas as classes de anos de estudo: tanto as mulheres com grau de escolarização igual ou inferior a três anos de estudo ganham menos que os homens com o mesmo grau de escolaridade, quanto as mulheres com maior grau de escolarização (11 anos ou mais de estudo) (Fundação IBGE 2002).

É possível que a baixa renda individual relatada pela maioria da população investigada esteja relacionada à escolaridade, visto que $34,2 \%$ dos idosos que recebiam renda de até dois salários mínimos afirmaram não ter completado o ensino fundamental. Atualmente, os idosos ainda ativos acabam sendo pressionados pelo sistema competitivo que o mercado exige, principalmente no que diz respeito à escolaridade, o que dificulta a busca por melhores salários. Este quadro deve ser alterado para as próximas gerações, principalmente pelo fato da mulher estar buscando cada vez mais seu espaço no mercado de trabalho, necessitando, conseqüentemente, de melhor nível educacional.

Em termos de saúde pública, uma das variáveis mais importantes que têm sido utilizada em diversos estudos para se avaliar o estado nutricional da população é o IMC. Neste estudo, optou-se por utilizar os padrões de IMC estabelecidos por Kuczmarski e col. (2000), valores compreendidos entre 22,4 e $27,1 \mathrm{~kg} / \mathrm{m}^{2}$ para homens, e 21,7 e $28,4 \mathrm{~kg} / \mathrm{m}^{2}$ para mulheres, devido a similaridade com padrões desenvolvidos por outros estudos, como Perissinoto e col. (2002), American Academy of Family Physicians (1997), e OPAS (2004). Perissinoto e col. (2002) estabeleceram padrões antropométricos para a população italiana com idade igual ou superior a 65 anos. Para estes autores, valores adequados de IMC estão 
compreendidos entre 23,0 e $27,4 \mathrm{~kg} / \mathrm{m}^{2}$, para homens, e 23,5 e $30,1 \mathrm{~kg} / \mathrm{m}^{2}$ para mulheres, utilizando-se os mesmos percentis, entre P25 e P75. A American Academy of Family Physicians (1997) estabeleceu padrão adequado de IMC para a população americana com idade igual ou superior a 65 anos como sendo entre 22 e $27 \mathrm{~kg} / \mathrm{m}^{2}$. A OPAS, para o desenvolvimento da pesquisa SABE, considerou IMC adequado os valores compreendidos entre 23 e $28 \mathrm{~kg} / \mathrm{m}^{2}$ para homens e mulheres.

$\mathrm{Na}$ investigação do grupo de idosos de Joinville, a maioria $(57,2 \%)$ dos individuos foi classificada como adequada quanto ao IMC (entre P25 e P75), segundo Kuczmarski e col. (2000). Mesmo assim, a considerável prevalência de ambos os sexos $(24,0 \%$ homens e $39,8 \%$ mulheres) com IMC elevado (valores $>$ P75), revelou um quadro preocupante. Quando utilizou-se a classificação da OMS (1997) para individuos com sobrepeso, descrito como IMC igual ou superior a 25,0 $\mathrm{kg} / \mathrm{m}^{2}$, a maior prevalência de obesidade também foi encontrada no sexo feminino, dados que são consistentes com os retratados por outros estudos no Brasil (Marucci 1992, Cervato e col. 1997, Tavares e Anjos 1999, Cabrera e Jacob Filho 2001, Barreto e col. 2003, Marucci e Barbosa 2003), e em outros países (Groot e col. 1991, Ukoli e col. 1995, Velazquez Alva e col. 1996, Vellas e col. 1997).

Segundo Marucci e Barbosa (2003), em estudo realizado no município de São Paulo, no ano de 2000 (Projeto SABE), 21,7\% dos homens e 40,5\% das mulheres apresentaram sobrepeso e obesidade. Outro estudo também realizado em São Paulo, com 154 mulheres atendidas no Ambulatório de Saúde da Mulher Climatérica - USP, revelou que apenas $24,0 \%$ das mulheres apresentaram-se adequadas em relação ao estado nutricional, e 75,3\% apresentaram IMC igual ou superior a $25,0 \mathrm{~kg} / \mathrm{m}^{2}$ (Montilla e col. 2003).

O excesso de peso é um dos principais fatores de risco de uma série de doenças crônicas não transmissíveis, entre elas, a hipercolesterolemia, o diabetes, as doenças cardiovasculares, algumas formas de câncer, entre outras, e representa, atualmente, um preocupante desafio para à saúde pública.

O sobrepeso é um problema eminentemente urbano, com algumas diferenciações por região. No sul, o excesso de peso é também elevado na área rural. Tais resultados podem estar refletindo a presença diferenciada de fatores determinantes de sobrepeso relacionados a condições de vida, história ocupacional e 
estilos de vida, principalmente atividade física e consumo alimentar, conforme gênero, nas diversas realidades sociais brasileiras (Tavares e Anjos 1999).

Vários autores têm relatado que o IMC diminui com o avanço da idade (Delarue e col 1994, WHO 1995, Schlenker 1998a). Neste estudo, esta característica pareceu ocorrer somente após os 80 anos de idade, entretanto, não necessariamente tendendo a diminuir os valores médios de IMC, mas sim, não ocorrendo valores superiores a $30 \mathrm{~kg} / \mathrm{m}^{2}$.

A obesidade também mostrou ser influenciada pela renda e escolaridade. $O$ fato de a maioria dos idosos não ter completado o ensino fundamental e receber até dois salários mínimos, pode estar relacionado ao IMC elevado encontrado, visto que a renda está diretamente relacionada à educação, a qual garante acesso a informações sobre dieta e estilo de vida saudáveis, permitindo que a população atinja a terceira idade ainda economicamente ativa.

Coitinho e col. (1991), em estudo desenvolvido na área urbana do Sul do Brasil em 1989, relataram que 8,8\% dos homens e 16,3\% das mulheres com 18 ou mais anos de idade e que recebiam entre 0,5 e 2,2 salários mínimos, também apresentaram $\mathrm{IMC} \geq 30,0 \mathrm{~kg} / \mathrm{m}^{2}$. Somando-se os mesmo indivíduos com $\mathrm{IMC} \geq 25,0$ $\mathrm{kg} / \mathrm{m}^{2}$, obteve-se $37,0 \%$ dos homens e $44,6 \%$ das mulheres com excesso de peso e baixa renda. Esta questão também foi discutida por Monteiro e col. (2003), que relacionaram a tendência da relação entre escolaridade e risco de obesidade no Brasil em três inquéritos: 1975, 1989 e 1997. Segundo esses autores, "enquanto no primeiro período (1975-1989), o risco de obesidade foi ascendente em todos os níveis de escolaridade, tendendo a ascensão a ser máxima para homens e mulheres com maior escolaridade, no segundo período (1989-1997), o aumento da obesidade foi máximo para indivíduos sem escolaridade, registrando-se estabilidade ou mesmo diminuição da enfermidade nos estratos femininos de média ou alta escolaridade. Como resultado da tendência recente, diminui a relação positiva entre escolaridade e risco de obesidade em homens e acentua-se a relação inversa que já vinha sendo observanda na população feminina".

Outro fato importante a ser considerado, e que ocorre de forma global, é a exclusão dos idosos do mercado de trabalho. Esta característica reduz drasticamente o poder aquisitivo, fato que certamente, resulta na aquisição de alimentos de custos 
mais acessíveis e contribui para a monotonia da alimentação (Campos e col. 2000). Possivelmente, a monotonia da alimentação é devida a falta de recursos que é peculiar para este grupo etário. Os baixos valores de aposentadoria e pensão destinados aos aposentados direcionam ao consumo de alimentos com menor qualidade, dificultando a prática de uma dieta adequada.

Não menos importante que os indivíduos apresentando IMC elevado são os indivíduos que apresentaram IMC classificado como insuficiente $(\mathrm{P}<25)$, valores $<22,4 \mathrm{~kg} / \mathrm{m}^{2}$ para homens, e $<21,7 \mathrm{~kg} / \mathrm{m}^{2}$ para mulheres, segundo Kuczmarski e col. (2000). Neste estudo, 10,0\% dos idosos apresentaram IMC insuficiente, sendo os homens cerca de três vezes mais $(16,0 \%)$ freqüentes que as mulheres $(5,2 \%)$. Marucci e Barbosa (2003) encontraram resultado similar no município de São Paulo, onde o sexo masculino também apresentou maior prevalência de baixo peso. Barreto e col. (2003), também relataram maior freqüência de baixo peso no sexo masculino em estudo desenvolvido na cidade de Bambuí, MG.

A literatura científica sobre peso corporal tem enfatizado os riscos associados a sobrepeso, dispendendo pouca atenção a problemas relacionados com baixo peso. Uma questão importante abordada por vários estudos sobre obesidade e que merece atenção, diz respeito ao direcionamento da informação: excesso de peso é sempre danoso à saúde, sendo melhor o menor peso (Troiano e col. 1996). O IMC insuficiente também traz conseqüências sérias e, em algumas situações, irreversíveis a qualquer pessoa, merecendo ser melhor investigado. A detecção precoce de eventual alteração do estado nutricional de uma população é essencial para o desenvolvimento de trabalho preventivo ou intervenção terapêutica, evitando o desenvolvimento de doenças no futuro. É importante, para os profissionais de saúde, saber distinguir entre alterações normal e anormal a partir dos indicadores de estado nutricional, principalmente para o grupo etário de idosos (Troiano e col. 1996).

A investigação das variáveis antropométricas perímetro do braço e prega cutânea tricipital, também freqüentemente utilizadas para avaliar o estado nutricional (Kuczmarski e col. 2000), confirmaram os resultados obtidos com o IMC neste estudo, onde a maioria dos homens e das mulheres apresentou valores médios dentro do considerado como adequado, segundo a classificação de Kuczmarski e col. (2000). Entretanto, novamente os homens foram os mais freqüentes na classificação 
de valores considerados como insuficiente (valores $<\mathrm{P} 25$ ), e as mulheres foram as mais freqüentes na classificação de valores considerados como elevado (valores >P75) sugerindo, desta forma, maior quantidade de gordura subcutânea para as mulheres. O maior acúmulo de gordura subcutânea parece ser uma característica do sexo feminino, como confirmado em outros estudos (Groot e col. 1991, Marucci 1992, Marucci e Barbosa 2003).

Os valores médios de perímetro do braço (homens $=29,9 \mathrm{~cm}$; mulheres $=$ $31,3 \mathrm{~cm}$ ) e prega cutânea tricipital (homens $=10,7 \mathrm{~mm}$; mulheres $=21,9 \mathrm{~mm}$ ), encontrados neste estudo, foram similares aos encontrados na pesquisa SABE em São Paulo, onde os valores para perímetro do braço foram: $29,16 \mathrm{~cm}$ e $31,02 \mathrm{~cm}$, respectivamente para homens e mulheres, e para prega cutânea tricipital foram: 13,71 $\mathrm{cm}$ e $25,22 \mathrm{~cm}$, respectivamente para homens e mulheres.

As variações de valores antropométricos existentes entre as populações de diferentes países e regiões (Delarue e col. 1994) refletem a importância de se estabelecer padrões antropométricos para a população brasileira. A maioria dos estudos realizados com idosos em outros países têm investigado esta categoria considerando pessoas com idade igual ou superior a 65 anos, o que dificulta a comparação com os dados brasileiros. Há que se considerar, ainda, as variações regionais existentes em um pais com dimensões continentais, como é o caso do Brasil. Enquanto a população brasileira não possuir um padrão antropométrico, a comparação com estudos de outros países deve ser realizada com cautela. Os dados obtidos neste estudo podem contribuir com outros estudos nacionais para a construção desse padrão, ainda inexistente no país.

Menos freqüente, devido ao alto custo e às características do método (invasivo, requer profissional específico para a coleta do sangue, exigência de laboratório para o processamento das amostras, entre outras), a análise das variáveis bioquímicas é outra forma de se investigar o estado nutricional de uma população. Os resultados obtidos neste estudo revelaram que apenas a variável bioquímica glicose foi significativamente maior $(p<0,05)$ nas mulheres, não havendo diferença entre os sexos para colesterol total, HDL-c, LDL-c e triglicerídeos. $O$ fato da maioria dos homens e das mulheres terem apresentado valores médios das variáveis bioquímicas analisadas, neste estudo, dentro dos limites considerados como 
desejáveis, segundo a American Diabetes Association (2001) e a "III Diretrizes Brasileiras sobre Dislipidemias e Diretriz de Prevenção da Aterosclerose do Departamento de Aterosclerose da Sociedade Brasileira de Cardiologia" (Sociedade Brasileira de Cardiologia 2001), reforça os resultados obtidos com as variáveis antropométricas obtidas neste estudo, em que a maioria dos indivíduos examinados apresentou estado nutricional adequado. Mesmo assim, cabe ressaltar que alguns indivíduos apresentaram valores médios para as variáveis bioquímicas analisadas considerados como acima do desejável, tanto homens como mulheres. Dos 218 indivíduos examinados, $15,6 \%$ e $27,5 \%$ apresentaram valores de concentrações de glicose e colesterol considerados como sendo, respectivamente, hiperglicemia e hipercolesterolemia. Embora o estudo não tenha solicitado relato de doença aos participantes, e a coleta de sangue tenha sido realizada somente uma vez em cada indivíduo, não se deve descartar a possibilidade do direcionamento desses indivíduos ao desenvolvimento de doenças crônicas não transmissíveis, como diabetes e doenças cardiovasculares, em futuro próximo. É provável, também, que a maioria desse grupo já possua tais doenças. Kafatos e col. (1991), também descreveram as mulheres como mais freqüentes em relação às concentrações de colesterol total.

As variáveis bioquímicas LDL-c e triglicerídeos investigadas, também revelaram situação preocupante quanto ao desenvolvimento de doenças crônicas não transmissíveis, visto que $19,6 \%$ e $21,1 \%$ dos indivíduos apresentaram, respectivamente, valores médios de LDL-c e triglicerídeos considerados como altos.

Outros estudos também descreveram a presença de valores bioquímicos aumentados na população. Fornés e col. (2000), em estudo desenvolvido em CotiaSP com 1.045 adultos (20 ou mais anos de idade), relataram que 12,0\% dos indivíduos apresentaram LDL-c alto $(\geq 160,0 \mathrm{mg} / \mathrm{dL})$, sendo a maioria $(63,2 \%)$ mulheres. Kafatos e col. (1991), descreveram os homens como mais freqüentes para as concentrações de triglicerideos. Os níveis de lipidios no sangue, principalmente, colesterol total e LDL-c, são considerados um dos principais fatores de risco para o surgimento de doenças cardiovasculares, principalmente em idosos (Kafatos e col. 1991, Fornés e col. 2000, Trumbo e col. 2002).

Nos últimos 25 anos, o papel do colesterol ficou bem demonstrado por meio de estudos clinicos e observacionais, comprovando que a redução dos seus níveis, 
principalmente LDL-c, promove beneficio na prevenção da doença arterial coronariana (Sociedade Brasileira de Cardiologia 2001).

Apesar da constatação de variáveis bioquímicas com valores elevados em um grupo de indivíduos deste estudo, a análise da variável bioquímica HDL-c revelou a presença de uma característica positiva: $99,1 \%$ dos indivíduos apresentaram valores de HDL-c superiores a $40 \mathrm{mg} / \mathrm{dL}$, fator considerado como protetor contra o desenvolvimento de doenças crônicas não transmissíveis, principalmente a doença arterial coronariana (Giannini 1998, Kuczmarski 1998). Apesar de não haver diferença estatisticamente significante para a concentração média de HDL-c entre os sexos neste estudo, outros estudos relataram valores de HDL-c maiores para o sexo feminino (Kafatos e col. 1991, Marucci 1992). Fornés e col. (2000), relataram em seus estudos, que $60,0 \%$ das mulheres apresentaram HDL-c superior a $35 \mathrm{mg} / \mathrm{dL}$, realçando a importância do efeito protetor ao desenvolvimento de doenças do aparelho circulatório.

É possivel que os elevados valores de HDL-c encontrados na maioria dos indivíduos examinados neste estudo, estejam relacionados a característica da população idosa joinvillense ainda manter um estilo de vida ativo, visto que o aumento da concentração de HDL-c no sangue está, também, relacionado à prática de atividade fisica constante (Campbell 2001).

Ainda há que ser melhor investigado, mas a relação entre as três categorias de IMC consideradas (insuficiente, adequado e elevado) e perfil bioquímico alto (glicose, colesterol total, LDL-c e triglicerídeos), neste estudo, sugere relação positiva entre IMC elevado e perfil bioquímico alto, ou seja, parece haver uma tendência dos indivíduos que apresentaram IMC $>$ P75 $\left(>27,1 \mathrm{~kg} / \mathrm{m}^{2}\right.$ para homens, e $>28,4 \mathrm{~kg} / \mathrm{m}^{2}$ para mulheres) a desenvolverem concentrações de glicose, colesterol total, LDL-c e triglicerídeos, acima dos valores considerados como alto, segundo os valores de referência. Este resultado é compreensível, visto que, como discutido anteriormente, o desenvolvimento de doenças crônicas não transmissíveis está diretamente relacionado ao aumento do IMC.

Somado as avaliações antropométrica e bioquímica para verificar o estado nutricional, os idosos examinados foram também investigados quanto ao total calórico e consumo de macronutrientes. Apesar dos homens terem apresentado maior 
valor de energia $(1.515,1 \mathrm{kcal})$ em relação às mulheres $(1.339,6 \mathrm{kcal})$, não houve diferença estatisticamente significante entre os sexos, estando homens e mulheres com valores abaixo do estabelecido pelo National Research Council - NRC (1989), que é de $2.300 \mathrm{kcal}$ para homens e $1.900 \mathrm{kcal}$ para mulheres deste grupo etário. Cervato e col. (1997), em um estudo realizado em Cotia-SP, encontraram resultados similares a este estudo, sendo $1.300 \mathrm{kcal}$ para as mulheres e $1.900 \mathrm{kcal}$ para os homens. Na Espanha, Lasheras e col. (1999), que avaliaram a dieta de 352 idosos com idade entre 65 e 95 anos revelaram que o valor energético obtido da dieta também foi considerado baixo, sendo $1.893,8 \mathrm{kcal}$ para homens e $1.621,8 \mathrm{kcal}$ para mulheres, ambos não institucionalizados. Em estudo recente conduzido com idosos americanos, Ledikwe e col. (2003), revelaram que o total calórico diário dos homens foi significativamente superior $(1.810 \mathrm{kcal})$ ao das mulheres $(1.410 \mathrm{kcal})$, mais uma vez, ambos considerados abaixo do recomendado pelo NRC. Um estudo que avaliou o consumo alimentar de mulheres no climatério, em São Paulo, relatou que $88,6 \%$ das mulheres com idade entre 51-65 anos apresentaram adequação de energia, entretanto, essa adequação estabeleceu-se próxima ao limite inferior ao recomendado pelo NRC (Montilla e col. 2003). Vários outros autores (Moreiras e col. 1991, Dror e col. 1996, Ritchie e col. 1997 e Ledikwe e col. 2003), também encontraram em seus estudos, maior valor de energia para o sexo masculino, com valores superiores aos encontrados para os idosos examinados em Joinville, tanto para homens como para mulheres.

Independentemente do sexo, segundo alguns autores, o total calórico da dieta reduz com a idade (Cervato e cols. 1997). Os resultados obtidos no estudo em Joinville sugerem uma sensível tendência da contribuição calórica total não exceder 2.000 kcal a partir de 80 anos de idade. Esta redução do valor total calórico com o aumento da idade pode estar relacionada a vários fatores, como: alterações do paladar, olfato e visão, diminuindo o prazer da alimentação; uso de medicamentos (Marucci e Gomes 1997); mau estado da dentição; entre outros fatores inerentes ao processo de envelhecimento.

O baixo valor médio de energia encontrado para homens e mulheres neste estudo contrastou com as prevalências das variáveis antropométricas investigadas, visto que os valores médios destas foram considerados como adequados segundo os 
valores de referência. Acredita-se que os baixos valores de energia obtidos neste estudo para ambos os sexos, seja resultado do tipo de método utilizado para a obtenção desses dados. Durante o desenvolvimento do inquérito alimentar, é provável que os idosos não tenham tido dificuldade em lembrar os diferentes tipos de alimentos ingeridos ao longo do dia anterior, mas, quando questionados quanto a quantidade de cada alimento, é possível que estes dados tenham sido subestimados. Como o total calórico foi calculado a partir da quantidade de alimentos ingeridos, provavelmente a menor quantidade de alimentos relatada tenha sido a responsável pelos baixos valores de energia obtidos. Mesmo assim, foi possível verificar a presença de uma dieta hipercalórica em cerca de $11,0 \%$ dos indivíduos.

Quando construiu-se a relação entre valor total calórico e IMC, ao contrário do que se esperava, não houve aumento do valor calórico total com o aumento do IMC. Como também observado por outros autores (Montilla e col. 2003), é importante colocar que os valores de energia, obtidos através do inquérito alimentar pelo método recordatório de 24 horas, forneceram dados da dieta um dia antes da avaliação antropométrica, ao passo que um indivíduo com IMC inadequado, representa um processo crônico, estabelecido ao longo do tempo.

Quanto à contribuição percentual média de macronutrientes na dieta, a tendência à diminuição de carboidratos com aumento na proporção de proteínas e lipídios tem sido verificada em diferentes países e até mesmo no Brasil (Cervato e col. 1997). Neste estudo, e segundo os valores de referência propostos por Trumbo e col. (2002), os idosos examinados em Joinville enquadraram-se dentro dos valores considerados como aceitáveis. Assim como em outros estudos (Moreiras e col. 1991, Lasheras e col. (1999), os homens relataram maior consumo de proteínas em relação às mulheres. Segundo Trumbo e col. (2002), o valor para contribuição na dieta de carboidratos, estabelecido em não menos do que $45,0 \%$, objetiva prevenir a alta ingestão de gordura, a qual deve corresponder a, no máximo, 35,0\% e no mínimo $20,0 \%$ do valor total calórico, para adultos. O limite inferior de $20,0 \%$ foi estabelecido com o objetivo de prevenir a diminuição da concentração de HDL-c a qual está associada à diminuição de gordura na dieta.

Seguindo-se a classificação proposta por Young e col. (1988) para proteínas (12-14\%), e Norum e col. (1988), para carboidratos (>55\%) e lipídios $(25-30 \%)$, 
ambos estudos citados por Horwitz (1988), verificou-se que os idosos examinados apresentaram consumo abaixo do recomendado para carboidratos, consumo excessivo de proteínas e limite máximo para o consumo de lipídios.

Acredita-se que nova recomendação de contribuição percentual de macronutrientes na dieta, proposta por Trumbo e col. (2002), irá possibilitar a classificação da maioria dos idosos investigados em estudos epidemiológicos como sendo adequados quanto à distribuição de macronutrientes. Principalmente no que diz respeito ao consumo de proteínas, onde Trumbo e col. (2002) sugeriram aumento do limite máximo de $14 \%$ para $35 \%$, e que era a principal evidência de excesso no consumo, principalmente na região sul do país, agora provavelmente passará a ser enquadrada como condição adequada, como ocorreu neste estudo com os idosos em Joinville, onde $88,0 \%$ destes relataram consumir entre $10-35,0 \%$ de proteínas na dieta. Esta questão também pôde ser verificada quando construiu-se a relação entre IMC e variáveis dietéticas consideradas como acima do recomendável, segundo Trumbo e col. (2002). Nesta relação, o consumo excessivo de proteínas praticamente não exerceu influência em nenhuma das três categorias de IMC analisadas. O mesmo não ocorreu para consumo excessivo de lipídios $(>35,0 \%)$, onde para as três categorias de IMC consideradas, a contribuição acima do desejável de lipídios na dieta foi a mais freqüente. Este é um fato relevante, visto que o consumo elevado de lipídios na dieta possui relação com doenças cardiovasculares. Estudos demonstraram que pessoas de diferentes paises, grupos sociais ou raças, que consomem grandes quantidades de gordura, têm níveis elevados de colesterol sérico e maior incidência de aterosclerose coronariana $\mathrm{e}$ aórtica em relação àqueles que consomem menos gordura (Sociedade Brasileira de Cardiologia 2001). Segundo Barreto e col. (2003), uma das principais causas da obesidade parece ser o direcionamento à dieta rica em lipídios associada à redução da atividade fisica.

Em países desenvolvidos, tem sido observado aumento na densidade energética da dieta devido, principalmente, ao aumento do consumo de gordura, estilo de vida sedentário e conseqüente aumento da prevalência de obesidade (Fornés e col. 2000). 
O elevado consumo de lipídios na dieta de alguns indivíduos examinados chamou a atenção para uma possível relação positiva com valores de colesterol total, LDL-c e triglicerídeos aumentados. Apesar do inquérito alimentar ter sido realizado no dia em que se fez a coleta de sangue, onde o resultado bioquímico correspondeu realmente à dieta consumida cerca de 24 horas antes da coleta de sangue, os resultados obtidos sugerem não haver relação, neste estudo, entre as variáveis bioquímicas aumentadas (colesterol total, LDL-c e triglicerídeos) e consumo de lipidios superior a $35,0 \%$.

De acordo com o exposto, estudos para determinar o estado nutricional de populações idosas servem como importante ferramenta para trabalhos preventivos no âmbito da saúde. Em situações onde o acesso a estabelecimentos públicos de saúde é precário, informações bioquímicas e dietéticas da população são fundamentais para o desenvolvimento de intervenções educacionais, que acabam beneficiando não só o grupo etário investigado, mas toda a população. 


\section{CONCLUSÕES}

A avaliação do estado nutricional e do consumo alimentar de idosos da área urbana da cidade de Joinville-SC, permitiu as seguintes conclusões:

a) em relação às variáveis antropométricas:

- a maioria dos idosos apresentou-se adequado quanto a IMC, perímetro do braço e prega cutânea tricipital, segundo o padrão de referência utilizado (Kuczmarski e col. 2000);

- as mulheres apresentaram valores médios de IMC, perímetro do braço e prega cutânea tricipital, significativamente maiores $(p<0,05)$ que os homens;

- cerca de um terço dos indivíduos apresentaram valores médios de IMC, perímetro do braço e prega cutânea tricipital $>$ P75, considerado elevado;

b) em relação às variáveis bioquímicas:

- a maioria dos idosos apresentou-se adequado quanto à concentrações, no sangue, de glicose, colesterol total, HDL-c, LDL-c e triglicerídeos, segundo os valores de referência utilizados;

- as mulheres apresentaram concentrações médias de glicose significativamente superiores $(p<0,05)$ em relação aos homens;

- apesar de ter sido realizado somente um exame por indivíduo, os idosos identificados como hiperglicêmicos $(15,6 \%)$, hipercolesterolêmicos $(27,5 \%)$, hiperlipidêmicos $(19,6 \%)$ e hipertrigliceridêmicos $(21,1 \%)$, mostraram situação preocupante quanto ao desenvolvimento de doenças crônicas não transmissíveis, merecendo serem melhor investigados;

c) em relação às variáveis dietéticas:

- o grupo estudado apresentou risco nutricional, tendo em vista os baixos valores de energia quando comparados ao recomendado; 
- as mulheres consumiram significativamente $(\mathrm{p}<0,05)$ maior $(54,1 \%)$ percentual médio de carboidratos em relação aos homens $(49,2 \%)$;

- os homens consumiram significativamente $(\mathrm{p}<0,05)$ maior $(19,6 \%)$ percentual médio de proteínas em relação às mulheres $(17,0 \%)$;

- não houve diferença estatisticamente significativa $(p<0,05)$ para consumo médio de lipídios entre os sexos. 


\section{REFERENCIAS}

1. American Academy of Family Physicians. The American Dietetic Association. National Council on the Aging Inc. Incorporating Nutrition Screening and Interventions into Medical Practice: A monograph for physicians. 1997.

2. American Diabetes Association (Committee Report). Report of the Expert Committee on the Diagnosis and Classification of Diabetes Mellitus. Diabetes Care 2001; 24 (Supplement 1): S5-S20.

3. Barreto SM, Passos VMA, Costa MFFL. Obesity and underweight among Brazilian elderly. The Bambuí Health and Aging Study. Cad. Saúde Pública $2003 ; 19(2): 605-12$.

4. BioSystems S.A. Glucose: Enzymatic - spectrophotometric Glucose Oxidase/Peroxidase, Espanha 2003.

5. Brasil. Conselho Nacional do Meio Ambiente. Resolução n' 283, de 12 de julho de 2001: dispões sobre o tratamento e destinação final dos resíduos dos serviços de saúde. [on line]. Disponível em: <URL http// www.mma.gov.br/port/conama/res/res01/res283.html> [2002 Jan 12]

6. Brasil. Decreto $\mathrm{n}^{\circ} 1948$ de 3 de julho de 1996. Dispõe sobre a Política Nacional do Idoso e dá outras providências. Diário Oficial da União, Brasília, 1996.

7. Brasil. Ministério da Saúde. Conselho Nacional de Saúde. Comissão Nacional de Ética em Pesquisa. Normas para pesquisa envolvendo seres humanos (Res. CNS196/96 e outras). Série Cadernos Técnicos. Brasilia, MS-CNS-CONEP: 5 $87,2000$.

8. Bray GA. Overweight is risking fate. Definition, classification, prevalence, and risks. Ann NY Acad Sci 1987; 499: 14-28. Review.

9. Brenner BM, Meyer TW, Hostetter TH. Dietary intake and the progressive nature of kidney disease. N Eng J Med 1982; 304:652-60.

10. Brown G, Alberts JJ, Fischer LD. Regression of coronary atherosclerosis during treatment of familial hypercholesterolemy with combined drug regiments. JAMA 1990; 264: 3007-12.

11. Bunout DB, Cambiazo VA. Nutrición y envejecimiento. Rev Méd Chile 1999; 127: 82-8. 
12. Burr ML, Phillips KM. Anthropometric norms in the elderly. British J Nutr $1984 ; 51: 165-9$.

13. Cabrera MAS, Jacob Filho W. Obesidade em idosos: prevalência, distribuição e associação com hábitos e co-morbidades. Arq Bras Endocrinol Metab 2001; 45 (5): 494-501.

14. Callaway CW, Chumlea WC, Bouchard C, Himes JH, Lohman TG, Martin AD et al. Circumferences. In: Lohman TG, Roche AF, Martorell R. Anthropometric Standartization Reference Manual. Champaign, Illinois: Human Kinetics Books; 1988. p. 39-54.

15. Camargo ABM, Saad PM. A transição demográfica no Brasil e seu impacto na estrutura etária da população. In: Fundação SEADE. O idoso na grande São Paulo. São Paulo: SEADE; 1990.

16. Campbell MK. Bioquímica. Porto Alegre: Artmed Editora. 2001.

17. Campos MTFS, Monteiro JBR, Ornelas APRC. Fatores que afetam o consumo alimentar e a nutrição do idoso. Rev. Nutr. 2000; 13 (3): 157-65.

18. Cançado FAX. Epidemiologia do envelhecimento. In: Noções Práticas de Geriatria 1994; p.17-43.

19. Carvalho JAM, Garcia RA. O envelhecimento da população brasileira: um enfoque demográfico. Cad. Saúde Pública 2003; 19 (3): 725-33.

20. Centers for Disease Control and Prevention. Biosafety in Microbiological and Biomedical Laboratories. National Institute of Health, Department of Health and Human Services. $4^{\text {th }}$ Edition. 1999.

21. Cervato AM, Mazzilli RN, Martins IS, Marucci MFN. Dieta habitual e fatores de risco para doenças cardiovasculares. Rev. Saúde Pública 1997; 31 (3): 227-35.

22. Chaimowicz F. A saúde dos idosos brasileiros às vésperas do século XXI: problemas, projeções e alternatives. Rev. Saúde Pública 1997; 31 (2): 184-200.

23. Chumlea WC, Roche AF, Mukherjee D. Nutritional assessment of the elderly through anthropometry. Columbus, Ohio: Ross Laboratories 1987; 47pp.

24. Coelho Filho JM, Ramos LR. Epidemiologia do envelhecimento no Nordeste do Brasil: resultados de inquérito domiciliar. Rev. Saúde Pública 1999; 33 (5): 445 53. 
25. Coelho RG. Interações nutricionais: Interações ao nivel do trato gastrointestinal. R. Metab. Nutr 1995.

26. Coeli CM, Ferreira LGFD, Drbal MM, Veras RP, Camargo-Jr. KR, Cascão AM. Mortalidade em idosos por diabetes mellitus como causa básica e associada. Rev. Saúde Pública 2002; 36 (2): 135-40.

27. Coitinho DC, Leão MM, Recine ESR, Sichieri R. Condições nutricionais da população brasileira: adultos e idosos. Brasília, INAN, 1991. [Pesquisa Nacional sobre Saúde e Nutrição].

28. Cruz IBM, Alho CS. Envelhecimento populacional: panorama epidemiológico e de saúde do Brasil e do Rio Grande do Sul. In: Jeckel Neto E, Cruz IBM (Orgs.). Aspectos biológicos e geriátricos do envelhecimento II. Porto Alegre: EDIPUCRS; 2000. p. 175-91.

29. Cunha DF. Joinville: Um rápido olhar sobre sua história. 2001. Disponível em <URL: http://www.joinville.sc.gov.br/história> [2003 Ago 01]

30. Czajka-Narins DM. Avaliação do estado nutricional. In: Mahan KL (Org.). Krause: alimentos, nutrição e dietoterapia. São Paulo: Roca; 1995. p. 309-30.

31. Delarue J, Constans T, Malvy D, Pradignac A, Couet C, Lamisse F. Anthropometric values in an elderly French population. British J Nutr 1994; 71 : 295-302.

32. Dror Y, Stern F, Nemesh L, Hart J, Grinblat J. Macronutrient consumption and nutritional status in selected well-established group of elderly people in a home for the age in Israel. J Am Coll Nutr 1996; 15 (5): 475-80.

33. Fornés NS, Martins IS, Hernan M, Meléndez GV, Ascherio A. Food frequency consumption and lipoproteins serum levels in the population of an urban area, Brazil. Rev. Saúde Pública 2000; 34 (4): 380-7.

34. Friedewald WT, Levy RI, Frederickson DS. Estimation of the concentration of LDL cholesterol in plasma without use of the preparative ultracentrifuge. Clin Chem 1972; 18: 499-504.

35. Frisancho AR. New standards of weight and body composition by frame size and height for assessment of nutritional status of adults and the elderly. Am J Clin Nutr 1984; 40: 808-19. 
36. Fundação IBGE. Censo demográfico 2000: Agregados de setores censitários dos resultados do universo. Documentação dos arquivos de dados. Rio de Janeiro; julho: 2002.

37. Fundação IBGE. Censo demográfico 2000: Cartograma e folhas para fins estatísticos. Descrição dos Setores Censitários. Mapa dos Setores Censitários. Joinville-SC. [CD ROM]. Rio de Janeiro; 2000a.

38. Fundação IBGE. Censo demográfico 2000: resultados do universo. IBGE Instituto Brasileiro de Geografia e Estatística. 2003: [3]. Disponível em <URL:http://www.ibge.gov.br/home/estatistica/populacao/censo2000/tabelabrasil 111.shtm $>$ [2003 Jul 31]

39. Fundação IBGE. Manual do Recenseador CD 1.09: Censo 2000. Rio de Janeiro. 2000b.

40. Fundação IBGE. Perfil dos idosos responsáveis pelos domicílios. IBGE Instituto Brasileiro de Geografia e Estatística. 2002: [7]. Disponível em <URL:http://www.ibge.gov.br/home/presidencia/noticias/25072002pidoso.shtm> [2004 Jan 11]

41. Fundação IBGE. Tábua de vida. Evolução da Mortalidade - 2001, Brasil. IBGE - Instituto Brasileiro de Geografia e Estatística. 2001: [7]. Disponível em <URL:http://www.ibge.gov.br/home/estatistica/populacao/tabuadevida/evolucao da_mortalidade 2001.shtm> [2003 Ago 10]

42. Giannini SD. Aterosclerose e Dislipidemias. São Paulo: BG Cultural. 1998.

43. Gordon CC, Chumlea WC, Roche AF. Stature, recumbent length, and weight. In: Lohman TG, Roche AF, Martorell R. Anthropometric Standartization Reference Manual. Champaign, Illinois: Human Kinetics Books; 1988, p. 3-8.

44. Groot LCPGM, Sette S, Zajkás G, Carbajal A, Cruz JAA. Nutritional satatus: anthropometry. Eur J Clin Nutr 1991; 45 (Suppl. 3): 31-42.

45. Harrison GG, Buskirk ER, Carter JEL, Johnston FE, Lohman TG, Pollock ML et al. Skinfold thicknesses and measurement technique. In: Lohman TG, Roche AF, Martorell R. Anthropometric Standartization Reference Manual. Champaign, Illinois: Human Kinetics Books; 1988. p. 55-68.

46. Hayflick L. Como e por quê envelhecemos? São Paulo: Editora Campus, 1996. 
47. Horwitz A. Guias alimentarias y metas nutricionales en el envejecimiento. Arch Latinoamer Nutr 1988; 38 (3): 723-49.

48. Jeckel Neto E. Gerontologia: desafio para o século XXI. In.: Jeckel Neto E, Cruz IBM (Orgs.). Aspectos biológicos e geriátricos do envelhecimento II. Porto Alegre: EDIPUCRS; 2000. p. 15-21.

49. Joinville. Joinville Turística e Cultural. Guia turístico e cultural. Editora Ana Paula Ltda. 2003.

50. Kafatos A, Schlienger JL, Deslypere JP, Luzzi AN, Cruz JAA. Nutritional status: serum lipids. Eur J Clin Nutr 1991; 45 (Suppl. 3): 53-61.

51. Kalache A, Veras RP, Ramos LR. O envelhecimento da população mundial: um desafio novo. Rev. Saúde Pública 1987; 21 (3): 200-10.

52. Kish L. Survey Sampling. New York: John Wiley \& Sons; 1965.

53. Korn EL, Graubard BI. Examples of differing weighted and unweighted estimates from a sample survey. Am Stat 1995; 49: 291-5.

54. Kuczmarski MF, Kuczmarski RJ, Najjar M. Descriptive anthropometric reference data for older Americans. J Am Diet Assoc 2000; 100 (1): 59-66.

55. Kuczmarski MF, Kuczmarski RJ. Nutritional assessment of older adults. In: Schlenker ED. Nutrition in Aging. $3^{\text {rd }}$ ed. McGraw-Hill; 1998. p. 261-94.

56. Kuczmarski MF. Nutritional status of older adults. In: Schlenker ED. Nutrition in Aging. $3^{\text {rd }}$ ed. McGraw-Hill: Boston; 1998. p. 208-27.

57. Lasheras C, González C, García A, Patterson A, Fernández S. Dietary intake and biochemical indicators of nutritional status in an elderly institutionalized and non-institutionalized population. Nutrition Research 1999; 19 (9): 1299-312.

58. Lebrão ML. O projeto SABE em São Paulo: uma visão panorâmica. In: Lebrão ML, Duarte YAO (Orgs.). SABE: Saúde, Bem-estar e Envelhecimento. O Projeto SABE no Município de São Paulo: uma abordagem inicial. Brasília: Organização Pan-Americana de Saúde; 2003. p.35-43.

59. Lebrão ML, Duarte YAO. SABE: Saúde, Bem-estar e Envelhecimento. O Projeto SABE no Município de São Paulo: uma abordagem inicial. Brasília: Organização Pan-Americana de Saúde; 2003. 
60. Ledikwe JH, Wright HS, Mitchell DC, Jensen GL, Friedmann JM, Still CD. Nutritional risk assessment and obesity in rural older adults: a sex difference. Am J Clin Nutr 2003; 77: 551-8.

61. Lemeshow S, Letenneur L, Dartigues JF, Lafont S, Orgogozo JM, Commenges D. Illustration of analysis taking into account complex survey considerations: The association between wine consumption and dementia in the PAQUID Study. Am J Epidemiol 1998; 148 (3): 298-306.

62. Lima Costa MFFL, Uchoa E, Guerra HL, Firmo JOA, Vidigal PG, Barreto SM. The Bambuí health and ageing study (BHAS): methodological approach and preliminary results of a population-based cohort study of the elderly in Brazil. Cad. Saúde Pública 2000; 38 (2): 126-35

63. Marucci MFN. Aspectos nutricionais e hábitos alimentares de idosos matriculados em ambulatório geriátrico. São Paulo; 1992. [Tese de Doutorado - Faculdade de Saúde Pública da USP].

64. Marucci MFN, Barbosa AR. Estado nutricional e capacidade física. In: Lebrão ML e Duarte YAO (Orgs.). SABE - Saúde, Bem estar e Envelhecimento. O projeto SABE no município de São Paulo: Uma abordagem inicial. Brasília: Organização Pan-Americana da Saúde. 2003. p. 95-117.

65. Marucci MFN, Gomes MMBC. Interação droga-nutriente em idosos. In: Papaléo Netto M. Gerontologia. São Paulo: Atheneu; 1997. p. 273-83.

66. Ministério da Saúde. Sistema de Informações sobre Mortalidade. Mortalidade Santa Catarina - Joinville. DATASUS. 2000. Disponível em <URL:http://tabnet.datasus.gov.br/cgi/tabcgi.exe?sim/cnv/obtsc.def> [2003 Dez 21]

67. Ministério da Saúde. Sistema de Informações Ambulatoriais do SUS. Rede ambulatorial do SUS - Santa Catarina - Joinville. DATASUS. 2003. Disponível em <URL:http://www.ibge.gov.br/home/estatistica/populacao/censo2000/tabelabrasil 111.shtm $>$ [2003 Dez 17]

68. Monteiro CA, Conde WL, Castro IRR. A tendência cambiante da relação entre escolaridade e risco de obesidade no Brasil (1975-1997). Cad. Saúde Pública 2003; 19 (Sup. 1): S67-75. 
69. Montilla RNG, Marucci MFN, Aldrighi JM. Avaliação do estado nutricional e do consumo alimentar de mulheres no climatério. Rer Assoc Med Bras 2003; 49(1): $91-5$.

70. Moreiras O, Staveren WA, Cruz JAA, Nes M, Larsen KL. Intake of energy and nutrients. Eur J Clin Nutr 1991; 45 (Suppl. 3): 105-19.

71. Najas MS, Andrezza R, Souza ALM, Sachs A, Guedes LRS, Ramos LR, Tudisco ES. Padrão alimentar de idosos de diferentes estratos sócio-econômicos residentes em localidade urbana da Região Sudeste, Brasil. Rev. Saúde Pública $1994 ; 28$ (3): 187-91.

72. National Research Council, NRC: Recommended dietary allowances. $10^{\text {th }} \mathrm{ed}$., Washington. National Academy of Sciences, 1989.

73. Nikolaus T, Bach M, Siezen S, Volkert D, Oster P, Schlierf G. Assessment of nutritional risk in the elderly. Ann Nutr Metab 1995; 39 (6): 340-5.

74. Norum KR, Pedersen J, Sem SW. Fat and carbohydrates. In: Horwitz A. Guias alimentarias y metas nutricionales en el envejecimiento. Archivos Latinoamericanos de Nutricion 1988; 38(3): 724-49.

75. Onis M, Habicht JP. Anthropometric reference data for international use: recommendations from World Health Organization Expert Committee. Am J Clin Nutr 1996; 64: 650-8.

76. OPAS. Organização Pan-Americana da Saúde. Envelhecimento: Mitos na berlinda. Programa Envelhecimento e Saúde. Escritório Regional da Organização Mundial da Saúde. 1999.

77. OPAS. Organização Pan-Americana da Saúde. XXXVI Reunión del Comitê Asesor de Investigaciones en Salud - Encuestra Multicêntrica - Salud Beinestar y Envejecimeiento (SABE) en América Latina y el Caribe Informe preliminar. Disponivel em <URL:http://www.opas.org/program/sabe.htm> [2004 Jan 11]

78. OPS. Organización Panamericana de la Salud. Las condiciones de salud en las Américas. Washington; 1994.

79. Ortega RM, Andres P, Redondo MR, Zamora MJ, Lopez-Sobaler AM, EncinasSotilhos A. Dietary assessment of a group of elderly Spanish people. Int J Food Sci Nutr 1995; 46 (2): 137-44. 
80. Paschoal SMP. Epidemiologia do envelhecimento. In: Papaléo Netto $M$. Gerontologia. São Paulo: Atheneu; 1997. p. 26-43.

81. Perissinotto E, Pisent C, Sergi G, Grigoletto F, Enzi G. Anthropometric measurements in the elderly: age and gender differences. British $\mathbf{J}$ of Nutri 2002; 87: 177-86.

82. Pfeffermann D. The use of sampling weights for survey data analysis. Stat Methods Méd Res 1996; 5: 239-61.

83. Philippi ST, Szarfarc SC, Latterza AR. Virtual Nutri [software]. Versão 1.0, for Windows. São Paulo: Departamento de Nutrição - Faculdade de Saúde Pública/USP; 1996.

84. Ramos LR, Goihman S. Geographical stratification by socio-economics status: methodology from household survey with elderly people in S. Paulo, Brazil. Rev. Saúde Pública 1989; 23 (6): 478-92.

85. Ramos LR, Rosa TEC, Oliveira ZM, Medina MCG, Santos FRG. Perfil do idoso em área metropolitana na região sudeste do Brasil: resultados de inquérito domiciliar. Rev. Saúde Pública 1993; 27 (2): 87-94.

86. Ramos LR, Toniolo JN, Cendoroglo MS, Garcia JT, Najas MS, Perracini M e col. Two-year follow-up study of elderly residents in S. Paulo, Brazil: methodology and preliminary results. Rev. Saúde Pública 1998; 32 (5): 397 407.

87. Ramos LR, Veras RP, Kalache A. Envelhecimento populacional: uma realidade brasileira. Rev. Saúde Pública 1987; 21 (3): 211-24.

88. Rio Grande do Sul. Conselho Estadual do Idoso. Os idosos do Rio Grande do Sul: estudo multidimensional de suas condições de vida: relatório de pesquisa. Conselho Estadual do Idoso. Porto Alegre: CEI; 1997.

89. Ritchie CS, Burgio KL, Locher JL, Cornwell A, Thomas D, Hardin M. Nutritional status of urban homebound older adults. Am J Clin Nutr 1997; 66: 815-8.

90. Roland DA. Nutrição na idade adulta e na velhice. In: Krause MV, Mahan LK. Alimentos, nutrição e dietoterapia. $7^{\mathrm{a}}$ ed. São Paulo: Editora Roca; 1991. p. 317-31. 
91. Santa Catarina. História de Santa Catarina. 2003. Disponível em URL:http://www.sc.gov.br/santacatarina/historia/paginas/02reconhecimento.html [2003 Set 15]

92. Schlenker ED. Body composition, energy, and physical activity. In: Nutrition in Aging. $3^{\text {rd }}$ ed. McGraw-Hill: Boston; 1998a. p. 92-119.

93. Schlenker ED. Who are the aging? In: Nutrition in Aging. $3^{\text {rd }}$ ed. McGraw-Hill: Boston; 1998b. p. 1-16.

94. Schlienger JL, Pradignac A, Grunenberger F. Nutrition of the elderly: a challenge between facts and needs. Horm Res 1995; 43: 46-51.

95. Silva NN. Amostragem probabilística: Um curso introdutório. $2^{a}$ ed. rev. São Paulo: EDUSP; 2000.

96. Sociedade Brasileira de Cardiologia. III Diretrizes Brasileiras sobre Dislipidemias e Diretriz de Prevenção da Aterosclerose do Departamento de Aterosclerose da Sociedade Brasileira de Cardiologia. Arq Bras Cardiol 2001; 77 (suplemento III): 1-48.

97. Statacorp. 2001. Stata Statistical Software: Release 7.0. Stata Corporation, College Station, TX, USA

98. Tavares EL, Anjos LA. Perfil antropométrico da população idosa brasileira. Resultados da Pesquisa Nacional sobre Saúde e Nutrição. Cad Saúde Pública 1999; 15(4): 327-33.

99. Troiano RP, Frongillo Jr EA, Sobal J, Levitsky DA. The relationship between body weight and mortality: a quantitative analysis of combined information from existing studies. Int J Obesity 1996; 20: 63-75.

100. Trumbo P, Schlicker S, Yates AA, Poos M. Dietary Reference Intakes for energy, carbohydrate, fiber, fat, fatty acids, cholesterol, protein and amino acids. J Am Diet Assoc 2002; 102 (11): 1621-30.

101. Ukoli FA, Bunker CH, Fabio A, Olomu AB, Egbagbe EE, Kuller LHI. Body fat distribution and other anthropometric blood pressure correlates ina a Nigerian urban elderly population. Cent J Méd 1995; 41 (5): 54-161.

102. Velazquez AMDC, Castillo ML, Camacho EI, Zepeda MAS, Robledo LMG, Moysen PC. Estudio antropométrico en un grupo de hombrens e mujeres de la tercera edad em la Ciudad de México. Salud Publ Mex 1996; 38: 466-74. 
103. Vellas BJ, Hunt WC, Romero LJ, Koehler KM, Baumgartner RN, Garry PJ. Changes in nutritional status and patterns of morbidity among free-living elderly persons: a 10-year longitudinal study. Nutrition 1997; 13 (6) 515-9.

104. Veras RP, Silva SD, Souza CAM, Milioli R, Ventura F. Proposta metodológica para inquérito domiciliar com populações idosas em um centro urbano do Estado do Rio de Janeiro (Brasil). Rev. Saúde Pública 1989; 23 (5): 429-38.

105. WHO. World Health Organization. Diet, nutrition, and the prevention of chronic diseases: report of a WHO study group. Geneva, 1990. World Health Organization, Technical Report Series; 797.

106. WHO. World Health Organization. Obesity: preventing and managing the global epidemic - report of a WHO consultation on obesity, Geneva: WHO; 3 5 June 1997.

107. WHO. World Health Organization. Technical Report Series, 854. Physical status: the use and interpretation of anthropometry. Geneva, 1995. p. 375409.

108. Wiener lab. Vademécum: Reactivos para Laboratórios clínicos. Argentina 1994.

109. Wilmoth JR. The future of human longevity: a demographer's perspective. Science 1998; 280 (5362): 395-7.

110. Young VR, Munro HN, Fukagawa N. Protein and functional consequences of deficiency. In: Horwitz A. Guias alimentarias y metas nutricionales en el envejecimiento. Archivos Latinoamericanos de Nutricion 1988; 38(3): 724-49. 
ANEXOS 
IDENTIFICAÇÃO (ID):

Data: 1 12002

1. Nome:

2. Logradouro:

Tel.:

3. Nacionalidade: [1] Brasileiro nato

[2] Naturalizado brasileiro

[3] Estrangeiro

4. Estado civil:

[1] Solteiro(a)

[2] Casado(a)

[3] União consensual

[4] Desquitado(a) ou separado(a) judicialmente

[5] Viúvo(a)

5. Data de nascimento: 6. Idade: (anos) 7. Sexo: [1] Masculino

[2] Feminino

8. Cor ou grupo étnico: [1] Branca

[2] Negra [3] Parda [4] Amarela [5] Indigena

9. Faz uso de suplementação vitamínica? [1] Sim [2] Não

\section{DADOS SÓCIO-ECONÔMICOS (DS):}

10. Escolaridade:

[1] Não alfabetizado

[2] Alfabetizado

[3] Ensino fundamental incompleto

[4] Ensino fundamental completo

[5] Ensino médio incompleto

[6] Ensino médio completo

[7] Ensino superior incompleto

[8] Ensino superior completo

11. Renda familiar em salários mínimos (SM) (um salário mínimo = RS 200,00):

[1] Dependente (sem renda)

[2] até 2 (SM)

[3] 2-3 (SM)

[4] 3-5 (SM)

15] 5-6 (SM)

[6] 6-8 (SM)

[7] 8-10 (SM)

$[8] 10+(S M)$

\section{AVALIAÇÃO ANTROPOMÉTRICA (AA):}

12.1. Pesol: (kg)

12.2. $\mathrm{P} 2$ : $(\mathrm{kg})$

13.1. Estatural: (cm)

13.2. E2: (cm)

14.1. Altura do joelhol: (cm)

15.1. Perimetro da cintural: (cm)

14.2. $\mathrm{AJ} 2$ : (cm) 16.1. Perímetro do quadrill: (cm)

17.1. Perímetro do braçol: (cm)

15.2. PC2: (cm)

18.1. Perimetro da panturrilhal: (cm)

16.2. $\mathrm{PQ2}$ : (cm)

17.2. $\mathrm{PB} 2$ : (cm) 19.1. Prega cutânea subcscapularl (PCS): 18.2. PP2: (cm) 20.1. Prega cutânea triciptall (PCT): (mm) 19.2. PCS2: (mm) 19.3. PCS3: (mm) (mm) 20.2. PCT2: (mm) 20.3. РCT3: (mm)

\section{AVALIAÇĀO BIOQUÍMICA (AB):}

21.1. Glicose: (mg/dL)

22.1. Colesterol total: (mg/dL)

23.1. Triglicerídeos: (mg/dL)

24.1. HDL-c: $(\mathrm{mg} / \mathrm{dL})$ 
Estudo: Avaliação do estado nutricional e do consumo alimentar de idosos da cidade de Joinville, SC.

\section{INQUÉRITO ALIMENTAR - IA (Recordatório 24 h):}

\begin{tabular}{|c|c|c|c|}
\hline & [1] Segunda-feira & [2] Terça-feira & [3] Quarta-feiro \\
\hline & [5] Sexta-feira & [6] Sábado & [7] Domingo \\
\hline
\end{tabular}

\begin{tabular}{|c|c|c|}
\hline Hora & Alimentos sólidos e líquidos \\
\hline
\end{tabular}

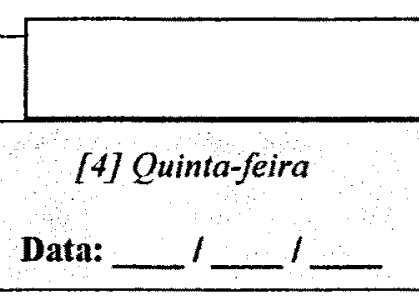

Medida caseira 
Estudo: Avaliação do estado nutricional e do consumo alimentar de idosos da cidade de Joinville, SC.

\section{TERMO DE CONSENTIMENTO INFORMADO}

\section{Conforme Resolução n 196 de 10 de outubro de 1996 (Conselho Nacional de Saúde)}

Eu,

aceito livremente participar do estudo Avaliação do estado mutricional e do consumo alimentar de idosos da cidade de Joinville-SC, sob responsabilidade dos pesquisadores Marco Fábio Mastroeni (UNIVILLE/USP), Gilmar Sidnei Erzinger (UNIVILLE) e Maria de Fátima Nunes Marucci (FSP/USP).

Este estudo tem como objetivo avaliar o estado nutricional e consumo alimentar de idosos da cidade de Joinville. O doutorando responsável pelo estudo prestará esclarecimentos sobre todos os procedimentos a serem realizados. Concordando, deverei me apresentar, em data, horário e local previamente marcados, ou, na impossibilidade de locomoção, serei atendido em meu domicílio. Serão realizadas medidas de peso, estatura, altura do joelho, perímetros da cintura, do quadril, do braço e da panturrilha, prega cutânea triciptal e subescapular e coleta de sangue. Estarei usando roupas leves para a realização das medidas. Para a coleta de sangue, iniciarei jejum 12 horas antes do exame.

Esta pesquisa não trará nenhum risco à minha integridade física ou moral. As informações obtidas neste estudo serão úteis cientificamente para possibilitar intervenções nutricionais oportunas. Cada participante receberá o resultado referente ao seu estado nutricional e ao seu consumo alimentar juntamente com um guia de orientações.

As informações científicas obtidas neste estudo poderão ser divulgadas em publicações e congressos, porém, sem a identificação dos participantes. Minha participação é, portanto, voluntária, podendo desistir a qualquer momento do estudo, sem qualquer conseqüência para mim.

Para outras informações ou esclarecimentos, entrar em contato com Marco através dos números: 47 461-9039 ou 47 9978-2590.

Para reclamações entrar em contato através do número 47 461-9091.

Data: / 2003, Joinville, SC. 


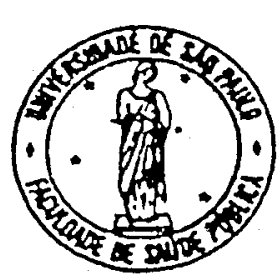

\section{UNIVERSIDADE DE SĀO PAULO \\ FACULDADE DE SAÚDE PÜBLICA \\ COMITÉ DE ÉTICA EM PESQUISA-COEP}

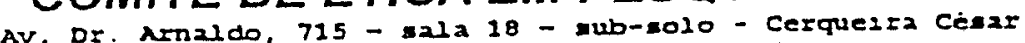

S3o Paulo-sP CPP: 01246-904

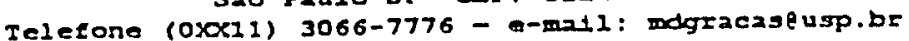

\section{Of.COEP/104/00}

17 de agosto de 2000

Pelo presente. informo que o Comitê de Ética em Pesquisa da Faculdade de Saúde Pública da Universidade de São Paulo, analisou e aprovou, em sua 3. $\%$ (0) Sessão Ordinária. de 15.08.00, de acordo com os requisitos da Resolução CNS/196/96, o protocolo de pesquisa n..$^{\circ} 341$. intitulado: "AVALIAÇÃO DO ESTADO NUTRICIONAL E DO CONSUMO ALIMENTAR DE IDOSOS DA CIDADE DE GRAVATAİ-RS", apresentado pelo pesquisador Marco Mastroeni.

Atenciosamente,

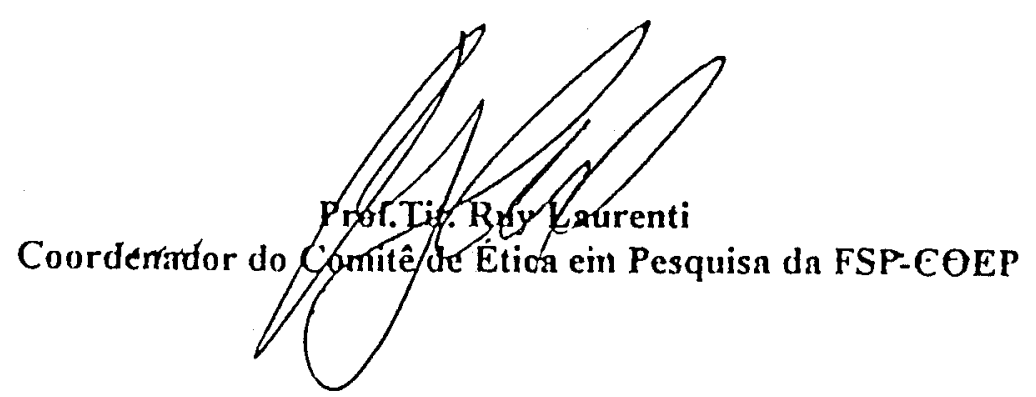




\section{Resultados da análise ponderada}

Tabela 16. Médias, erros-padrão e intervalos de confiança de variáveis antropométricas dos idosos que compareceram na segunda etapa do estudo, segundo sexo. 2002.

\begin{tabular}{|c|c|c|c|c|c|}
\hline \multirow{2}{*}{$\begin{array}{c}\text { Variáveis } \\
\text { antropométricas }\end{array}$} & & \multicolumn{2}{|c|}{ Sexo } & \multirow{2}{*}{ Total } & \multirow{2}{*}{$p$} \\
\hline & & Masculino & Feminino & & \\
\hline \multirow{3}{*}{ Peso (kg) } & Média & 70,2 & 67,2 & 68,4 & \multirow{3}{*}{0,1050} \\
\hline & Erro Padrão & 1,62 & 1,44 & 1,27 & \\
\hline & I.C. $95 \%$ & {$[66,9 ; 73,5]$} & {$[64,3 ; 70,1]$} & {$[65,8 ; 71,0]$} & \\
\hline \multirow{3}{*}{ Estatura $(\mathrm{cm})^{*}$} & Média & 165,9 & 155,0 & 159,3 & \multirow{3}{*}{0,0000} \\
\hline & Erro Padrão & 0,93 & 0,72 & 0,84 & \\
\hline & I.C. $95 \%$ & {$[164,0 ; 167,8]$} & {$[153,5 ; 156,4]$} & {$[157,6 ; 161,1]$} & \\
\hline \multirow{3}{*}{$\operatorname{IMC}\left(\mathrm{kg} / \mathrm{m}^{2}\right)$} & Média & 26,5 & 27,8 & 26,9 & \multirow{3}{*}{0,0000} \\
\hline & Erro Padrão & 0,42 & 0,51 & 0,37 & \\
\hline & I.C. $95 \%$ & {$[24,6 ; 26,3]$} & {$[26,8 ; 28,9]$} & {$[26,1 ; 27,6]$} & \\
\hline \multirow{3}{*}{$\begin{array}{l}\text { Perimetro do braço } \\
\text { (cm)* }\end{array}$} & Média & 29,8 & 31,0 & 30,0 & \multirow{3}{*}{0,0260} \\
\hline & Erro Padrão & 0,36 & 0,46 & 0,33 & \\
\hline & I.C. $95 \%$ & {$[29,1 ; 30,6]$} & {$[30,1 ; 32,0]$} & {$[29,9 ; 31,2]$} & \\
\hline \multirow{3}{*}{$\begin{array}{l}\text { Prega cutânea } \\
\text { tricipital }(\mathrm{mm})^{*}\end{array}$} & Média & 10,9 & 21,5 & 17,2 & \multirow{3}{*}{0,0000} \\
\hline & Erro Padrão & 0,45 & 0,59 & 0,47 & \\
\hline & I.C. $95 \%$ & {$[9,9 ; 11,8]$} & {$[20,4 ; 22,7]$} & {$[16,3 ; 18,2]$} & \\
\hline
\end{tabular}

Tabela 17. Freqüências relativas (\%) dos percentis IMC de 217 idosos da área urbana de Joinville-SC, segundo proposto por Kuczmarski e col. (2000) por sexo. 2002.

\begin{tabular}{|c|c|c|c|c|c|}
\hline \multirow[b]{2}{*}{ IMC } & \multicolumn{2}{|c|}{ Sexo } & \multirow{2}{*}{$\begin{array}{l}\text { Total } \\
(\%)\end{array}$} & \multirow[b]{2}{*}{$\chi^{2}$} & \multirow[b]{2}{*}{$p$} \\
\hline & $\begin{array}{l}\text { Masculino } \\
(\%)\end{array}$ & $\begin{array}{c}\text { Feminino } \\
(\%)\end{array}$ & & & \\
\hline $\begin{array}{l}\text { Inadequado } \\
\text { (insuficiente): valores } \\
<\text { P25 }\end{array}$ & 16,1 & 6,9 & 10,6 & & \\
\hline $\begin{array}{l}\text { Adequado: } \\
\text { valores entre P25 e P75 }\end{array}$ & 58,6 & 53,8 & 55,8 & 2,80 & 0,0730 \\
\hline $\begin{array}{l}\text { Inadequado (elevado): } \\
\text { valores }>\text { P75 }\end{array}$ & 25,3 & 39,3 & 33,6 & & \\
\hline Total & 100,0 & 100,0 & 100,0 & & \\
\hline
\end{tabular}


Tabela 18. Freqüências relativas (\%) dos percentis de perímetro do braço de 218 idosos da área urbana de Joinville-SC, segundo proposto por Kuczmarski e col. (2000), por sexo. 2002.

\begin{tabular}{lccccc}
\hline \multicolumn{1}{c}{ Perímetro do braço } & $\begin{array}{c}\text { Masculino } \\
(\mathbf{\%})\end{array}$ & $\begin{array}{c}\text { Feminino } \\
(\%)\end{array}$ & $\begin{array}{c}\text { Total } \\
(\%)\end{array}$ & $\chi^{2}$ & $p$ \\
\hline $\begin{array}{l}\text { Inadequado } \\
\text { (insuficiente): valores } \\
<\text { P25 }\end{array}$ & 20,4 & 6,2 & 11,9 & & \\
$\begin{array}{l}\text { Adequado: } \\
\text { valores entre P25 e P75 }\end{array}$ & 56,8 & 53,1 & 54,6 & 4,64 & 0,0204 \\
$\begin{array}{l}\text { Inadequado (elevado): } \\
\text { valores }>\text { P75 }\end{array}$ & 22,8 & 40,7 & 33,5 & & \\
\hline Total & 100,0 & $\mathbf{1 0 0 , 0}$ & $\mathbf{1 0 0 , 0}$ & & \\
\hline $\mathrm{p}<0,05$. &
\end{tabular}

Tabela 19. Distribuição das freqüências absoluta (n) e relativa (\%) dos percentis de prega cutânea tricipital de 218 idosos da área urbana de Joinville-SC, segundo proposto por Kuczmarski e col. (2000), e sexo. 2002.

\begin{tabular}{|c|c|c|c|c|c|}
\hline \multirow{2}{*}{$\begin{array}{l}\text { Prega cutânea } \\
\text { tricipital }\end{array}$} & \multicolumn{2}{|c|}{ Sexo } & \multirow{2}{*}{$\begin{array}{c}\text { Total } \\
(\%)\end{array}$} & \multirow[b]{2}{*}{$\chi^{2}$} & \multirow[b]{2}{*}{$p$} \\
\hline & $\begin{array}{c}\text { Masculino } \\
(\%)\end{array}$ & $\begin{array}{c}\text { Feminino } \\
(\%) \\
\end{array}$ & & & \\
\hline $\begin{array}{l}\text { Inadequado } \\
\text { (insuficiente): valores } \\
<\mathrm{P} 25\end{array}$ & 33,0 & 10,8 & 19,7 & & \\
\hline $\begin{array}{l}\text { Adequado: } \\
\text { valores entre P25 e P75 }\end{array}$ & 44,3 & 45,4 & 45,0 & 11,08 & 0,0001 \\
\hline $\begin{array}{l}\text { Inadequado (elevado): } \\
\text { valores }>\text { P75 }\end{array}$ & 22,7 & 43,8 & 35,3 & & \\
\hline Total & 100,0 & 100,0 & 100,0 & & \\
\hline
\end{tabular}


Tabela 22. Médias, erros-padrão e intervalos de confiança (I.C.) de variáveis bioquímicas de idosos da área urbana de Joinville-SC, segundo sexo. 2002.

\begin{tabular}{|c|c|c|c|c|c|}
\hline \multirow{2}{*}{$\begin{array}{c}\text { Variáveis } \\
\text { bioquímicas }\end{array}$} & & \multicolumn{2}{|c|}{ Sexo } & \multirow{2}{*}{ Total } & \multirow[b]{2}{*}{$p$} \\
\hline & & Masculino & Feminino & & \\
\hline \multirow{3}{*}{ Glicose* } & Média & 104,9 & 115,6 & 111,2 & \multirow{3}{*}{0,0300} \\
\hline & Erro Padrão & 2,69 & 3,26 & 2,46 & \\
\hline & I.C. $95 \%$ & {$[99,4 ; 110,3]$} & {$[109,0 ; 122,2]$} & {$[106,3 ; 116,2]$} & \\
\hline \multirow{3}{*}{ Colesterol total } & Média & 205,9 & 216,6 & 212,3 & \multirow{3}{*}{0,0820} \\
\hline & Erro Padrão & 5,06 & 5,41 & 4,35 & \\
\hline & I.C. $95 \%$ & {$[195,7 ; 216,2]$} & {$[205,7 ; 227,6]$} & {$[203,4 ; 221,1]$} & \\
\hline \multirow{3}{*}{ HDL-c } & Média & 50,1 & 50,9 & 50,6 & \multirow{3}{*}{0,3920} \\
\hline & Erro Padrão & 0,87 & 0,44 & 0,44 & \\
\hline & I.C. $95 \%$ & {$[48,4 ; 51,9]$} & {$[50,1 ; 51,8]$} & {$[49,7 ; 51,5]$} & \\
\hline \multirow{3}{*}{ LDL-c** } & Média & 125,5 & 132,9 & 129,8 & \multirow{3}{*}{0,1720} \\
\hline & Erro Padrão & 4,66 & 4,80 & 3,96 & \\
\hline & I.C. $95 \%$ & {$[116,0 ; 134,9]$} & {$[123,2 ; 142,6]$} & {$[121,8 ; 137,9]$} & \\
\hline \multirow{3}{*}{ Triglicerideos } & Média & 151,8 & 153,6 & 152,9 & \multirow{3}{*}{0,8500} \\
\hline & Erro Padrão & 9,69 & 8,22 & 7,44 & \\
\hline & I.C. $95 \%$ & {$[132,2 ; 171,4]$} & {$[137,0 ; 170,3]$} & {$[137,8 ; 167,9]$} & \\
\hline
\end{tabular}

${ }^{*} \mathrm{p}<0,05$.

Tabela 26. Médias, erros-padrão e intervalos de confiança (I.C.) de variáveis dietéticas de 221 idosos da área urbana de Joinville-SC, segundo o valor energético da dieta e de macronutrientes por sexo. 2002.

\begin{tabular}{|c|c|c|c|c|c|}
\hline \multirow{2}{*}{ Variáveis dictéticas } & & \multicolumn{2}{|c|}{ Sexo } & \multirow{2}{*}{ Total } & \multirow{2}{*}{$p$} \\
\hline & & Masculino & Feminino & & \\
\hline \multirow{3}{*}{ Energia (kcal) } & Média & $1.496,7$ & $1.305,6$ & $1.383,4$ & \multirow{3}{*}{0,0100} \\
\hline & Erro Padrão & 66,89 & 53,88 & 47,96 & \\
\hline & I.C. $95 \%$ & {$[1.361,3 ; 1.631,9]$} & {$[1.196,6 ; 1.414,6]$} & {$[1.286,4 ; 1.656,5]$} & \\
\hline \multirow{3}{*}{ Carboidratos $(\%)^{*}$} & Média & 50,64 & 53,86 & 52,55 & \multirow{3}{*}{0,0480} \\
\hline & Erro Padrão & 1,24 & 1,14 & 0,91 & \\
\hline & I.C. $95 \%$ & {$[48,1 ; 53,2]$} & {$[51,5 ; 56,2\}$} & {$[50,7 ; 54,4]$} & \\
\hline \multirow{3}{*}{ Proteinas $(\%)^{*}$} & Média & 19,5 & 17,2 & 18,2 & \multirow{3}{*}{0,0030} \\
\hline & Erro Padrão & 0,60 & 0,40 & 0,34 & \\
\hline & I.C. $95 \%$ & {$[18,3 ; 20,7]$} & {$[16,4 ; 18,0]$} & {$[17,5 ; 18,8]$} & \\
\hline \multirow{3}{*}{ Lipidios (\%) } & Média & 29,9 & 28,9 & 29,3 & \multirow{3}{*}{0,4970} \\
\hline & Erro Padrão & 1,07 & 0,96 & 0,76 & \\
\hline & I.C. $95 \%$ & {$[27,7 ; 32,0]$} & {$[27,0 ; 30,9]$} & {$[27,8 ; 30,8]$} & \\
\hline
\end{tabular}

$* \mathrm{p}<0,05$. 